\title{
Estimating the Energy-Efficiency Potential in the Eastern Interconnection
}

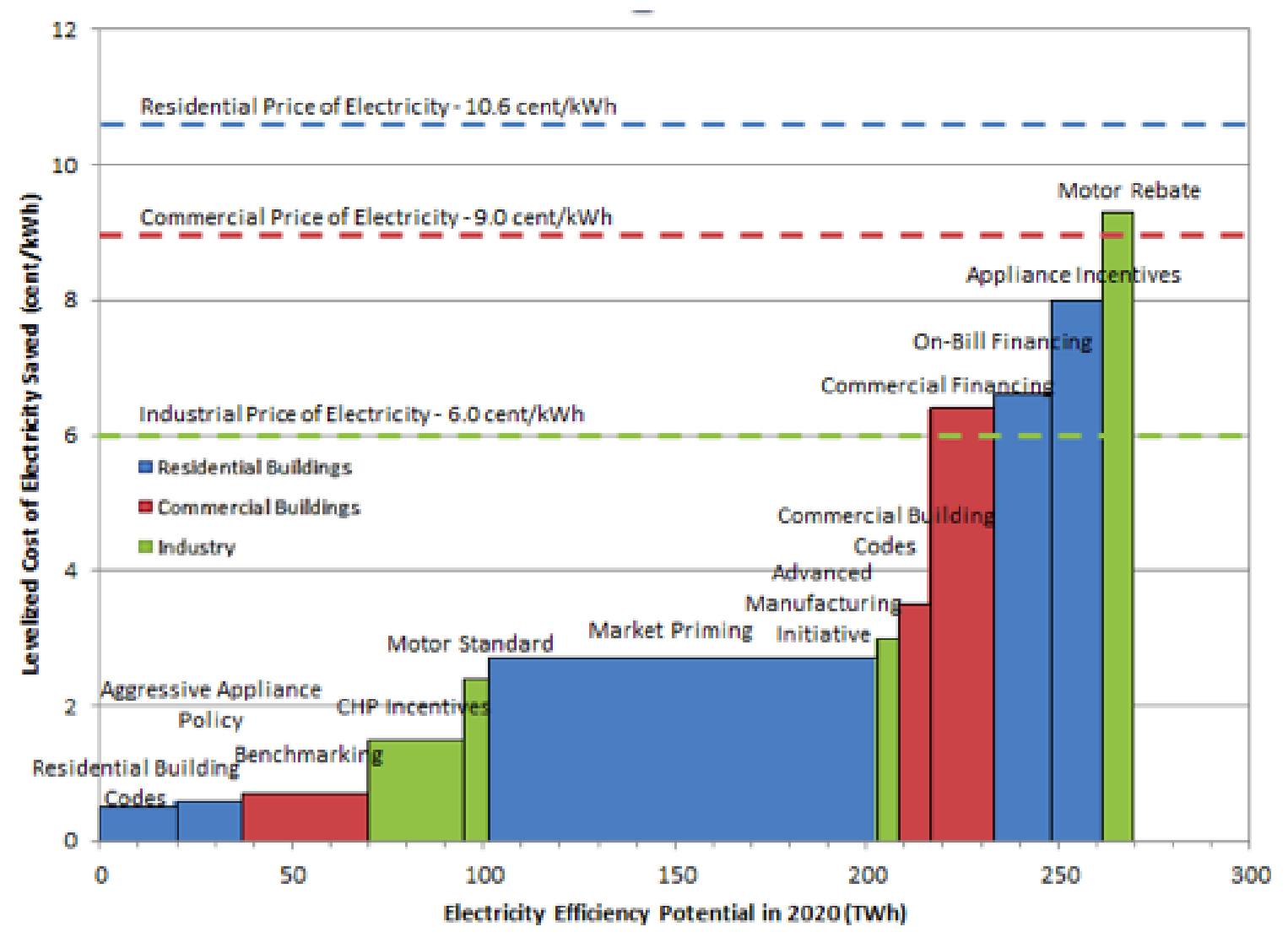

\section{January 2013 (Revised April 2013)}

\section{Prepared by}

Marilyn A. Brown ${ }^{1}$

Yu Wang ${ }^{1}$

${ }^{1}$ School of Public Policy, Georgia Institute of Technology 


\section{DOCUMENT AVAILABILITY}

Reports produced after January 1, 1996, are generally available free via the U.S. Department of Energy (DOE) Information Bridge.

Web site http://www.osti.gov/bridge

Reports produced before January 1, 1996, may be purchased by members of the public from the following source.

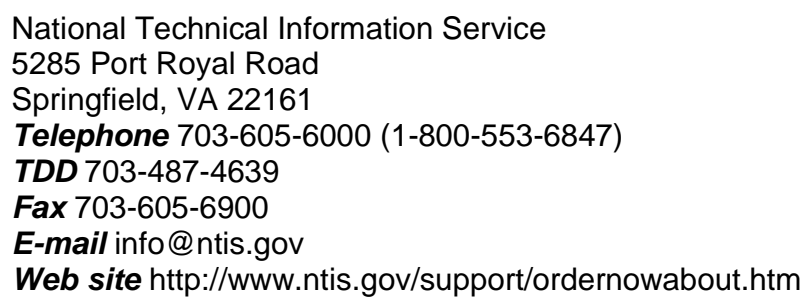

Reports are available to DOE employees, DOE contractors, Energy Technology Data Exchange (ETDE) representatives, and International Nuclear Information System (INIS) representatives from the following source.

Office of Scientific and Technical Information

P.O. Box 62

Oak Ridge, TN 37831

Telephone 865-576-8401

Fax 865-576-5728

E-mail reports@osti.gov

Web site http://www.osti.gov/contact.html

This report was prepared as an account of work sponsored by an agency of the United States Government. Neither the United States Government nor any agency thereof, nor any of their employees, makes any warranty, express or implied, or assumes any legal liability or responsibility for the accuracy, completeness, or usefulness of any information, apparatus, product, or process disclosed, or represents that its use would not infringe privately owned rights. Reference herein to any specific commercial product, process, or service by trade name, trademark, manufacturer, or otherwise, does not necessarily constitute or imply its endorsement, recommendation, or favoring by the United States Government or any agency thereof. The views and opinions of authors expressed herein do not necessarily state or reflect those of the United States Government or any agency thereof. 
Power and Energy Systems Group

\title{
ESTIMATING THE ENERGY-EFFICIENCY POTENTIAL IN THE EASTERN INTERCONNECTION
}

\author{
Marilyn A. Brown \\ Yu Wang \\ School of Public Policy \\ Georgia Institute of Technology
}

Date Published: January 2013

\author{
Prepared by \\ OAK RIDGE NATIONAL LABORATORY \\ Oak Ridge, Tennessee 37831-6283 \\ managed by \\ UT-BATTELLE, LLC \\ for the \\ U.S. DEPARTMENT OF ENERGY \\ under contract DE-AC05-000R22725
}




\section{TABLE OF CONTENTS}

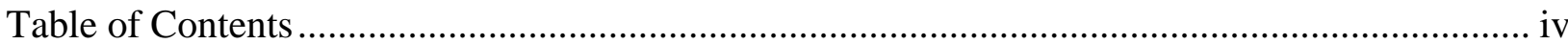

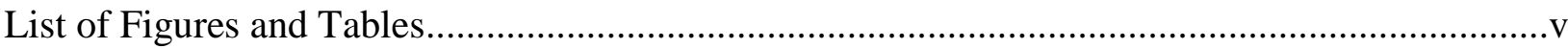

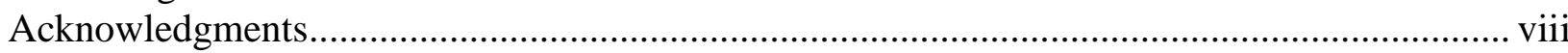

Executive Summary ...................................................................................................... ix

1 Introduction, Objectives, and Background .................................................................. 1

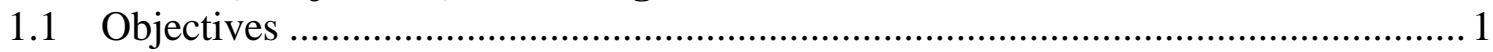

1.2 Review of Energy-Efficiency Potential ...........................................................

1.3 Barriers, Drivers, and Current Policies ……………........................................... 6

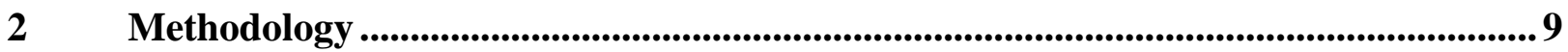

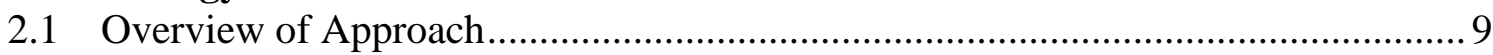

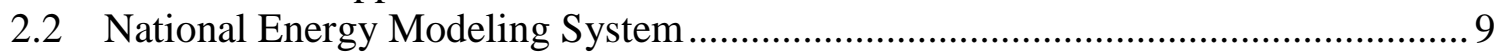

2.3 Energy Efficiency Policy Levers ....................................................................... 10

2.4 Calculation of Levelized Cost of Electricity........................................................ 12

2.5 Method for Deriving State-Specific Estimates ……….......................................... 13

$3 \quad$ Energy-Efficiency Potential in Residential Buildings.....................................................15

3.1 Overview of Previous Literature on the Energy-Efficiency Potential in Residential Buildings...................................................................... 16

3.2 Residential Efficiency Policy Options and Modeling Approach ............................ 17

3.3 Modeling Results for Individual Residential Policies .........................................22

3.4 Integrated Residential Policy Bundle...............................................................2

3.5 Summary and Discussion............................................................................. 31

$4 \quad$ Energy-Efficiency Potential in Commercial Buildings.............................................. 33

4.1 Overview of Previous Literature on the Energy-Efficiency

Potential of Commercial Buildings....................................................................... 34

4.2 Commercial Efficiency Policy Options and Modeling Approach ……………….....35

4.3 Modeling Results for Individual Commercial Building Policies.............................. 38

4.4 Integrated Commercial Policy Bundle ............................................................. 42

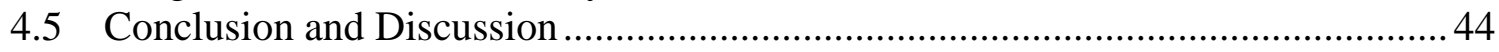

$5 \quad$ Energy Efficiency Potential in Industrial Sector ................................................................. 45

5.1 Overview of Previous Literature on the Energy-Efficiency

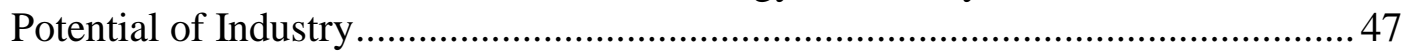

5.2 Industrial Efficiency Policy Options and Modeling Approach................................. 49

5.3 Modeling Results for Industry Policies.............................................................51

5.4 Integrated Industrial Policy Bundle ...............................................................58

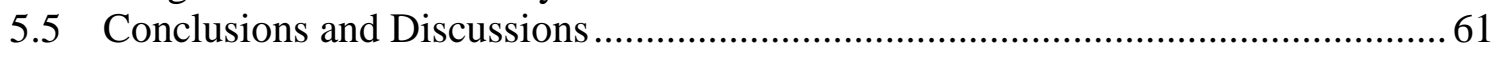

$6 \quad$ Integrated Policy Case ...........................................................................................................66

6.1 The Achievable Potential of Electricity Savings ……….........................................66

6.2 Policy Impacts on Electricity Rates and the Power Sector ..................................... 70 
6.3 Policy Impacts on Other Fuels and Carbon Emissions ...................................... 73

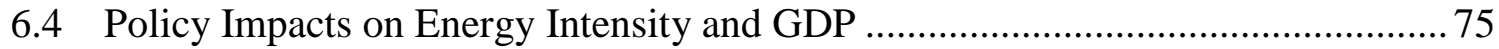

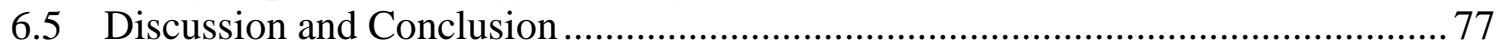

\section{Appendices}

A GT-NEMS Modeling of Residential Energy Efficiency Policies ............................... 85

B GT-NEMS Modeling of Commercial Energy Efficiency Policies ...............................89

C GT-NEMS Modeling of Industrial Energy Efficiency Policies................................... 96

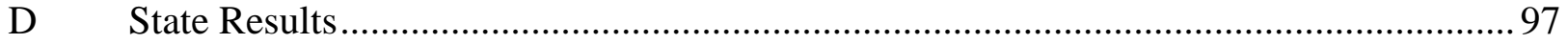

\section{LIST OF FIGURES AND TABLES}

Figures

ES.1 Total Energy Savings Potential of an Integrated Policy Scenario in the Eastern Interconnection (in Quads) .................................................................................. ix

ES.2 Protential Electricity Savings (all sectors) from the Integrated Policy Scenario in the

Eastern Interconnection $\mathrm{X}$

ES.3 Electricity-Savings Potential by Sector Based on the Integrated Policy Scenario (in TWh) $\mathrm{xi}$

ES.4 Supply Curve for Electricity Efficiency Policies in 2020 in the Eastern Interconnection xii

1.1 Interconnections of the National Electricity Reliability Council (top) and Regions and Divisions of the U.S. Census Bureau (bottom).

3.1 Residential Energy Consumption in the Eastern Interconnection in 2009 .................... 15

3.2 Reference Case Forecast of Residential Consumption in the Eastern Interconnection ... 16

3.3 Building Energy Code Retirement Years by Census Division ................................... 19

3.4 Adoption Status of Residential Building Energy Codes as of April, 2012 ................... 19

3.5 States with On-Bill Financing Programs ............................................................20

3.6 Estimated Reduction in Electricity Demand by Individual Residential Policies.............22

3.7 Electricity Savings by Census Division for Individual Policies ..................................23

3.8 Residential Electricity Savings Potential in the Eastern Interconnection ......................28

4.1 Commercial Energy Consumption in the Eastern Interconnection...............................33

4.2 Reference Case Forecast of Commercial Electricity Consumption in the Eastern

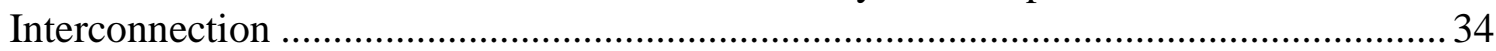

4.3 Mandated Disclosure and Benchmarking Efforts in the United States......................... 36

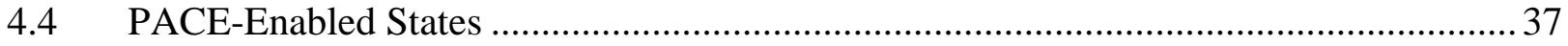

4.5 Estimated Reductions in Electricity Demand by Individual Policies ........................... 38

4.6 Electricity Savings by Census Division for Individual Policies .................................. 39

4.7 Commercial Electricity Savings Potential in the Eastern Interconnection ..................... 42

5.1 Industrial Energy Consumption in the Eastern Interconnection ................................ 45

5.2 Primary Energy Consumption by Manufacturing Industries in 2006, Nationwide ......... 46

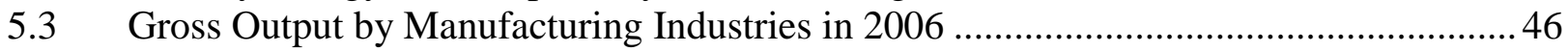


5.4 Reference Case Forecast of Industrial Electricity Consumption in the Eastern

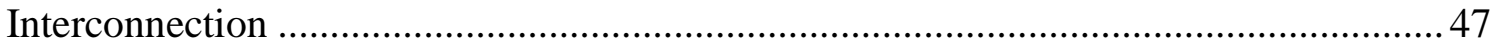

5.5 Estimated Reductions in Electricity Demand by Individual Policies (Excluding CHP) . 51

5.6 CHP Generation and Reductions in Electricity Purchase ………………………...........52

5.7 Potential for Expanded CHP Generating Capacity in the Eastern Interconnection..........53

$5.8 \quad$ Natural Gas Consumption by Industry Sector in the Eastern Interconnection .................53

$5.9 \quad$ Electricity Retail Price in the Industry Sector...............................................................5

5.10 Electricity Savings by Census Division from Motor Rebates, Motor Standard, and Advanced Manufacturing Initiative (West South Central Excluding Texas) ...................55

5.11 Electricity Savings by Census Division from CHP (West South Central Excluding

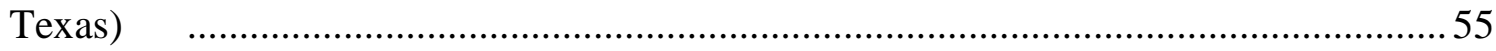

5.12 U.S. Industrial Consumption by Size of Firm.............................................................58

5.13 Industrial Electricity Savings Potential in the Eastern Interconnection............................59

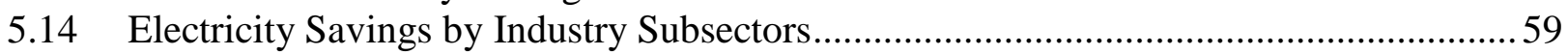

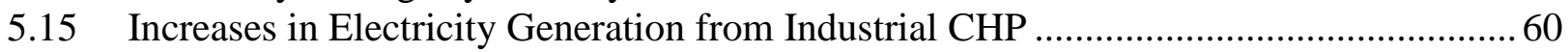

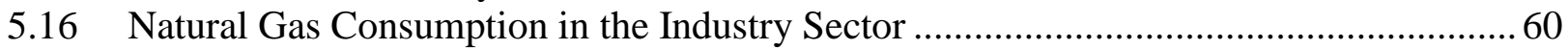

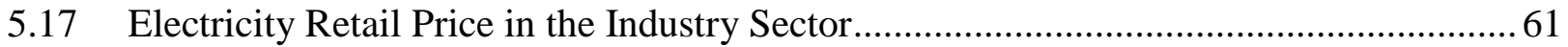

6.1 Supply Curve for Electricity Policies in 2020 ..........................................................6 65

6.2 Electricity Savings from the Integrated Policy Case in the Eastern Interconnection .......67 67

6.3 Electricity-Savings Potential by Sector, Based on the Integrated Policy Case (in TWh) 67

6.4 Achievable Potential for Electricity Savings by State in 2020 ......................................69

6.5 Electricity Price Changes by Census Division................................................................ 71

6.6 Power Generations by Source in the U.S., in TWh (EE=Energy Efficiency) ..................73

6.7 Total Energy Savings in the Eastern Interconnection (Quads) .........................................74

$6.8 \quad \mathrm{CO}_{2}$ Emissions in the Eastern Interconnection (Million Tonnes) .....................................74

6.9 Forecasted Changes in Energy Intensity by Economic Sectors .........................................76

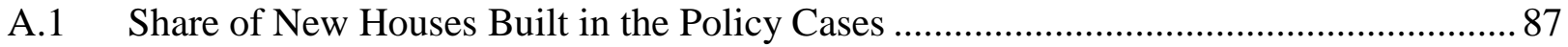

$\underline{\text { Tables }}$

ES-1 Potential Electricity Savings by Sector Policy Bundles in the Eastern Interconnection ..xi

$1.1 \quad$ Assessments of Energy-Efficiency Potential ................................................................ 4

$1.2 \quad$ Market Failures and Barriers Inhibiting Energy Efficiency ........................................... 7

2.1 Selected Policies for Electric End-Use Efficiency ........................................................... 11

3.1 GT-NEMS Lever for Residential Efficiency Policies .................................................... 18

3.2 Natural Gas Savings from Individual Policies ...........................................................2

3.3 Total Energy Savings from Individual Policies, Residential Sector ................................2.25

3.4 Cost Estimations from Appliance Incentives..............................................................2. 26

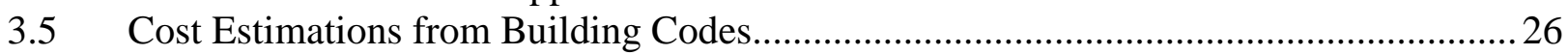

3.6 Cost Estimations from On-Bill Financing ………..................................................2

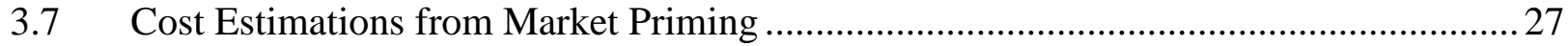

3.8 Cost Estimations from Aggressive Appliance Policy …………………………….........2 27

3.9 Electricity Savings Potential by End-use in the US .......................................................2 29

3.10 Technology Demand Shift from Residential Policies in the Eastern Interconnection.....29

3.11 Demand share of Electric Heat Pumps for Cooling in the Eastern Interconnection..........30

3.12 Potential savings of natural gas and total energy in the Eastern Interconnection..............30

3.13 Potential Reduction in $\mathrm{CO}_{2}$ Emissions from Residential Policies ..................................30 
3.14 Comparison of Policy Impacts in the Eastern Interconnection.........................................31

4.1 GT-NEMS Lever for Commercial Energy Efficiency Policies ........................................35

4.2 Natural Gas Savings from Individual Policies ...............................................................4 40

4.3 Total Energy Savings from Individual Policies ............................................................ 40

4.4 Cost Estimates from Benchmarking ………….......................................................... 41

4.5 Cost Estimates from Financing ………………...................................................... 41

4.6 Cost Estimates from Building Codes .......................................................................... 41

4.7 Electricity-Savings Potential by End-Use in the US.....................................................4 43

4.8 Potential Savings of Natural Gas and Total Energy ……..............................................4 43

4.9 Potential Reduction in $\mathrm{CO}_{2}$ Emissions from Commercial Policies .................................43

$5.1 \quad$ GT-NEMS Lever for Industrial Efficiency Policies ........................................................5 50

5.2 Natural Gas Savings from Advanced Manufacturing Initiative .......................................56

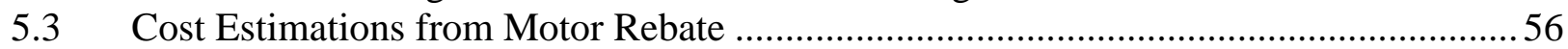

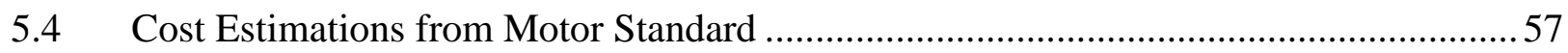

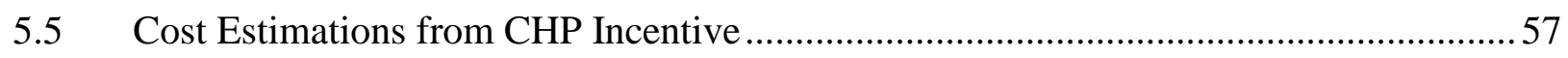

5.6 Cost Estimations from Advanced Manufacturing Initiative …………………................58

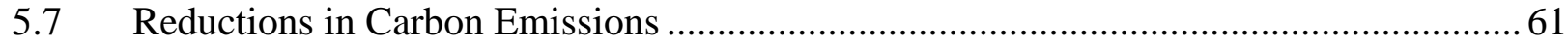

6.1 Savings Potential and Levelized Cost of Electric End-Use Efficiency, by Policy …........64 64

6.2 The Levelized Cost of Electricity Efficiency by Type of Policy (in cents $/ \mathrm{kWh}$ ) .............66 66

6.3 Electricity-Savings Potential in 2020, by Census Division (as percentages of Reference case consumption in 2020) ......................................................................68

6.4 Electricity Rate Changes in 2020, Reference versus Integrated Policy Case ................... 70

6.5 Electricity Generation by Source in the U.S. (in TWh), Reference Forecast versus Integrated Policy Case ............................................................................................... 72

6.6 Energy-Savings Potential of Natural Gas and Total Energy ……...................................73

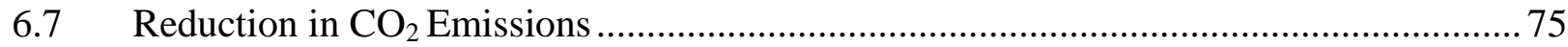

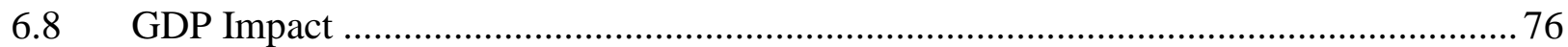

A.1 Most Efficient Home Appliances and Equipment ………………................................. 85

A.2 Building Energy Codes Profile for Residential Buildings ............................................... 86

A.3 Residential Technologies Forced Early Retirement ……….............................................. 88

B.1 Discount Rates Across Scenarios for Space Heating and Lighting in 2015 .................... 90

B.2 Commercial Building Shell Efficiency Improvement* ................................................... 91

B.3 Incentivized Technologies in Financing Policy Case …………....................................... 91

C.1 Electricity and Natural Gas Saving Estimations from IAC Reports .................................96

D.1 Electricity Efficiency Potential By State (TWh) ...........................................................97 


\section{ACKNOWLEDGMENTS}

Funding for this research was provided by Oak Ridge National Laboratory and the Department of Energy (DOE). This sponsorship is greatly appreciated.

Bob Pauley of Eastern Interconnection States Planning Council (EISPC) contributed meaningfully to communications with EISPC members and the Navigant team regarding the completion of this report. Valuable comments on earlier drafts of the report were received from Youngson Baek and Stanton Hadley (Oak Ridge National Laboratory). Faculty and students in the School of Public Policy at Georgia Tech also provided feedback on this research, including Professors Paul Baer and Doug Noonan and PhD students Matt Cox, Gyungwon Kim, Alexander Smith, and Xiaojing Sun. Gyungwon Kim also provided valuable assistance with the graphics, especially the GIS analysis and maps.

The authors are grateful for the willingness of these individuals to engage in a dialogue about the potential to expand energy-efficiency resources.

Any remaining errors are the sole responsibility of the authors. 


\section{EXECUTIVE SUMMARY}

Comprehensive and integrated resource planning considers the potential for increases in energy efficiency to reduce the requirements for new generation and transmission investments. This study supports such planning efforts by developing robust estimates of the economically achievable potential for improving the energy-efficiency of homes, commercial buildings, and industrial plants located in the Eastern Interconnection. The approach of this study involves identifying a series of energy-efficiency policies and examining their impacts and cost-effectiveness using Georgia Tech's version of the National Energy Modeling System (GT-NEMS). The project emphasizes the impacts on electricity consumption, the levelized cost of policy-driven electricity savings, and distributive effects at the state and regional levels. Thirty-six states and the District of Columbia are covered by this study, and the time frame extends to 2035 .

Using GT-NEMS, we model twelve policy options designed to stimulate energy-efficiency investments and practices by providing better information, more effective regulations, and affordable financing. These policies are evaluated individually, combined into Policy Bundles and evaluated for each sector, and evaluated in an Integrated Policy scenario. While the policies are designed to address different market failures and barriers and to focus on distinct market segments and technologies, the level of savings driven by the policies diminishes as more policies are combined. We focus on the achievable energy-efficiency potential, which is the subset of the technically feasible and cost-effective potential that can be achieved through policy intervention.

Based on GT-NEMS estimates from the Integrated Policy scenario, the twelve policies could significantly drive down energy consumption, reduce energy rates, and generate energy bill savings for end-users. Figure ES.1 illustrates the projected energy consumption of the region in the Reference case and Integrated Policy case.

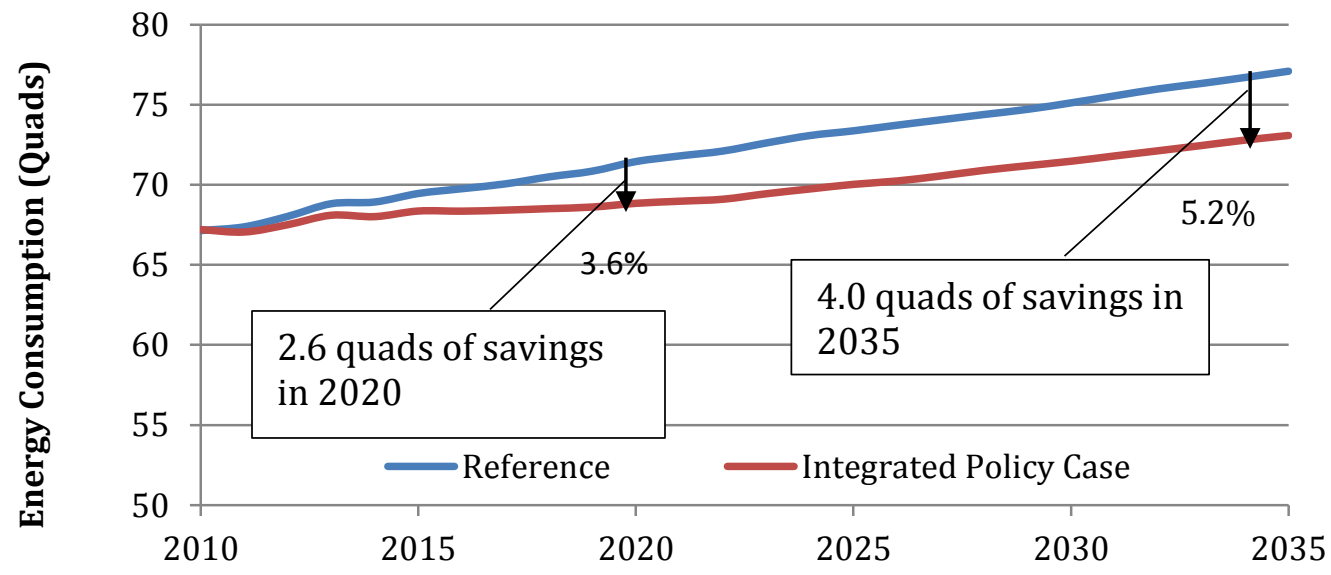

Figure ES.1 Total Energy Savings Potential of an Integrated Policy Scenario in the Eastern Interconnection (in Quads) 
In the Eastern Interconnection, electricity consumption is forecast to grow at an average rate of $0.77 \%$ per year, and to go up to 3,200 TWh in 2035 in the Reference case. With the twelve energy-efficiency policies, the growth of electricity consumption slows down to an average rate of $0.35 \%$ per year. The combination of twelve policies could save the region about 190 TWh $(6.6 \%)$ of electricity in 2020, and 332 TWh (10.3\%) of electricity in 2035 (Figure ES.2).

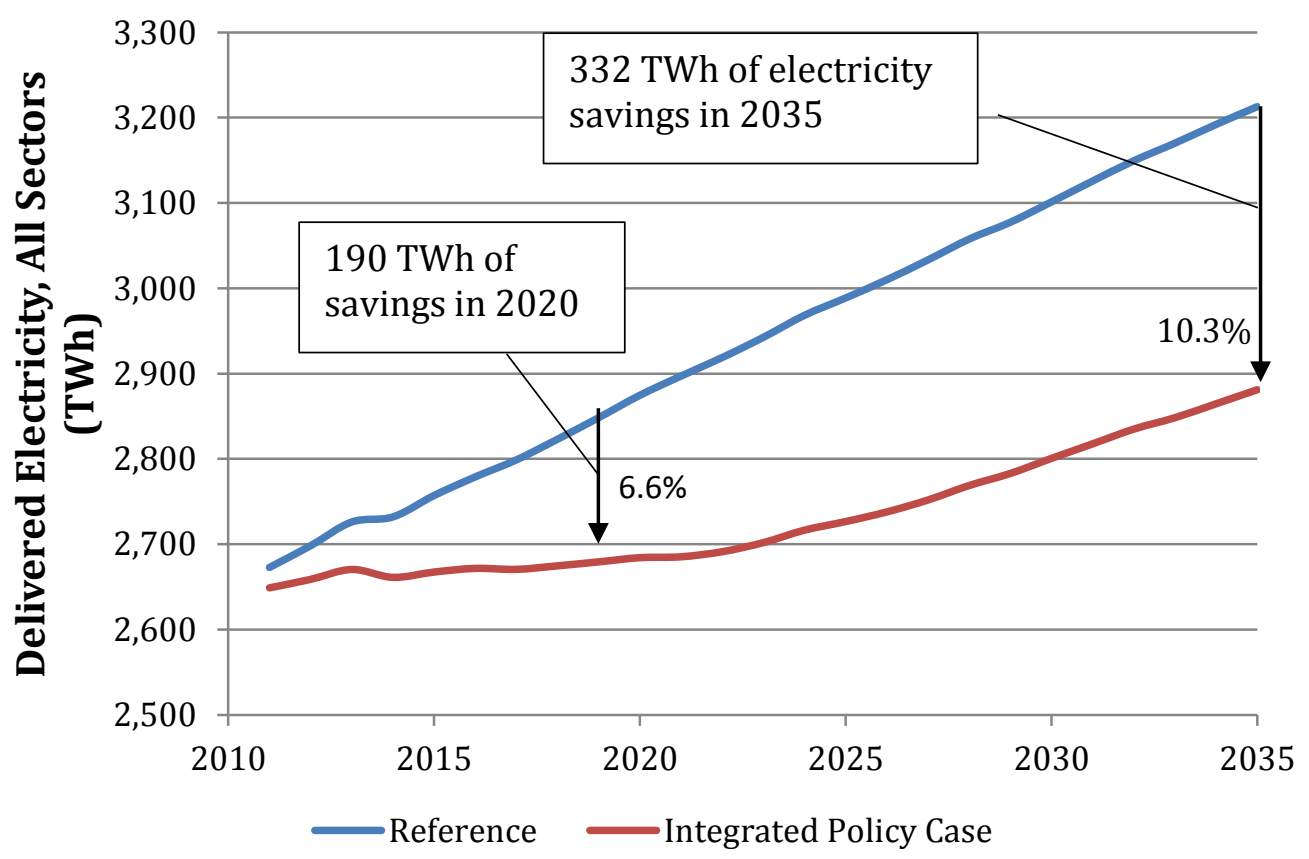

Figure ES.2 Potential Electricity Savings (all sectors) from the Integrated Policy Scenario in the Eastern Interconnection

The energy-efficiency potential driven by the twelve policies comes largely from the residential sector, with additional savings from the commercial and industrial sectors (Figure ES.3). In the Integrated Policy case, the residential sector is estimated to save $13.2 \%$ of electricity in 2035, which is slightly lower than the estimated savings (15.4\% in 2035) from the residential Policy Bundle. Similarly, the estimated savings potential from the commercial sector is $7.9 \%$ in 2035 , lower than the estimation ( $8.4 \%$ in 2035) from the commercial sector Policy Bundle. Overlap in the electricity savings identified by the policies underlies these differences, and an overlap of $10-20 \%$ is suggested by these results. In contrast, the industrial sector potential in the Integrated Policy case is estimated to be comparable (10.4\% in 2035) to the savings potential identified by the industrial Policy Bundle. The electricity from industrial CHP generation that is sold back to the grid is not shown in this figure. An additional $39 \mathrm{TWh}$ are generated by CHP systems (28 TWh are consumed at the industrial plant and $11 \mathrm{TWh}$ are sold back to the grid). 


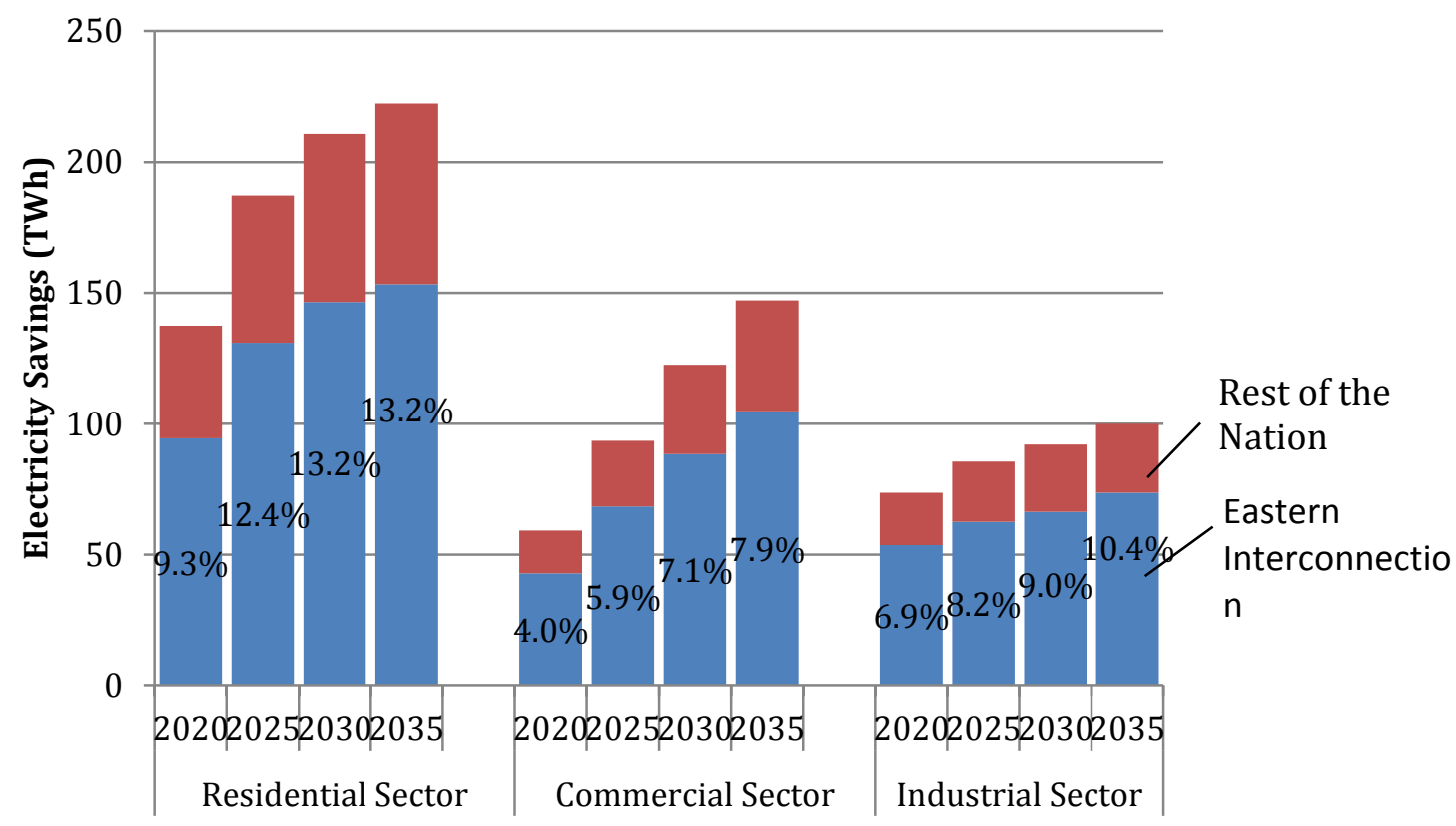

Figure ES.3 Electricity-Savings Potential by Sector, Based on the Integrated Policy Scenario (in TWh)

Table ES.1 illustrates the detailed savings potential for electricity end-use by sector, based on the individual policy bundles.

Table ES-1. Potential Electricity Savings by Sector Policy Bundles in the Eastern Interconnection

\begin{tabular}{|c|c|c|c|c|c|c|}
\hline \multirow{2}{*}{} & \multicolumn{2}{|c|}{ Residential Sector } & \multicolumn{2}{c|}{ Commercial Sector } & \multicolumn{2}{c|}{ Industrial Sector } \\
\cline { 2 - 7 } & $\begin{array}{c}\text { Potential } \\
\text { Savings } \\
(\text { TWh })\end{array}$ & $\begin{array}{c}\% \\
\text { Savings }\end{array}$ & $\begin{array}{c}\text { Potential } \\
\text { Savings } \\
(\text { TWh })\end{array}$ & $\begin{array}{c}\% \\
\text { Savings }\end{array}$ & $\begin{array}{c}\text { Potential } \\
\text { Savings } \\
(\text { TWh })\end{array}$ & $\begin{array}{c}\% \\
\text { Savings }\end{array}$ \\
\hline 2020 & 102 & $10.1 \%$ & 60 & $3.9 \%$ & 48 & $6.3 \%$ \\
\hline 2035 & 179 & $15.4 \%$ & 153 & $8.4 \%$ & 68 & $10.4 \%$ \\
\hline
\end{tabular}

According to GT-NEMS modeling supplemented by spreadsheet calculations, the electricity savings could be achieved at relatively low cost. Specifically, the levelized cost of electricity savings estimates in 2009 \$ per $\mathrm{kWh}$ range from 0.5-0.8 cents/kWh for Residential Building Codes and 0.6-0.7 cents/kWh for the Aggressive Appliance Policy to 6.7-8.0 cents/kWh for Appliance Incentives and 9.3-11.5 for Motor Rebates.

Together with the levelized cost estimations, the electricity-savings potentials produce a policy supply curve (Figure ES.3). This curve suggests that regulatory policies have relatively low levelized cost of electricity and financial policies have relatively high LCOEs, 
with the CHP Incentive as an exception. Taking average electricity rates as benchmarks, all twelve policies except for the Motor Rebate are cost-effective, representing $98 \%$ of the savings potential. Information programs have particularly large energy-savings potential, most notably residential Market Priming and commercial Benchmarking.

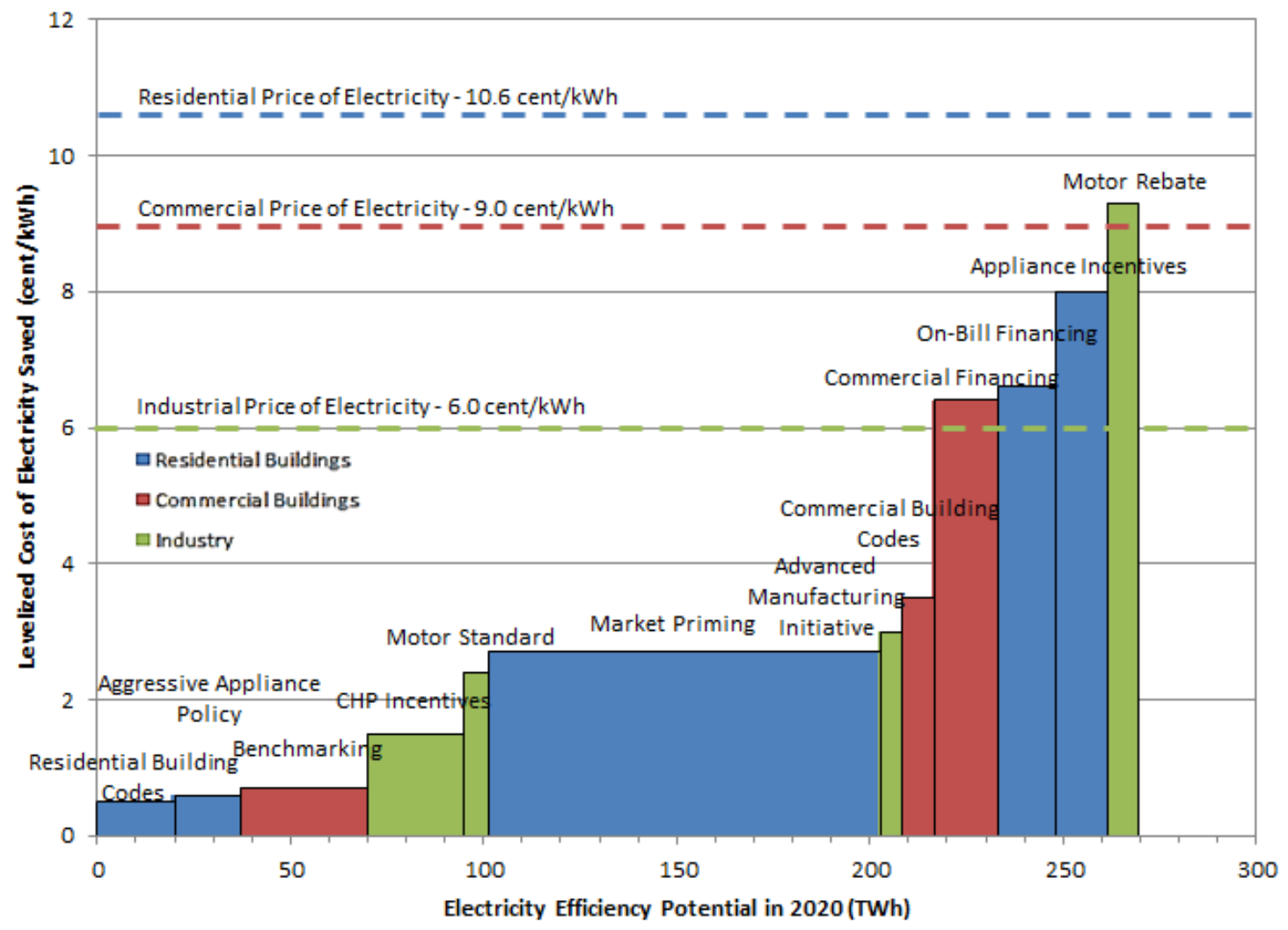

Figure ES.3 Supply Curve for Electricity Efficiency Policies in 2020 in the Eastern Interconnection

The electricity savings of energy-efficiency policies would be accompanied by other benefits, including natural gas savings and savings in other fuel types. These energy-efficiency policies are able to drive down electricity retail prices in most regions and produce savings for consumers in their energy bills. For example, residential customers are estimated to save about $\$ 13$ Billion in reduced energy costs in 2020; savings would also be experienced by commercial customers ( $\$ 5$ Billion) and industrial customers ( $\$ 4$ Billion), and energy bill savings for all sectors would expand in later years. The electric power sector is also affected by these policies, as a result of slower generation growth. Overall, these policies are estimated to reduce energy and carbon intensity without significantly impacting GDP growth.

The sizable reduction in energy consumption is associated with reductions in carbon dioxide emissions. The energy efficiency policies trim carbon emissions by 161 million tonnes of 
$\mathrm{CO}_{2}(4.0 \%)$ in 2020 , increasing to 246 million tonnes of $\mathrm{CO}_{2}(5.6 \%)$ in 2035 . The percentage numbers of carbon emission reductions are slightly higher than the percentage reductions in energy consumption, reflecting a shift to less-intensive energy sources. The energy efficiency policies are estimated to generate higher savings in electricity, which is more carbon intensive than natural gas in the EIPC region.

In summary, this study shows that energy-efficiency policies would save the Eastern Interconnection $332 \mathrm{TWh}$ of electricity in 2035. The primary energy savings would reach 4.0 Quads if all types of energy are included. The reduced demand for electricity leads to lower electricity rates, which result in significant energy bill savings for residential, commercial and industrial consumers. The policies would also reduce the carbon emissions of the region, with no significant impact on GDP. 


\section{INTRODUCTION, OBJECTIVES, AND BACKGROUND}

The potential for improved electric end-use efficiency has invoked great interest over the past several decades because the cheapest megawatt hour of electricity is often the one that is not needed (Croucher, 2011). In addition, reducing electricity consumption through energy efficiency also helps reduce carbon dioxide emissions, improve air quality, and strengthen grid stability.

Comprehensive and integrated resource planning should consider the potential for increases in energy efficiency to reduce the requirements for new generation and transmission investments. Electricity planners have many options at their disposal: supply-side options, such as central power plants, distributed generation, and energy storage; as well as demand-side options, such as demand response and energy efficiency. What combination of these resources can deliver the most reliable, affordable, and clean electricity? Improvements to the knowledge base and modeling capabilities surrounding energy-efficiency resources are critical to the integrity of transmission expansion planning and the optimization of state and regional energy policies.

\subsection{Objectives}

The principal objective of this study is to accurately estimate the achievable potential for improving the energy-efficiency of homes, commercial buildings, and industrial plants located in the Eastern Interconnection. What are the potential impacts of energy-efficiency programs and policies in this region? A companion study led by Oak Ridge National Laboratory is examining the potential for greater demand response in this same region (Baek, et al., 2012). The results of both studies are intended to be used by the Eastern Interconnection States Planning Council (EISPC) and the Eastern Interconnection Planning Collaborative (EIPC) in their transmission planning.

Secondary objectives include:

- Reviewing existing assessments of energy-efficiency potential in the Eastern Interconnection, and

- Refining methodologies to construct estimates of energy-efficiency potential in the Eastern Interconnection.

The region served by the EIPC consists of 36 states and the District of Columbia corresponding closely to the coverage of seven census divisions: the East North Central, West North Central, East South Central, West South Central, Middle Atlantic, South Atlantic, and New England divisions. The Eastern Interconnection, including Washington D.C., was home to 211 million individuals in 2010 , or $68.6 \%$ of the nation's population of 309 million in in that year. 

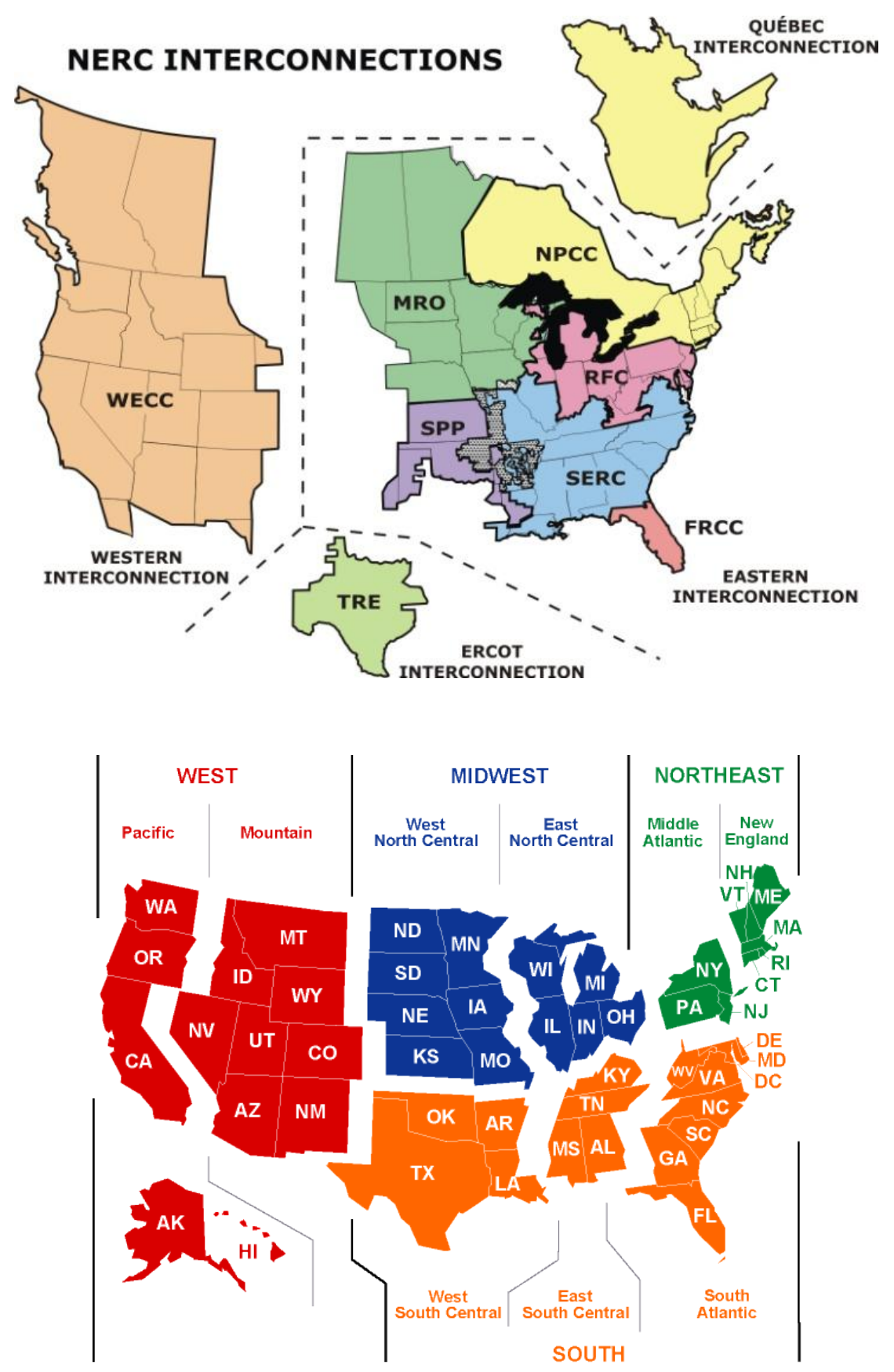

Figure 1.1 Interconnections of the National Electricity Reliability Council (top) and Regions and Divisions of the U.S. Census Bureau (bottom)

(Source: http://www.ercot.com/content/news/mediakit/maps/NERC_Interconnections_color.jpg)

\subsection{Review of Energy-Efficiency Potential}

\subsubsection{The Energy-Efficiency Gap}

The term "energy-efficiency gap" refers to the unexploited economic potential for energy efficiency; in other words, it emphasizes the technically feasible energy-efficiency technologies and practices that are cost-effective but are not being deployed. The energy-efficiency gap has 
attracted wide attention among energy policy analysts, since society has forgone many costeffective investments in energy efficiency. This term was first "coined" by Hirst and Brown (1990) in a paper titled "Closing the Efficiency Gap: Barriers to the Efficient Use of Energy." Many other studies have used similar definitions, such as the International Energy Agency (2007) and Jaffe and Stavins (1994). The energy-efficiency gap exists in many sectors, including households, small businesses, corporations, and governments (Dietz, 2010).

It is difficult to quantify the exact magnitude of the energy-efficiency gap. One approach to characterizing its size is through modeling. This typically involves enumerating on a technologyby-technology basis the difference between current practice and best practice, where best practice is defined as the utilization of the most cost-effective energy-efficient technologies. Keeping in mind the natural rate of equipment turnover through consumer purchases, one can then estimate the size of the gap that exists and that can be reduced by policy efforts.

\subsubsection{Defining the Potential for Energy Efficiency}

We define the "achievable potential" for energy efficiency as that portion of the energyefficiency gap that can be narrowed by the implementation of policies and programs. This terminology has been used by other analysts, in conjunction with the terms "technical potential" and "economic potential" (Rufo and Coito, 2002; NYSERDA, 2003). Specifically:

Technical potential: Assumes that all technically feasible energy-efficiency measures are adopted. These are also referred to as engineering estimates because they do not consider costs. In some cases, the technical potential assumes that the technology available changes over time via innovation.

Economic potential: Generally a subset of technical potential that must pass a cost test. For example, the net present value of total benefits minus costs must be positive, and the rate of return on the investment must meet a particular threshold. In a utility planning context, this means that the levelized cost of the electricity saved must be less than the forecast cost of electricity generation that it would offset.

Achievable potential: Generally a subset of economic potential that considers what portion of the cost-effective efficiency measures could reasonably be achieved by policy efforts; estimates generally consider a policy incentive of less than $30 \%$ of the energy-efficiency investment's incremental costs.

Among the three types of potential, we focus on estimating the achievable potential for improved energy efficiency in the EIPC region.

\subsubsection{A Review of Estimates of Energy-Efficiency Potential}

A large body of literature has focused on the economic potential for energy-efficiency measures, as summarized in Table 1.1. These assessments of energy-efficiency potential are derived from theory, simulation, and real-world practices, and they have been conducted at various geographic scales, covering different time frames. 
Table 1.1. Assessments of Energy-Efficiency Potential

\begin{tabular}{|c|c|c|c|c|c|c|c|}
\hline \multirow{2}{*}{ Publication } & \multicolumn{3}{|c|}{ Application } & \multicolumn{2}{|c|}{ Potential Assessment } & \multirow[t]{2}{*}{ Cost Estimate } & \multirow[t]{2}{*}{ Policy Relevance } \\
\hline & Area & End-use sector & Fuel & Type & Estimation & & \\
\hline \multirow[b]{3}{*}{ Brown et al (2001) } & \multirow[b]{3}{*}{ U.S. } & Residential & \multirow{3}{*}{$\begin{array}{l}\text { Total } \\
\text { energy }\end{array}$} & \multirow[b]{3}{*}{ Achievable } & $9-20 \%$ by 2020 & \multirow{3}{*}{$\begin{array}{l}\text { Total net saving: } 62- \\
108 \text { Billion } 1997 \$ \text { in } \\
2020\end{array}$} & \multirow{3}{*}{$\begin{array}{l}\text { Estimation based on } \\
\text { moderate and advanced } \\
\text { policy scenarios examining } \\
\text { about } 50 \text { policy options }\end{array}$} \\
\hline & & Commercial & & & $9-18 \%$ by 2020 & & \\
\hline & & Industrial & & & $8-17 \%$ by 2020 & & \\
\hline $\begin{array}{l}\text { Tonn \& Peretz } \\
(2007)\end{array}$ & U.S. & $\begin{array}{l}\text { Residential and } \\
\text { Industry }\end{array}$ & $\begin{array}{l}\text { Total } \\
\text { energy }\end{array}$ & Achievable & $\begin{array}{l}20-30 \% \text { over a } 20- \\
\text { year period }\end{array}$ & $\begin{array}{l}\mathrm{B} / \mathrm{C} \text { ratio greater than } \\
3: 1\end{array}$ & $\begin{array}{l}\text { Potential achieved by } \\
\text { standard energy efficiency } \\
\text { programs }\end{array}$ \\
\hline Scott, et al (2008) & U.S. & \begin{tabular}{|l|} 
Residential and \\
Commercial
\end{tabular} & \begin{tabular}{|l} 
Total \\
energy
\end{tabular} & Achievable & $27 \%$ by 2030 & & $\begin{array}{l}\text { Impacts of the } 2005 \text { Building } \\
\text { Technology program }\end{array}$ \\
\hline $\begin{array}{l}\text { Granade et al. } \\
(2009)\end{array}$ & U.S. & $\begin{array}{l}\text { Building and } \\
\text { Industry }\end{array}$ & $\begin{array}{l}\text { Total } \\
\text { energy }\end{array}$ & Economic & $23 \%$ by 2020 & $\begin{array}{l}\text { Average annualized } \\
\text { cost: } \$ 4.4 / \mathrm{MMBtu}(\end{array}$ & \\
\hline $\begin{array}{l}\text { Brown, et al. } \\
(2010)\end{array}$ & $\begin{array}{l}\text { U.S. } \\
\text { southeast } \\
\text { states }\end{array}$ & \begin{tabular}{|l|} 
Residential, \\
Commercial and \\
Industry
\end{tabular} & $\begin{array}{l}\text { Total } \\
\text { energy }\end{array}$ & Achievable & $\begin{array}{l}9-12 \% \text { in } 2020 \\
13-18 \% \text { in } 2035\end{array}$ & $\begin{array}{l}\text { Levelized cost of } \\
\text { electricity: } 0.9-15 \\
\text { cent/kWh }\end{array}$ & $\begin{array}{l}\text { Explores } 8 \text { policy options } \\
\text { promoting efficiency }\end{array}$ \\
\hline Kneifel (2010) & $\begin{array}{l}16 \text { cities in } \\
\text { the U.S. }\end{array}$ & Commercial & $\begin{array}{l}\text { Total } \\
\text { energy }\end{array}$ & Economic & $\begin{array}{l}20-30 \% \text { for new } \\
\text { buildings }\end{array}$ & & \\
\hline $\begin{array}{l}\text { Saygin, et al } \\
(2011)\end{array}$ & U.S. & $\begin{array}{l}\text { Chemical and } \\
\text { petrochemical } \\
\text { industry } \\
\end{array}$ & $\begin{array}{l}\text { Total } \\
\text { energy }\end{array}$ & Economic & $\begin{array}{l}24 \% \text { with top-down } \\
\text { approach; } 10.9 \% \text { with } \\
\text { bottom-up approach }\end{array}$ & & \\
\hline $\begin{array}{l}\text { Sadineni,et al } \\
(2011)\end{array}$ & U.S. & Residential & $\begin{array}{l}\text { Total } \\
\text { energy }\end{array}$ & Economic & $42.5 \%$ & & \\
\hline $\begin{array}{l}\text { Laitner, et al. } \\
(2012)\end{array}$ & U.S. & All Sectors & $\begin{array}{l}\text { Total } \\
\text { energy }\end{array}$ & Economic & $42-59 \%$ by 2050 & & $\begin{array}{l}\text { Technology advances and } \\
\text { policy improvements } \\
\text { modeled }\end{array}$ \\
\hline \multirow{2}{*}{$\begin{array}{l}\text { McKane and } \\
\text { Hasanbeigi (2011) }\end{array}$} & \multirow[b]{2}{*}{ Global } & \multirow{2}{*}{$\begin{array}{l}\text { Industrial motor } \\
\text { systems }\end{array}$} & \multirow{2}{*}{$\begin{array}{l}\text { Total } \\
\text { energy }\end{array}$} & Technical & $27-57 \%$ & & \\
\hline & & & & Economic & $14-49 \%$ & & \\
\hline \multirow[t]{2}{*}{ Fleiter, et al (2012) } & \multirow[t]{2}{*}{ Germany } & \multirow{2}{*}{$\begin{array}{l}\text { Pulp and paper } \\
\text { industry }\end{array}$} & $\begin{array}{l}\text { Total } \\
\text { energy }\end{array}$ & Economic & $21 \%$ by 2035 & & \\
\hline & & & Electricity & Economic & $16 \%$ by 2035 & & \\
\hline
\end{tabular}


Scenarios for a Clean Energy Future (Brown, et al., 2001) and a study by McKinsey and Company (Granade, et al., 2009) are national in scope and focus on the 2020 time frame. Brown et al. (2001) used this technology-based accounting approach and concluded that removing obstacles to energy efficiency through policy interventions initiated in the year 2000 could have reduced the forecasted U.S. energy consumption in 2010 by $10 \%$. The McKinsey and Company study estimates the NPV-positive potential for energy efficiency savings in non-transportation uses of energy. It finds that energy efficiency programs can save the nation 9.1 quadrillion Btu (23\%) in end-use energy and 18.4 quadrillion Btu in primary energy by 2020. The potential in the commercial sector is $29 \%$ of end-use energy and $30 \%$ of primary energy, which sums up to $\$ 290$ billion in total energy savings from 2009-2020.

An achievable potential study conducted by the Electric Power Research Institute (EPRI) forecasts the potential energy saving that would be achieved by energy-efficiency programs in 2030 to be 398-566 billion $\mathrm{kWh}(8-11 \%)$, with estimated levelized cost between $\$ 0.022 / \mathrm{kWh}$ and 0.032/kWh (EPRI, 2009).

The American Council for an Energy-Efficient Economy (ACEEE) completed a meta-review of energy efficiency potential assessments in the U.S. (Nadel et al., 2004). This review concluded that, across the U.S., the median technical potential is $33 \%$, the median economic potential is $20 \%$, and the median achievable potential is $24 \%$. The overall median achievable potential is an annual energy savings of $1.2 \%$, with similar savings from each end-use sector. The number of years estimated and the type of potential estimated vary widely from study to study, making the median numbers relatively unreliable estimations. The ACEEE study also summarizes the electricity savings actually achieved by utilities in some of the leading states based on historical data. The leading utilities were estimated to achieve annual electricity savings of 0.5-2.0\%.

A recent ACEEE study investigates the long-term efficiency potential associated with technology advances and policy improvements (Laitner, et al, 2012). By comparing their policy scenarios with EIA's projection - the Annual Energy Outlook 2010 - the overall potential of energy efficiency is estimated to be $42-59 \%$ by 2050 .

Many studies produce potential estimates at the state level. One of these, by Tonn and Peretz (2007), estimated that standard residential and industrial energy-efficiency programs have energy-efficiency potentials of $20-30 \%$ over a 20 -year period. The programs studied in that review are generally cost-effective, with benefit-to-cost ratios exceeding 3:1. Neuhoff, et al. (2012) conclude that the most aggressive Energy Efficiency Resource Standards (requiring utilities or program administrators to reach specific goals for energy savings) target energyefficiency savings of about $2 \%$ per year, or electricity savings of about $20 \%$ in total between 2010 and 2020. Policy instruments, such as subsidies, income taxes, and carbon taxes can make efficiency investments more profitable (Amstalden, et al, 2007), and energy labeling can improve efficiency in household energy use (Feng, 2010). Recent modeling assessments of 
energy-efficiency potential have documented a significant achievable potential in the South (Brown et al., 2010), in Appalachia (Brown et al., 2009), and in industry (Brown, et al., 2011).

\subsection{Barriers, Drivers, and Current Policies}

Numerous obstacles - including market failures and barriers - contribute to the energy efficiency gap (Table 1.2). Market failures occur when there are flaws in the way markets operate. The traditional literature on market failures tends to examine circumstances in which market prices fail to provide sufficient information or incentives to achieve Pareto optimality within the context of a perfectly competitive market. Pareto optimality exists when gains from trade are exhausted and when the situation prevails that no individual's well-being can be improved without a worsening of some other individual's well-being.

Market failures are conditions of a market that violate one or more neoclassical economic assumptions that define a competitive market, such as rational behavior, costless transactions, and perfect information. Traditionally, market failures were attributed to (1) misplaced incentives; (2) distortionary fiscal and regulatory policies; (3) unpriced costs such as air pollution; (4) unpriced goods such as education, training, and technological advances; and (5) monopoly power. A more recent literature focuses on information-based market failures including a general lack of information, information asymmetries, and price signaling. This literature draws upon advances in behavioral economics that focus on incentives provided by distributions of information that are less than perfect, but which are arguably commonplace (Jaffe and Stavins, 1994) (Table 1.2).

"Market barriers" refer to other obstacles that contribute to the slow diffusion and adoption of energy-efficient innovations (Jaffe and Stavins, 1994, Hirst and Brown, 1990, Levine et al., 1995, and U.S. Department of Energy). To the extent that it is in society's best interest to use its energy more efficiently, improve grid reliability, and reduce emissions from fossil fuel combustion, it is important to understand the full range of obstacles to energy-efficient technologies. These barriers include: (1) the low priority of energy issues among consumers, (2) capital market imperfections, (3) incomplete markets for energy-efficient features and products, and (4) infrastructure longevity. 
Table 1.2 Market Failures and Barriers Inhibiting Energy Efficiency

\begin{tabular}{|c|c|}
\hline $\begin{array}{c}\text { Market Failures: Flaws in the way markets } \\
\text { operate }\end{array}$ & $\begin{array}{c}\text { Market Barriers: Other factors inhibiting } \\
\text { rapid adoption }\end{array}$ \\
\hline $\begin{array}{c}\text { Misplaced incentives including the } \\
\text { "principal-agent" problem }\end{array}$ & $\begin{array}{c}\text { Low priority of energy issues resulting } \\
\text { from the fact that energy is often a } \\
\text { small part of the cost of owning and } \\
\text { operating a building or factory }\end{array}$ \\
\hline $\begin{array}{c}\text { Distortionary fiscal and regulatory policies } \\
\text { including the preferential tax } \\
\text { treatment of capital versus operating } \\
\text { costs, fuel subsidies, and the coupling } \\
\text { of electricity sales to profits }\end{array}$ & $\begin{array}{c}\text { Capital market barriers due in part to the } \\
\text { lower interest rates available to } \\
\text { energy suppliers relative to energy } \\
\text { consumers }\end{array}$ \\
\hline $\begin{array}{c}\text { Unpriced costs such as air and water } \\
\text { pollution and greenhouse gas } \\
\text { emissions }\end{array}$ & $\begin{array}{c}\text { Incomplete markets for energy efficiency, } \\
\text { compounded by the complexity of } \\
\text { design, construction, and operation of } \\
\text { buildings making it difficult to } \\
\text { characterize their energy efficiency }\end{array}$ \\
\hline $\begin{array}{c}\text { Unpriced goods such as education, training } \\
\text { and technological advances }\end{array}$ & $\begin{array}{c}\text { Infrastructure longevity contributing to the } \\
\text { "lock-in" of incumbent technologies }\end{array}$ \\
\hline $\begin{array}{c}\text { Insufficient, inaccurate and asymmetric } \\
\text { information leading to suboptimal } \\
\text { decision-making }\end{array}$ & \\
\hline monopoly power hindering competition & \\
\hline
\end{tabular}

Apart from barriers, estimations of the achievable potential of energy efficiency and the design of effective policies must also consider economic and social/institutional drivers of energy efficiency. The business case for energy efficiency varies across market sectors, types of households, firm size, and region of the country, and it reflects a variety of motivations for using energy more wisely. Nevertheless, common motivations emerge from the literature, as summarized in the report on "Strategies for the Commercialization and Deployment of Greenhouse Gas Intensity-Reducing Technologies and Practices” (CCCSTI, 2009):

- Volatile and rising energy prices - "The sustained pain" of rising oil, coal, natural gas, and electricity prices is motivating a renewed interest in energy efficiency

- Environmental concerns and regulations - Energy-efficiency investments can tap into potentially lucrative revenue streams from $\mathrm{NO}_{\mathrm{x}}$ and $\mathrm{SO}_{2}$ offsets in non-attainment zones, RES/EERS compliance requirements, and tradable carbon allowances

- Demand charges and demand response incentives - The ability to cut peak electric load motivates many utilities to incentivize demand-side management. 
- Collateral benefits - Increased productivity, improved product quality, reduced labor costs, and enhanced reliability can result from energy-efficiency investments. In addition, improved stability of financial performance should lead to lower cost of capital, in terms of both access and cost of financing.

- International competition - When the cost of energy inputs makes a firm unable to compete, energy-efficiency improvements are often sought out. Energy cost reductions can also be used to offset other rising costs, such as labor.

- Corporate sustainability - Energy efficiency as a climate change mitigation strategy offers a way to boost shareholder/investor confidence, profit from future legislation, and access new markets.

- Consumer and shareholder activism, good corporate governance, and reputation management - these have proven to be a strong motivators for energy-efficiency and other investments in sustainability.

- Insurance access and costs, legal compliance, and concerns regarding fiduciary duty - All represent additional potential drivers.

Most of these drivers were highlighted in the study of Real Prospects for Energy Efficiency in the United States (National Academies, 2009).

Numerous policy levers are available to address traditional market failures and barriers and to leverage drivers for energy efficiency (Geller, 2002; Brown and Sovacool, 2011). One succinct typology of policies identifies three ways of exploiting the achievable potential for energy efficiency: (1) financial assistance, including subsidies, bulk procurements, and loan guarantees; (2) regulatory requirements, such as codes, standards, and cap and trade programs; and (3) information programs including labeling, education, R\&D support, and workforce training (Brown et al., 2011). The costs and benefits of different policy approaches will vary by market sector and technology opportunity, as reflected in subsequent chapters. 


\section{METHODOLOGY}

\subsection{Overview of Approach}

A portfolio of twelve energy-efficiency policies is modeled with the Georgia Institute of Technology's version of National Energy Modeling Systems (GT-NEMS) to estimate the longterm achievable potential in the Eastern Interconnection. Supplemental spreadsheet analysis is used to estimate the levelized cost of electricity (LCOE) that could potentially be saved, based on GT-NEMS output for each of the financial, regulatory and information policies. Similarly, estimates of carbon dioxide emissions and reductions in fuel consumption for all end-use sectors can also be extracted from GT-NEMS output. Based on this information, the benefit of reduced carbon emissions and avoided criteria air pollutions will be evaluated for climate change and environmental impacts in a benefit-cost analysis.

\subsection{National Energy Modeling System}

GT-NEMS is the principal modeling tool used in this study, supplemented by spreadsheet calculations. Specifically, we employ the version of NEMS that generated EIA's Annual Energy Outlook 2011 (EIA, 2011a), which forecasts energy supply and demand for the nation out to 2035. NEMS models U.S. energy markets and is the principal modeling tool used to forecast future U.S. energy supply and demand. Twelve modules represent supply (oil and gas, coal, and renewable fuels), demand (residential, commercial, industrial, and transportation sectors), energy conversion (electricity and petroleum markets), and macroeconomic and international energy market factors. A thirteenth "integrating" module ensures that a general market equilibrium is achieved among the other modules. Beginning with current resource supply and price data and making assumptions about future use patterns and technological development, NEMS carries through the market interactions represented by the thirteen modules and solves for the price and quantity of each energy type that balances supply and demand in each sector and region represented (EIA, 2009). Outputs are intended as forecasts of general trends rather than precise statements of what will happen in the future. As such, NEMS is highly suited to projecting how alternative assumptions about resource availability, consumer demand, and policy implementation may impact energy markets over time.

The GT-NEMS "Reference case" projections are based on federal, state, and local laws and regulations in effect at the time of the analysis. The baseline projections developed by the EIA via NEMS are published annually in the Annual Energy Outlook, which is regarded as a reliable reference in the field of energy and climate policy. We have used GT-NEMS to perform scenario analysis under a consistent modeling framework in order to compare policy options to the Reference case projections.

GT-NEMS also provides estimates of the carbon intensity of electricity generation based on generation resources over time. The benefit of reduced $\mathrm{CO}_{2}$ emissions are estimated by subtracting the emissions in the Reference case from the policy scenario and then multiplying by the "social cost of carbon" (SCC). The SCC is an estimate of the monetized damages caused by a metric ton of $\mathrm{CO}_{2}$ emitted in a given year. The social cost of carbon used in this analysis is the 
central value of the U.S. Government Interagency Working Group on the Social Cost of Carbon (EPA, 2010), growing from \$23/metric ton in 2011 to $\$ 47 /$ metric ton in 2050 (all values are in 2008-\$ and account for global avoided damages).

Present-value calculations for the levelized cost of electricity use a 3\% discount rate, consistent with Office of Management and Budget guidelines (OMB, 2002; 2010). The OMB guidelines recommend the use of $3 \%$ discount rates when evaluating regulatory proposals from a social perspective. This is less than the $10 \%$ value used in some other energy-efficiency studies such as McKinsey and Company's analysis (Granade, et al., 2009), which focus on investment decisionmaking from a private market perspective.

\subsection{Energy Efficiency Policy Levers}

A suite of twelve policies was selected to estimate the achievable potential for energy efficiency: four regulatory policies, five financial policies, and three information policies (Table 2.1). For residential buildings, five policies are designed to reduce the up-front cost of end-use technologies and energy-efficient building envelopes. For commercial buildings, three policies are designed to expand investments in energy-efficiency improvements. In the industrial sector, the policies target motor systems and other efficiency improvements in various industrial processes, as well as combined heat and power ("CHP") systems to make use of waste heat.

In the policy scenario, financial incentives are offered to energy-efficient technologies in the end-use sectors. For residential buildings, 25 energy-efficient home appliances and equipment were selected from the NEMS technology profile. Financial incentives (either a subsidy or zerointerest loan) were offered to cut down capital costs of these selected technologies. Similarly, 110 commercial building technologies were selected and offered flexible financing options. For industries, energy-efficient technologies include combined heat and power (CHP) systems which utilize waste heat, and electric motor systems which satisfy the Energy Independence and Security Act of 2007 minimum efficiency requirement. Industrial energy efficiency policies provide rebates and subsidies for CHP systems and premium motors.

Regulatory policies impose standards and mandates to enhance efficiency improvements. Building energy codes were modeled to represent shell efficiency improvements for residential and commercial buildings. For residential buildings, compliance with new building codes was assumed implicitly when less stringent codes were forced to gradually retire. In the commercial sector, the whole building stock is assumed to progress in shell efficiency gradually to reach the efficiency level equivalent to the most recent code, ASHRAE 90.1-2010, with 100\% compliance in 2035. Appliance standards were applied to remove inefficient residential technologies from the market. Motor standard were established to increase efficiency standard for electric motors used in industries.

In addition, a broad set of information instruments was explored in the policy scenario. For homes, the Market Priming policy is a combination of several information options, including mandated disclosure of home energy consumption or performance at the point of sale or lease of a residential unit, home rating, green labeling, and other technical assistance features such as home energy audits and assistance with green leases, etc. For commercial buildings, the benchmarking policy requires utilities to submit whole building energy consumption data to a 
uniform database accessible by building owners. Studies suggest that providing information can reduce discount rates used in investment decisions from 3\% to 22\% (Coller and Williams, 1999; Goett, 1983). Thus, adjusting discount rate was the NEMS lever used for modeling Market Priming and Benchmarking. For industries, Advanced Manufacturing Initiative is the information-based policy that provides information about efficiency opportunities for plant utility upgrades. The impact of this information is based on the potential efficiency improvements from the Industrial Assessment Centers (IAC) database.

\section{Table 2.1. Selected Policies for Electric End-Use Efficiency}

\begin{tabular}{|c|c|c|c|}
\hline Sector & Policy Type & Policy & Scenario Description \\
\hline \multirow[t]{5}{*}{ Residential } & Financial & $\begin{array}{l}\text { Appliance } \\
\text { Incentives }\end{array}$ & $\begin{array}{l}\text { Providing a } 30 \% \text { subsidy to cut down capital } \\
\text { costs for the most efficient technologies }\end{array}$ \\
\hline & Financial & $\begin{array}{l}\text { On-Bill } \\
\text { Financing }\end{array}$ & $\begin{array}{l}\text { Offering zero-interest loans for the most } \\
\text { efficient technologies }\end{array}$ \\
\hline & Regulatory & Building Codes & $\begin{array}{l}\text { Adding four new building codes to improve } \\
\text { shell and equipment efficiency }\end{array}$ \\
\hline & Regulatory & $\begin{array}{l}\text { Aggressive } \\
\text { Appliance Policy }\end{array}$ & $\begin{array}{l}\text { Accelerate market penetration for energy } \\
\text { efficiency technologies by eliminating the least } \\
\text { efficient ones from the market }\end{array}$ \\
\hline & Information & Market Priming & $\begin{array}{l}\text { Reducing high discount rates }(10-50 \%) \text { to } 7 \% \\
\text { for private investment in efficient technologies }\end{array}$ \\
\hline \multirow[t]{3}{*}{ Commercial } & Financial & Financing & $\begin{array}{l}\text { Offering flexible financing options to lower the } \\
\text { up-front costs of highly energy-efficient } \\
\text { equipment }\end{array}$ \\
\hline & Regulatory & Building Codes & $\begin{array}{l}\text { Requiring higher building shell efficiency and } \\
\text { more stringent standards on space heating and } \\
\text { cooling equipment }\end{array}$ \\
\hline & Information & Benchmarking & $\begin{array}{l}\text { Requiring utilities to submit whole building } \\
\text { energy consumption data to a uniform database } \\
\text { accessible by building owners }\end{array}$ \\
\hline \multirow[t]{4}{*}{ Industrial } & Financial & Motor Rebate & $\begin{array}{l}\text { Providing a } 30 \% \text { subsidy for premium motors } \\
\text { that satisfy the minimum efficiency } \\
\text { requirement of EISA } 2007\end{array}$ \\
\hline & Regulatory & Motor Standard & $\begin{array}{l}\text { New motor standard in } 2017 \text { requiring } 25 \% \\
\text { efficiency improvement and higher system } \\
\text { savings }\end{array}$ \\
\hline & Financial & CHP Incentives & $\begin{array}{l}\text { Offering a } 30 \% \text { investment tax credit for } \\
\text { industrial CHP systems for } 10 \text { years }\end{array}$ \\
\hline & Information & $\begin{array}{l}\text { Advanced } \\
\text { Manufacturing } \\
\text { Initiative }\end{array}$ & $\begin{array}{l}\text { Promoting plant utility upgrades by identifying } \\
\text { efficiency opportunities with cost assessments } \\
\text { and estimations of potential energy savings. }\end{array}$ \\
\hline
\end{tabular}


All twelve selected policies were modeled in GT-NEMS with energy consumption forecasts up to 2035. The specific levers used to model each of these policies is described in subsequent chapters and appendices.

\subsection{Calculation of Levelized Cost of Electricity}

The LCOE of each policy was calculated to estimate the cost of achieving the electricity-savings potentials in individual policy scenarios. The calculation of LCOE is based on the total resource cost test, where costs include the incremental private investment in energy-efficient equipment and improvements, program costs for incentives and loans, and program administrative costs.

We estimate the magnitude of technology investment costs differently for the three end-use sectors. In the residential sector, costs are an output of the GT-NEMS model, and are a function of the purchase costs assumed for a range of technologies in different equipment classes. In the commercial sector, the investment costs are estimated separately for new purchases, replacements, and retrofits for approximately 350 technologies uniquely defined by technology type, fuel use, purchase price, energy efficiency, and time frame of availability in the marketplace. Total costs are calculated using a spreadsheet analysis developed by Georgia Tech's Climate and Energy Policy Laboratory (CEPL). In each case, the calculation is based on GT-NEMS estimates of service demand for energy (SD), costs per unit of SD, and capacity factors (see Appendix B). In industry, costs for CHP investments are based on the installed costs per KW of capacity for eight different types of CHP systems. These costs per $\mathrm{kW}$ of installed capacity are specified in GT-NEMS. Other costs are based on multipliers derived from audit information produced by DOE's Industrial Assessment Centers and the "Save Energy Now" program as developed by CEPL and described in Brown, et al. (2011).

The LCOE is the weighted average cost, calculated by dividing the present value of total costs by total electricity savings, following the methodology described by the Electric Power Research Institute (EPRI, 2009). In addition to electricity benefits, natural gas savings are also generated for energy users impacted by energy efficiency policies. We singled out the part of the cost needed to achieve electricity savings by proportionate total cost to the value of electricity versus natural gas savings through 2035. Present-value calculations for the levelized cost of electricity use a $3 \%$ discount rate from a social perspective and $7 \%$ discount rate for the private-sector assessment. This is consistent with Office of Management and Budget guidelines (OMB, 2002; 2010), which recommend the use of $3 \%$ and $7 \%$ discount rates when evaluating regulatory proposals. Our use of a $7 \%$ discount rate for evaluating the private perspective is less than the $10 \%$ value used in some other energy-efficiency studies such as McKinsey and Company's analysis (Granade, et al., 2009). Since the social appropriateness of policies is being examined, a sensitivity was conducted where all costs were discounted at $3 \%$ for LCOE calculation. Other main assumptions in the LCOE calculation include:

- Avoided transmission and distribution losses are included as part of electricity savings. A multiplier of 1.07 was applied to electricity savings to account for the benefit of avoided electricity related losses.

- Program administrative costs are estimated to be $\$ 0.13 /$ MMBtu energy saved, unless specified otherwise (see Brown, et al., 2009, for details on these estimates). 
- We assume the twelve policies start from 2012 and end at 2035. Any costs stimulated from the policies occur through 2035.

- Electricity savings are then modeled to degrade at a rate of $5 \%$ after 2035 , such that benefits from the policy have ended by 2055 .

A spreadsheet tool was developed to estimate the LCOE for each of the twelve energy-efficiency policy options.

\subsection{Method for Deriving State-Specific Estimates}

A "proportioning" methodology is used to produce state specific electricity-demand forecasts for the 39 individual states that comprise the EIPC region. The forecasts are derived from the Annual Energy Outlook 2011 (EIA, 2011) reference projections. The methodology is based on the approach used by Hadley (2003) in a study of the energy efficiency and renewable energy potential in North Carolina.

EIA's Annual Energy Outlook 2011 provides energy consumption and production projections for the nation, its four census regions, and its nine census divisions. To create state estimates, we combine the electricity demand values from EIA's Annual Energy Outlook 2011 for all states in each census division and calculate the share of the total that each state constitutes. The process is described in greater detail through the bulleted list below.

The previous studies that have developed measurement and verification protocols to estimate the energy consumption of individual states have shown that the energy use per capita of each state in each sector has been relatively constant over the last decade (Brown, et al., 2010). This previous work supports our assumption that the energy use by state generally increases proportionally to population growth. The methodology used here involves four steps:

- First, we calculate the average electricity consumption from 2005 to 2009 with the historical energy consumption by sector and by state from the EIA's State Energy Data System (EIA, SEDS, 2011).

$\bullet$.

- Then, we derived the share of each state to the total division for residential, commercial, and industrial electricity usages, respectively.

- We assume that population distribution will continue with current trend and the state share of electricity consumption can be used to proportionate consumption to the state levels.

- Finally, using the state specific percentages, we allocated out the regional projections of the Annual Energy Outlook 2011 (EIA, 2011) to each state.

A more precise "proportioning" methodology would reflect the fact that states with strong energy-efficiency policies would not increase their energy consumption in lock-step with population growth. While there is an emerging literature that rates the effectiveness of state-level energy-efficiency policies (Foster, et al., 2012), the link to future energy and population growth rates has not been established. 


\section{ENERGY-EFFICIENCY POTENTIAL IN RESIDENTIAL BUILDINGS}

In 2010, the residential sector in the Eastern Interconnection consumed 1,069 TWh of electricity, which represents $74.0 \%$ of national residential electricity consumption. The region is home to $68.6 \%$ of the U.S. population, indicating a higher than national average residential electricity consumption per capita. In fact, the per capita residential electricity consumption in the Eastern Interconnection was about 5,070 kWh in 2009 (EIA, SEDS, 2010). In 2009, the households in the region consumed 990 TWh of electricity, slightly less than in 2008 due to the country's economic downturn. The $990 \mathrm{TWh}$ of electricity consumption accounts for $68 \%$ of the total residential energy consumed in the region in 2009 (15,600 TBtu) (Fig 3.1): delivered electricity consumption accounts for $22 \%$ and electric system energy losses make up another $46 \%$.

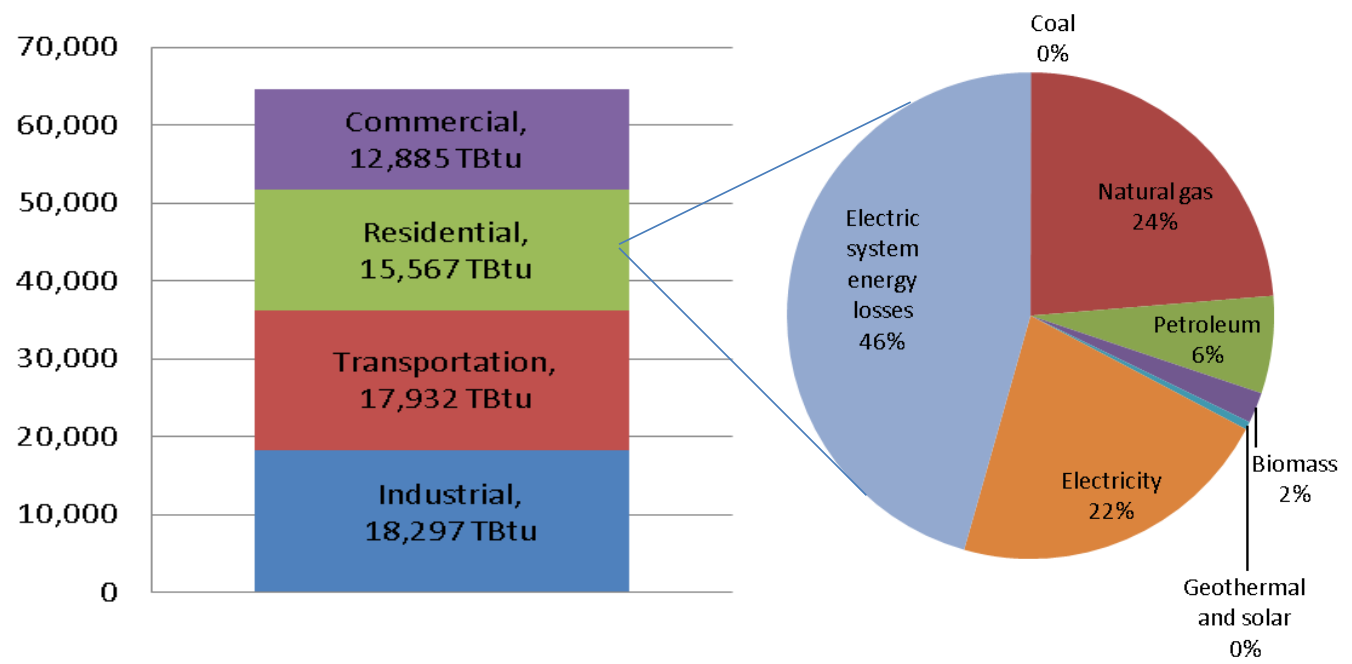

Figure 3.1 Residential Energy Consumption in the Eastern Interconnection in 2009 (Source: EIA, SEDS, 2010)

Residential electricity demand is forecast to be lower than the 2010 level over the next 10 years, but by 2035, EIA forecasts that residential electricity demand will grow to 1,166 TWh in the region, 9\% higher than in 2010 (Figure 3.2). 


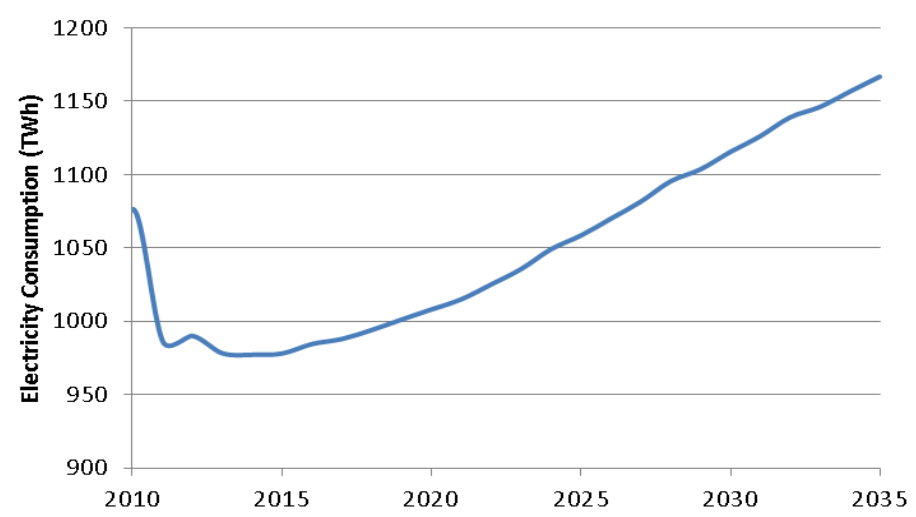

Figure 3.2 Reference Case Forecast of Residential Electricity Consumption in the Eastern Interconnection (EIA, 2011)

This chapter examines the achievable potential for increased residential energy efficiency from five policies. These policies target electricity consumption from all segments of residential buildings, including the building shell, HVAC equipment, and household appliances for both existing and new buildings. This chapter explores the electricity savings from these policies and examines the regional patterns by comparing the results across Census divisions. The other benefits from the energy-efficiency policies, such as natural gas savings, are also investigated. The last section of this chapter examines the impacts of implementing all five residential policies simultaneously.

\subsection{Overview of Previous Literature on the Energy-Efficiency Potential in Residential Buildings}

Numerous assessments of residential energy-efficiency potential in the U.S. have been conducted, at various geographic scales and covering different time frames. Some of these have estimated the impact and cost-effectiveness of implementing new or stronger residential energy policies.

A recent study of state and local programs in Arkansas estimates the total energy efficiency potential in the state to be $15 \%$ of the electricity demand, $14 \%$ of the natural gas demand, and $20 \%$ of the peak demand by 2025. The study focuses on the cost-effective resources in residential buildings in 2025, which is projected to produce 31 trillion Btu of energy savings (37\% of Reference case electricity consumption). The projected potential can be achieved by efficiency improvements in the building shell, HVAC equipment and other appliances in existing buildings with estimated levelized cost of \$5.76/MMBtu saved (Neubauer et al, 2011). A different study, however, examines the energy efficiency in residential and non-profit buildings in Cincinnati (Mackres, et al, 2011) and finds that the potential energy savings associated with current efficiency programs is $2.8 \%$ of electricity demand and $6.9 \%$ of natural gas demand in 2030. Its lower estimates reflect the focus on existing energy-efficiency programs and not the potential of new policies, which is the focus of our study.

For residential and commercial buildings, Laitner, et al. (2012) considers technology advancement as well as policy updates (e.g., energy code, appliance and equipment standards) and estimated efficiency potential to be $49-61 \%$ in 2050 . More specifically, the electric load reduction in 2050 is $73-87 \%$ from building codes and $38-47 \%$ from appliance standards. The 
savings from building codes are quite large compared with the Arkansas study, which models only 1.9-2.2\% of energy savings from building codes. This difference reflects the different modeling assumptions and time frames used in these two studies.

Numerous studies have focused specifically on energy-efficiency measures in the building sector. A recent study on energy efficiency in residential buildings estimates the cost-effective potential to be $42.5 \%$, with encouraging benefit/cost ratios (Sadineni, France, \& Boehm, 2011). In a different study, DOE estimated the impacts of its energy efficiency programs and found that the 2005 Building Technology program could save $27 \%$ of the energy consumed in residential and commercial buildings by 2030. These savings were evaluated to have the potential of increasing employment and reducing the need for capital stock in the energy sector (Scott, et al, 2008).

These studies present a wide range of energy-efficiency potentials due to differences in forecast methods, and state- and local-level estimates tend to generate projections slightly smaller than national-level studies. The difference calls for the attentions to the choice of forecast approaches and the definition of potential (technical, economic, or achievable potential).

\subsection{Residential Efficiency Policy Options and Modeling Approach}

Energy consumption in residential buildings comes from space heating and cooling, water heating, lighting and other end-uses, which are closely related to the efficiency of building shell, HVAC equipment and household appliances. Many state-, local- and utility-level programs and policies are designed to improve energy efficiency in residential buildings. To assess the electricity-savings potential from all building components, a policy bundle of five efficiency policies was designed, including: Appliance Incentives, National Building Codes, On-Bill Financing, an Aggressive Appliance policy, and Market Priming. Two of these policies are regulatory (energy codes and the aggressive appliance policy), two involve financial assistance (appliance incentives and on-bill financing), and one focuses on providing building performance information (market priming). Table 3.1 summarizes each of these policy scenarios, along with the GT-NEMS levers used to model it. Further details are provided in Appendix A.

The Appliance Incentives policy offers a 30\% subsidy to reduce the capital costs of the most efficient technologies in residential buildings based on the technology inventory in GT-NEMS, where the best type of technology in each of the equipment classes is selected (but only when there is more than one type specified in GT-NEMS). A list of the 25 incentivized technologies can be found in Table A.1. They cover space heating, space cooling, clothes washing, dishwashing, water heating, cooking, clothes drying, refrigeration, and freezing. Capital costs of these technologies (from the rtekty input file in GT-NEMS) were reduced by $30 \%$ in this policy scenario.

The Aggressive Appliance Policy uses appliance standards to eliminate the least efficient appliances from the marketplace. Appliance standards impose minimum efficiency requirements on equipment manufacturers. With the standards, certain appliances and equipment being manufactured must meet the minimum efficiency requirements before entering the market. EPA 2005 and EISA 2007 are both examples of federal appliance standards. These two federal rules cover a broad set of home appliances and building equipment, as well as motor systems for the industrial sector. Besides the federal rules, 11 states have adopted appliance/equipment standards with efficiency requirements for state selected efficiency technologies (DSIRE, 2012). 
Table 3.1 GT-NEMS Lever for Residential Efficiency Policies

\begin{tabular}{l|l|l|l}
\hline Policy type & Policy & Policy Scenario Description & GT-NEMS Lever \\
\hline Financial & $\begin{array}{l}\text { Appliance } \\
\text { Incentives }\end{array}$ & $\begin{array}{l}\text { 30\% subsidy to reduce the capital costs } \\
\text { for the most efficient equipment }\end{array}$ & $\begin{array}{l}\text { Equipment cost in } \\
\text { rtekty.txt }\end{array}$ \\
\hline Regulatory & $\begin{array}{l}\text { Aggressive } \\
\text { Appliance Policy }\end{array}$ & Eliminating the least efficient equipment & $\begin{array}{l}\text { Equipment available } \\
\text { years in rtekty.txt }\end{array}$ \\
\hline Regulatory & $\begin{array}{l}\text { National Building } \\
\text { Codes }\end{array}$ & $\begin{array}{l}\text { Additional three rounds of improvement } \\
\text { of building codes }\end{array}$ & $\begin{array}{l}\text { Building shell profile: } \\
\text { rtektyc.txt }\end{array}$ \\
\hline Financial & On-bill Financing & $\begin{array}{l}\text { Offering low interest loans for high } \\
\text { efficient appliances through on-bill } \\
\text { financing options }\end{array}$ & Source code + rtekty.txt \\
\hline Information & Market Priming & $\begin{array}{l}7 \% \text { hurdle rate for the most efficient } \\
\text { equipment }\end{array}$ & $\begin{array}{l}\text { Equipment choice } \\
\text { parameters in rtekty.txt }\end{array}$ \\
\hline
\end{tabular}

Appliance/equipment standards tackle the first cost sensitivity barriers by preventing consumers from buying the least-cost, least-efficient models. The observed savings from adopted federal or state appliance and equipment efficiency standards have been shown to be significant (Geller, 1997; Meier, 1997). The appliance standard programs are cost-effective in promoting energy efficiency in many case studies (Geller, 1997; Vine, du Pont, \& Waide, 2001). A recent study of high-efficient appliances from the U.S. Department of Energy's Appliances and Commercial Equipment Standards Program estimates the potential of cost-effective improvement ranging typically from $15 \%$ to $20 \%$ (McNeil \& Bojda, 2012).

Building Energy Codes generally impose efficiency requirements on building shell, HVAC and lighting equipment for new buildings. For residential buildings, states tend to adopt the International Energy Conservation Code (IECC), a prototypical codes developed and updated periodically by the International Code Council. Most of the states have adopted the IECC 2003 codes (or equivalent) or more stringent codes, with only 9 of the states having no statewide code for residential buildings (Figure 3.4) (DOE, 2012). Maryland is the first state to adopt the most recent 2012 codes for residential buildings (DOE, 2012).

This policy adds four more efficient codes to the suite of five less efficient codes available in the Reference case. The policy case also forces early retirement of the less stringent codes, as described in Appendix A. This policy recognizes the regional differences in code adoption based on historic patterns(Figure 3.4). 


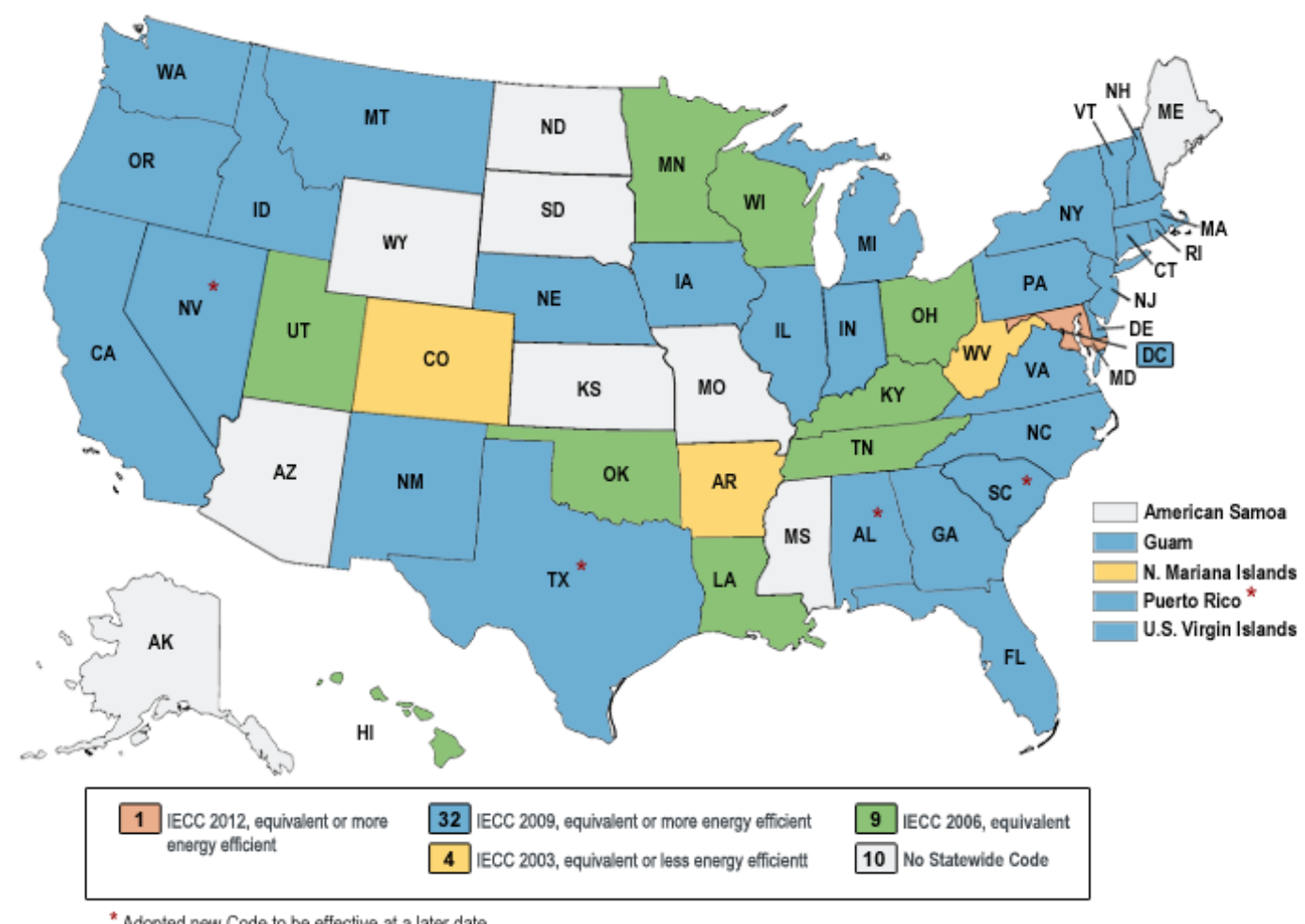

Figure 3.3 Adoption Status of Residential Building Energy Codes as of April, 2012 (Source: DOE, 2012)

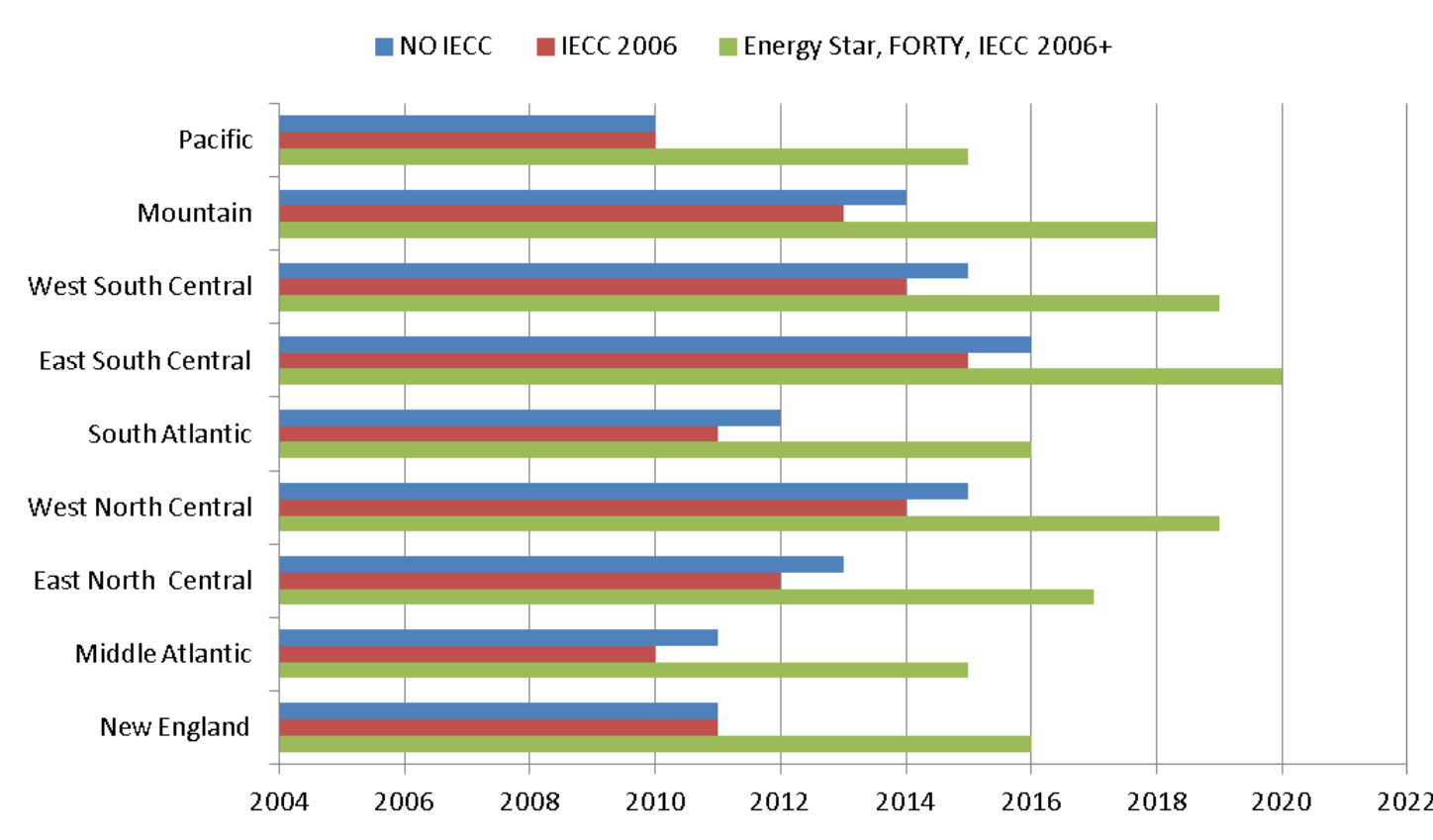

Figure 3.4 Building Energy Code Retirement Years by Census Division 
Building energy codes have been shown to generate large energy savings in various regions under diverse climates conditions (Chirarattananon, et al, 2010; Fayaz \& Kari, 2009). Studies on building code programs in the U.S. also exhibit evidence of cost-effectiveness in promoting energy efficiency: generating significant savings in energy expenditure with relatively low costs (Brown, 1993; Nelson, 2012). However, compared to other energy-efficiency programs, participation rates and voluntary compliance of building codes programs are relatively low, making it necessary to run assistance tools and supporting programs to increase compliance (Brown, 1993; Reichard \& Papamichael, 2005).

On-bill Financing refers to a financial product that is serviced by, or in partnership with, a utility company for energy efficiency improvements in buildings, and repaid by homeowners on their monthly utility bills (Bell, Nadel, and Hayes, 2011). While these programs require the participation of a local utility (investor-owned or municipal), they also often benefit from support of local governments in terms of legal authority and the initial financing. They provide a stream of revenue to the utility or financing institution and, as part of the utility bill, are not burdensome for the customers where long-term savings outweigh upfront costs. On-bill financing opportunities through utilities are also expanding, as shown in Figure 3.5 and, despite a variety of implementation barriers, energy savings have expanded with minimal defaults (Bell, Nadel, and Hayes, 2011).

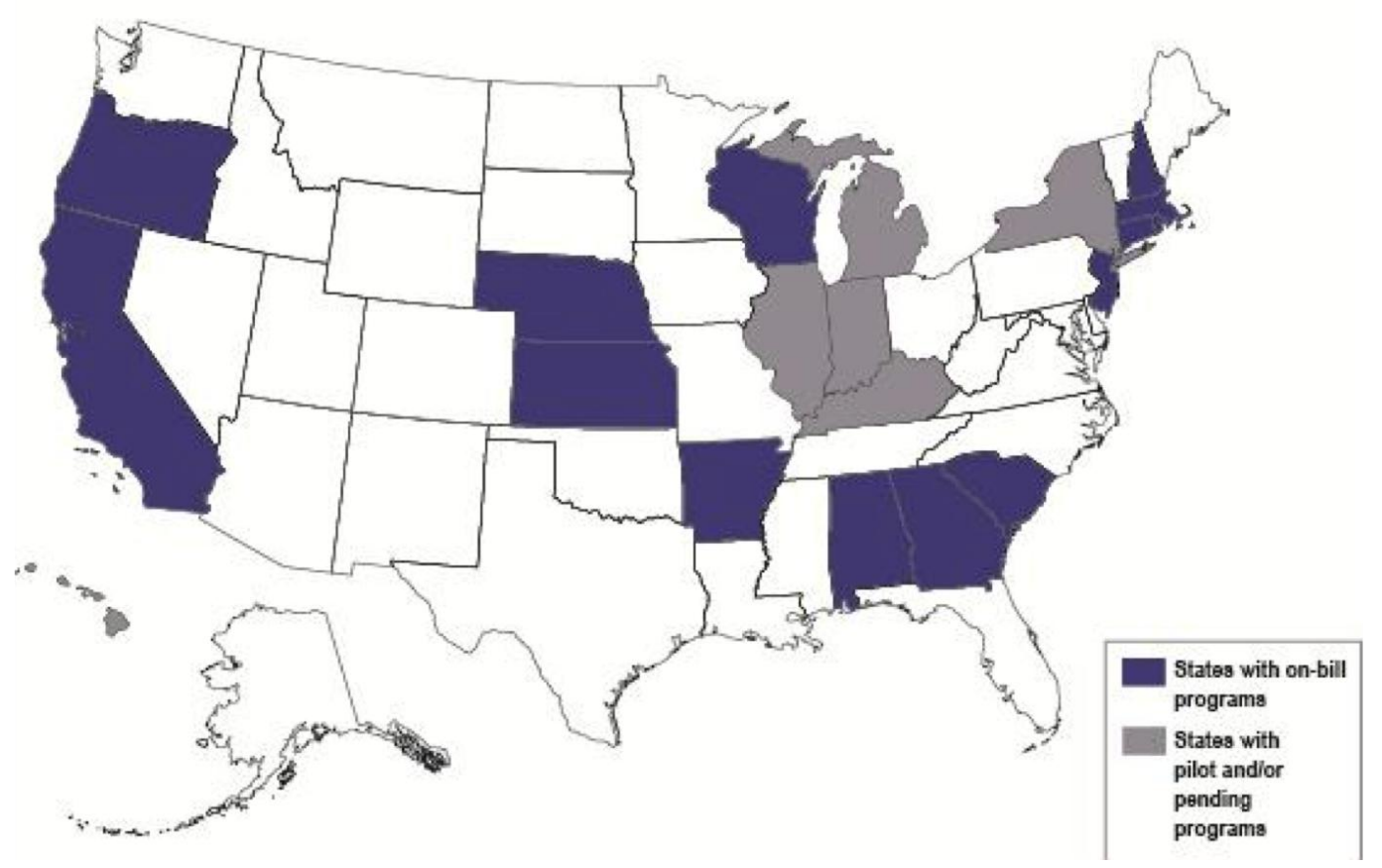

Figure 3.5 States with On-Bill Financing Programs

Source: Bell, Nadel, and Hayes, 2011

The policy modeled here offers zero-interest loans to upgrade to the most efficient residential appliances and equipment. The technologies eligible for zero-interest loans are the same technologies that are eligible for appliance subsidies as listed in Table A.1. 
Market Priming programs offer information and education to reduce consumers' perception of the uncertainties and investment risks associated with new and innovative energy-efficient technologies. This policy also targets the set of technologies shown in Table A.1, but with a different GT-NEMS lever. In this scenario, market assistance programs offer consumers information, technical support, and educational demonstration to help them gain better understanding of the energy-efficient technologies, and therefore lower their perception of risks which is manifested in a lower private discount rate for the technologies. We modeled this policy by changing the hurdle rates of these technologies to $7 \%$.

The achievable potentials of energy efficiency from these policies were modeled in GT-NEMS, which forecasts the future energy consumption out to 2035. The results of these policies were then compared to the Reference case forecast from AEO 2011, and the difference between the Reference case and policy scenario forecasts is the efficiency potential in residential buildings. The achievable potentials were modeled using the GT-NEMS High Tech scenario.

The GT-NEMS modeling levers for these five policies were purposely chosen to be relatively independent in terms of their policy impacts (Table 3.1). The technology profile from the Reference case was used to identify the equipment with the highest and lowest efficiencies of the same types. The most efficient equipment was offered either a 30\% subsidy as in the Appliance Incentives case, or a zero-interest loan for 10 years as in the On-Bill Financing case. The least efficient technologies were eliminated in the Aggressive Appliance Standards case. Building Energy Codes policy would add four new codes to the building shell profile to reflect the anticipation of future updates to building energy code, and also forces the less stringent codes to retire earlier.

\subsection{Modeling Results for Individual Residential Policies}

The energy consumption forecast of the each policy case was compared with the Reference case forecast, and the difference represents the achievable energy-efficiency potential. Figure 3.6 shows the estimated potential of each policy. The percentage number is the reduction in residential electricity demand as a percentage of the reference case forecast in each year.

In 2035, the electricity savings from these five policies in the Eastern Interconnection ranges from $19.0-119$ TWh $(1.6 \%-10.2 \%$ of reference case consumption), while the total electricity savings potential in the nation ranges from 33.4-164 TWh $(2.1 \%-10.2 \%$ of reference case consumption).

By lowering the hurdle rate for efficiency investment through the Market Priming policy, the residential sector is able to generate the highest level of electricity savings, amounting to 119 TWh in 2035 in the Eastern Interconnection (Fig 3.6). An Aggressive Appliance Policy is also able to produce a significant amount of electricity savings, about 42.3 TWh in 2035 in the Eastern Interconnection. Comparing to the Market Priming and Aggressive Appliance Policy, the other three residential policies are estimated to have smaller but still meaningful efficiency potentials for residential electricity savings, ranging from 19.0 - 25.6 TWh in 2035 in the region. 


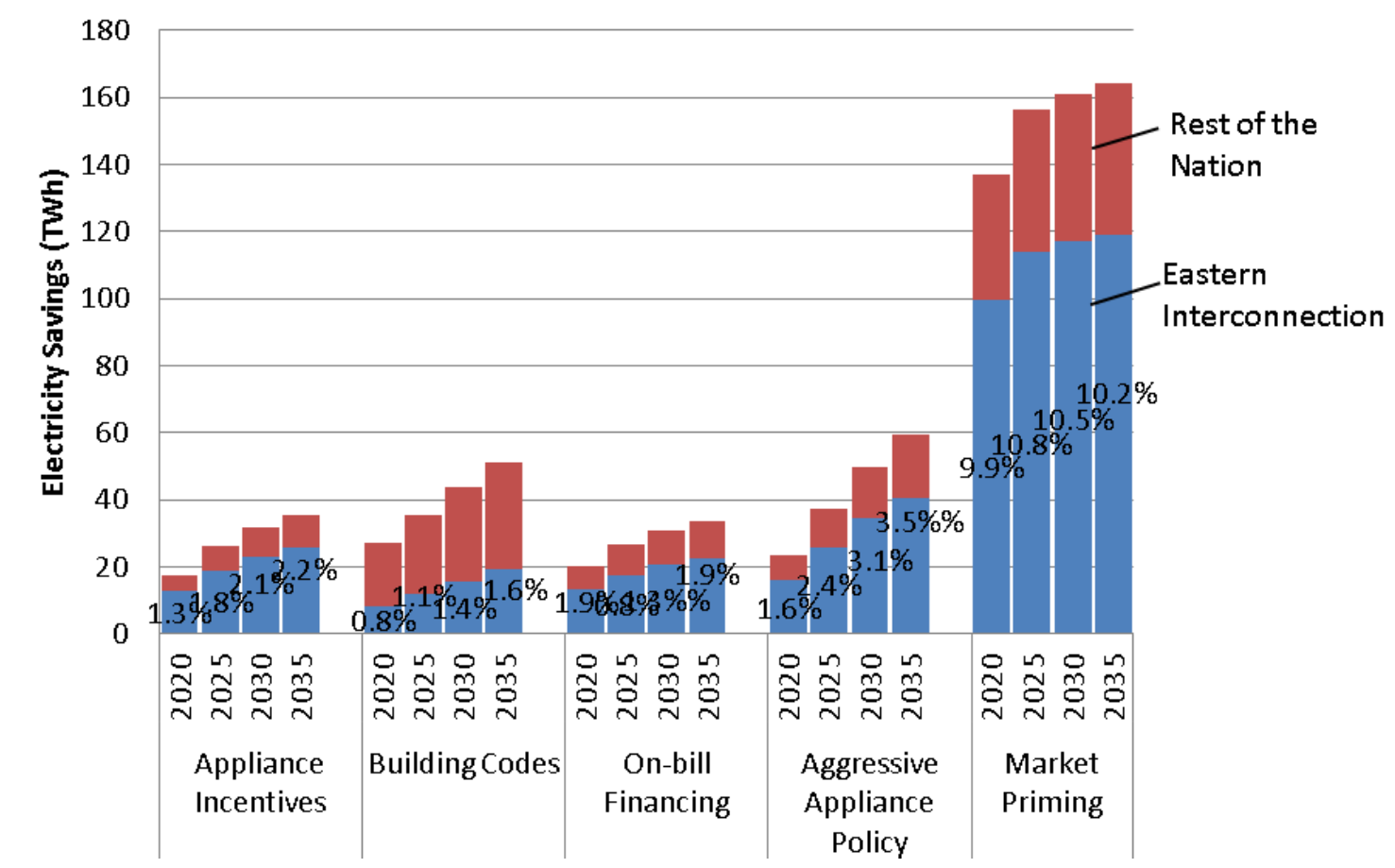

Figure 3.6 Estimated Reductions in Electricity Demand by Individual Residential Policies (Percentages of Residential Buildings Electricity Consumption)

All five policies, except for the National Building Energy Codes, generate electricity savings in the same proportion in the Eastern Interconnection as in the whole country (Figure 3.6). The percentage of electricity savings from National Building Codes in the Eastern Interconnection is only half (or less) of the national percentage saving. In the rest of the country, National Building Codes are able to generate electricity savings of $3.6 \%$ in $2020,5.9 \%$ in 2025 , and $7.2 \%$ in 2035 . The reason that National Building Codes benefit the Eastern Interconnection less than the other regions is partly due to the differences in technology profiles applied to building shell and HVAC systems in different areas. It also reflects different paces of code retirement: the Pacific region moves rapidly to the four new codes and the East South Central region is assumed to be the slowest to adopt new codes (Figure 3.5). GT-NEMS assumes a five-year lag in adoption between these two regions.

In the Eastern Interconnection, the cumulative electricity savings (2012 - 2035) generated from Appliance Incentives, Building Codes, On-bill Financing, Aggressive Appliance Standards, and Market Priming policy cases are 382 TWh, 257 TWh, 366 TWh, 531 TWh, and 2,407 TWh, respectively. In the meanwhile, the Reference case forecasts that electricity demand in the residential sector will increase from 986 TWh in 2011 to 1,166 TWh in 2035. The cumulative growth in electricity consumption can be offset by the five policies by $24 \%, 16 \%, 23 \%, 33 \%$, and $149 \%$, respectively. Since these policies deal with separate segments of energy consumption in residential buildings, it is plausible to assume that the demand growth of electricity usage can be completely offset by the combination of residential policies. 


\subsubsection{Regional Differences}

In the individual policy scenarios, each policy is assumed to be applied on the national level with regional deviations in implementation details, for example, the adoption years of Building Energy Codes. Local situations, such as the current state policies and current consumption levels, vary from state to state. Thus, the same policy would likely to generate different efficiency impacts in different regions. Figure 3.7 illustrates the regional differences in electricity savings from each residential policy, as estimated by GT-NEMS. To show the electricity savings in the Eastern Interconnection, Texas was excluded from the West South Central division, using the proportioning method described in Chapter 2.
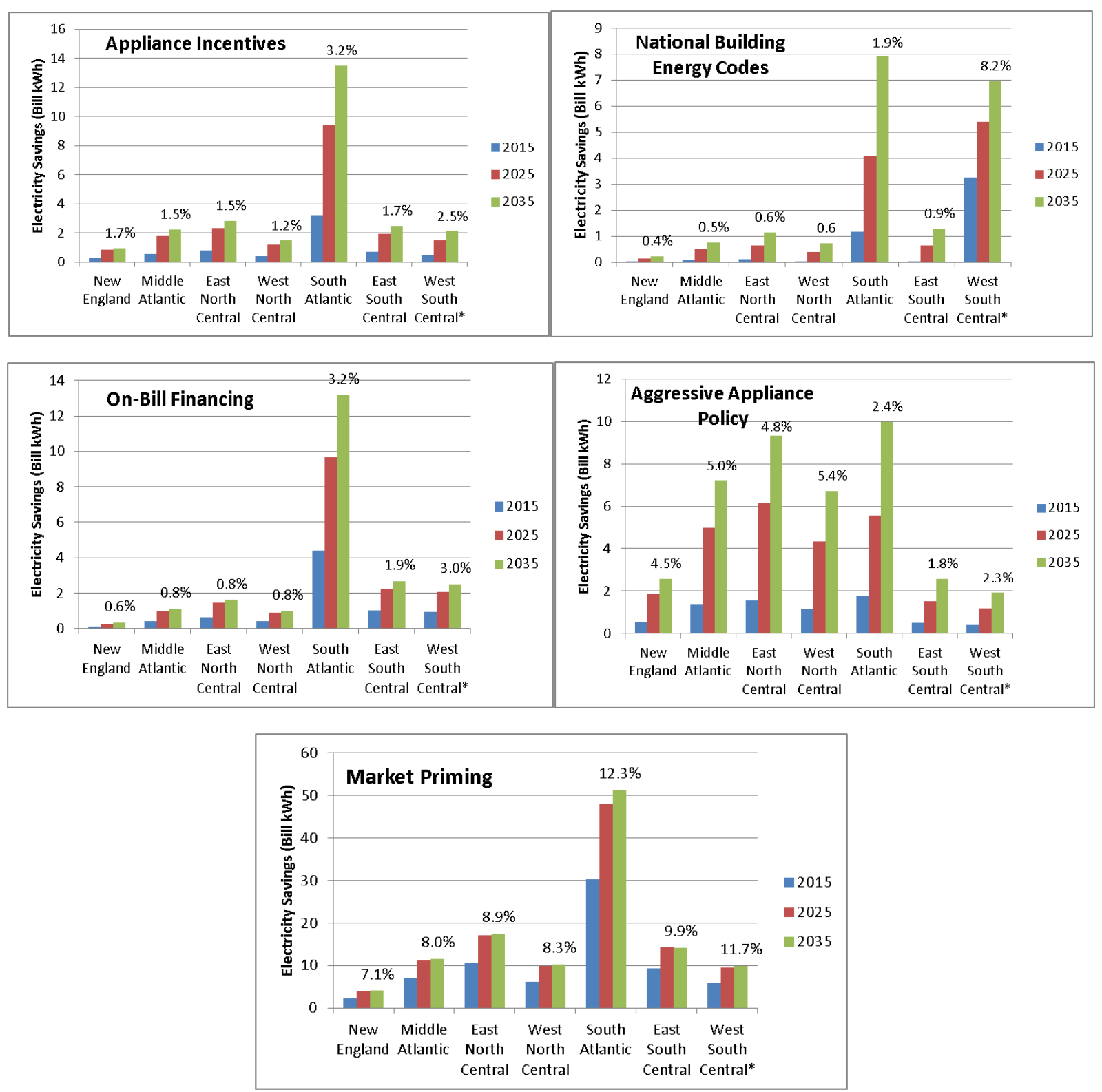

Figure 3.7 Electricity Savings by Census Division for Individual Policies

(*West South Central Excluding Texas) 
Appliance Incentives, On-bill Financing, and Market Priming share similar regional patterns. For each of these policies, the South Atlantic division, which is the largest area with the most population, possesses the largest electricity saving potential. The projected savings in the South Atlantic region as a percentage of regional electricity consumption is also higher than the percentage in other regions.

The regional distribution of electricity savings from the Aggressive Appliance Policy is more geographically dispersed. While the South Atlantic region has the highest energy savings, the Middle Atlantic and North Central regions also have large savings potential both in absolute terms and as a percentage of regional electricity consumption. This more equally distributed pattern may reflect the fact that the energy consumption of appliances is less weather-dependent than the energy consumption of HVAC equipment.

The National Building Energy Codes also shows an electricity savings potential that is geographically distributed quite differently from the other residential policies. In 2035, this policy generates 7.9 TWh of electricity savings in the South Atlantic region, and 6.9 TWh of electricity savings in the West South Central region (excluding Texas). The West South Central region is estimated to reduce $8.2 \%$ of its electricity consumption under the national building code policy, which is a much higher percentage than any other region. The West South Central region receives much higher benefit than other regions due to its unique technology profile. In singlefamily buildings, the heating and cooling equipment in the WSC region after code implementation generally exhibits relatively high cooling efficiency. For example, in houses using heat pumps for air conditioning and heating, the WSC has the highest cooling efficiency at the lowest cost.

\subsubsection{Spillover Benefits}

All selected policies aim to promote efficiency in residential buildings, including the efficient use of electricity and other fuel types. These policies are able to generate significant electricity savings as well as natural gas and fuel oil savings. Table 3.2 illustrates the projected reduction in natural gas consumption that is estimated to result from each individual policy. 
Table 3.2 Natural Gas Savings from Individual Policies

\begin{tabular}{l|l|l|ccccc}
\hline \multicolumn{2}{l|}{} & $\begin{array}{l}\text { Reference } \\
\text { Forecast } \\
\text { (TBtu) }\end{array}$ & $\begin{array}{l}\text { Appliance } \\
\text { Incentives }\end{array}$ & $\begin{array}{l}\text { Building } \\
\text { Codes }\end{array}$ & $\begin{array}{l}\text { On-bill } \\
\text { Financing }\end{array}$ & $\begin{array}{l}\text { Aggressive } \\
\text { Appliance Policy }\end{array}$ & $\begin{array}{c}\text { Market } \\
\text { Priming }\end{array}$ \\
\hline \multirow{3}{*}{2020} & EI & 4,683 & 94 & 39 & 98 & 80 & 230 \\
& US & 4,973 & 127 & 183 & 183 & 138 & 236 \\
\hline \multirow{3}{*}{2025} & EI & 3,612 & 120 & 64 & 134 & 144 & 241 \\
& US & 4,960 & 162 & 245 & 223 & 238 & 353 \\
\hline \multirow{3}{*}{2030} & EI & 3,587 & 144 & 90 & 165 & 201 & 249 \\
& US & 4,953 & 196 & 305 & 302 & 327 & 421 \\
\hline \multirow{2}{*}{2035} & EI & 3,530 & 159 & 110 & 186 & 244 & 245 \\
& US & 4,902 & 218 & 357 & 313 & 397 & 361 \\
\hline
\end{tabular}

Unlike the policy-specific estimates of electricity savings potential where Market Priming dominated, Aggressive Appliance Policy is the residential policy with the largest natural gas saving potential in the Eastern Interconnection as well as in the whole nation. The other four policies are also able to generate significant natural gas savings. Building Energy Codes offers the smallest natural gas savings in the Eastern Interconnection, but large savings in other areas of the nation. The observation of natural gas savings for Building Codes is consistent with its regional distribution of electricity savings.

The policies are also able to generate savings in fuels other than electricity and natural gas, such as fuel oil, diesel, and propane. Table 3.3 shows the potential savings in total energy, which is the projected reduction in total residential energy consumption. These savings were calculated without including the avoided electricity related losses. For the saving potential in total energy consumption, the difference between Market Priming and other residential policies is not as big as the difference in electricity saving potentials. Market Priming stands out differently from other policies because it imposes a big push for energy savings from the beginning of the program, while energy savings in other policy cases grow steadily with program implementation time.

Table 3.3 Total Energy Savings from Individual Policies, Residential Sector (TBtu, avoided electricity related losses not included)

\begin{tabular}{c|ccccc}
\hline & $\begin{array}{c}\text { Appliance } \\
\text { Incentives }\end{array}$ & $\begin{array}{c}\text { Building } \\
\text { Codes }\end{array}$ & $\begin{array}{c}\text { On-bill } \\
\text { Financing }\end{array}$ & $\begin{array}{c}\text { Aggressive } \\
\text { Appliance } \\
\text { Policy }\end{array}$ & $\begin{array}{c}\text { Market } \\
\text { Priming }\end{array}$ \\
\hline 2020 & 210 & 260 & 260 & 210 & 830 \\
2025 & 280 & 350 & 350 & 360 & 910 \\
2030 & 330 & 430 & 420 & 490 & 930 \\
2035 & 370 & 510 & 480 & 600 & 940 \\
\hline
\end{tabular}




\subsubsection{Cost Estimation}

The Appliance Incentives policy would incur two types of costs: the, private investment which is the expenditure spent by residential consumers to purchase equipment, and the public costs that include the cost of subsidizing the most efficient technologies, and program administrative costs. The total cost of the policy is the sum of both the private and public costs, and it is estimated to be $\$ 2.9$ billion in 2035 . The levelized cost of energy of this policy is estimated to be $\$ 0.13 / \mathrm{MM}$ Btu energy saved and the levlized cost of electricity (LCOE) in this policy case is estimated at 6.7-8.0 cent/kWh. Details of cost estimations associated with Appliance Incentives are shown in Table 3.4.

Table 3.4 Cost Estimations from Appliance Incentives

\begin{tabular}{|c|c|c|c|c|}
\hline Cost (Billion \$2009) ${ }^{\mathrm{a}}$ & 2020 & 2025 & 2030 & 2035 \\
\hline Private cost & -1.37 & -1.01 & -0.73 & -0.53 \\
\hline Subsidy Cost & 4.51 & 4.25 & 3.83 & 3.42 \\
\hline Administration Cost & 0.01 & 0.01 & 0.01 & 0.01 \\
\hline Total & 3.15 & 3.25 & 3.11 & 2.90 \\
\hline LCOE (cent/kWh) & \multicolumn{4}{|c|}{$6.7^{b}-8.0$} \\
\hline
\end{tabular}

a. Private cost was discounted at $7 \%$, and public cost was discounted at $3 \%$.

b. Levelized cost calculated in a sensitivity when all costs were discounted at $3 \%$.

For Building Energy Codes, the private investment is the incremental cost on equipment expenditure plus the installation cost for improvements to the building shell. By promoting investments in more thermally efficient envelopes, HVAC equipment can be down-sized, resulting in lower equipment expenditures relative to the Reference case. There is no public cost except for the program administrative costs. This policy assumes cost associated with building code enforcement would be represented by the budget of each state hiring their building code officials and inspectors. The administrative costs are based on each state adding one administrative office run at $\$ 150,000$ per annum budget and one code official at $\$ 75,000$ salary per annum. It also includes two additional building code inspectors for the verification of every 100 million square feet in the state at \$75,000 per year (Brown, et al., 2009). The LCOE in this policy case is estimated to be $0.5-0.8$ cent $/ \mathrm{kWh}$. Details of cost estimations associated with Building Codes are shown in Table 3.5.

Table 3.5 Cost Estimations from Building Codes

\begin{tabular}{c|cccc}
\hline Cost (Billion \$2009) $^{\mathrm{a}}$ & 2020 & 2025 & 2030 & 2035 \\
\hline Equipment Expenditure $^{-0.02}$ & -0.02 & -0.01 & -0.01 \\
Shell Installation Cost & 0.33 & 0.28 & 0.39 & 0.25 \\
Administration Cost & 0.02 & 0.02 & 0.02 & 0.02 \\
Total & 0.33 & 0.29 & 0.40 & 0.26 \\
\hline LCOE (cent/kWh) & \multicolumn{5}{|c}{$0.5-0.8^{\mathrm{b}}$} \\
\hline
\end{tabular}

a. Private cost was discounted at $7 \%$, and public cost was discounted at $3 \%$.

b. Levelized cost calculated in a sensitivity when all costs were discounted at $3 \%$.

In the On-bill Financing policy, private investment is the expenditure for purchasing equipment. Loan cost is the initial seed money put into the program for zero-interest loans. Program 
administrative cost is estimated as $\$ 0.13 / \mathrm{MMBtu}$ energy saved. The LCOE in this policy case is estimated to be 6.6-7.4 cent/kWh. Details of cost estimations associated with On-bill Financing are shown in Table 3.6.

Table 3.6 Cost Estimations from On-Bill Financing

\begin{tabular}{c|cccc}
\hline Cost (Billion \$2009) $^{\mathrm{a}}$ & 2020 & 2025 & 2030 & 2035 \\
\hline Private cost & 0.95 & 0.64 & 0.40 & 0.25 \\
Loan Cost & 1.48 & 0.02 & -0.09 & 0.01 \\
Administrative Cost & 0.01 & 0.01 & 0.01 & 0.01 \\
Total & 2.44 & 0.67 & 0.32 & 0.27 \\
\hline LCOE (cent/kWh) & \multicolumn{4}{|c}{$6.6-7.4^{\mathrm{b}}$} \\
\hline
\end{tabular}

a. Private cost was discounted at $7 \%$, and public cost was discounted at $3 \%$.

b. Levelized cost calculated in a sensitivity when all costs were discounted at $3 \%$.

The Market Priming policy lowers the hurdle rate to $7 \%$ for the most efficient equipment types. Private investment is the expenditure for purchasing equipment. There is no public cost except for program administrative cost, estimated as \$0.13/MM Btu energy saved. The LCOE in this policy case is estimated to be 2.7-3.6 cent/kWh. Details of cost estimations associated with Market Priming are shown in Table 3.7.

Table 3.7 Cost Estimations from Market Priming

\begin{tabular}{c|cccc}
\hline Cost (Billion \$2009) $^{\mathrm{a}}$ & 2020 & 2025 & 2030 & 2035 \\
\hline Private cost & 6.91 & 3.76 & 2.90 & 1.44 \\
Administration Cost & 0.03 & 0.03 & 0.02 & 0.02 \\
Total & 6.94 & 3.79 & 2.92 & 1.46 \\
\hline LCOE (cent/kWh) & \multicolumn{4}{|c}{$2.7-3.6^{\mathrm{b}}$} \\
\hline
\end{tabular}

a. Private cost was discounted at $7 \%$, and public cost was discounted at $3 \%$.

b. Levelized cost calculated in a sensitivity when all costs were discounted at $3 \%$.

Similar to the Market Priming policy, the cost estimation for Aggressive Appliance Policy has private cost from the expenditure for purchasing equipment, and public cost from program administrative costs estimated as \$0.13/MM Btu energy saved. The LCOE in this policy case is estimated to be $0.6-0.7$ cent $/ \mathrm{kWh}$. Details of cost estimations associated with Aggressive Appliance Policy are shown in Table 3.8.

Table 3.8 Cost Estimations from Aggressive Appliance Policy

\begin{tabular}{c|cccc}
\hline${\text { Cost }(\text { Billion } \$ 2009)^{\mathrm{a}}}^{\mathrm{a}}$ & 2020 & 2025 & 2030 & 2035 \\
\hline Private cost & 0.25 & 0.16 & 0.11 & 0.08 \\
Administration Cost & 0.01 & 0.01 & 0.01 & 0.01 \\
Total & 0.26 & 0.18 & 0.13 & 0.09 \\
\hline LCOE (cent/kWh) & \multicolumn{4}{|c}{$0.6-0.7^{\mathrm{b}}$} \\
\hline
\end{tabular}

a. Private cost was discounted at $7 \%$, and public cost was discounted at $3 \%$.

b. Levelized cost calculated in a sensitivity when all costs were discounted at $3 \%$.

\subsection{Integrated Residential Policy Bundle}


The projected savings change a little when the residential policies were integrated into one policy bundle. Figure 3.8 shows the efficiency potential estimated by the residential policy bundle. In 2035 , the savings potential from the integrated policy scenario reaches $179 \mathrm{TWh}(15.4 \%$ reduction from the reference consumption) in the Eastern Interconnection.

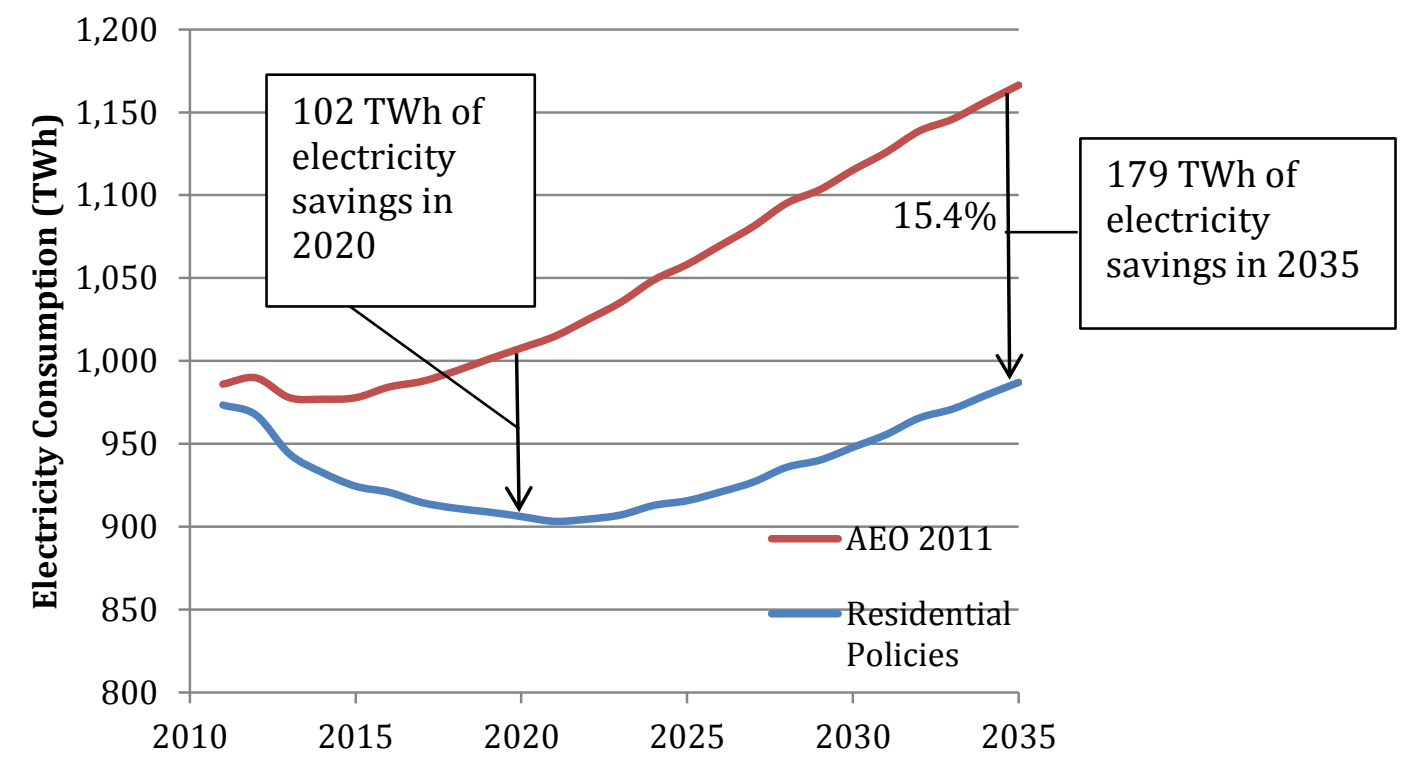

Figure 3.8 Residential Electricity Savings Potential in the Eastern Interconnection

With all five energy efficiency policies, homes and residential buildings is estimated to use 987 TWh of electricity in 2035 , which is below the 2010 consumption level. The cumulative savings in electricity is 2,886 TWh from 2011 to 2035 , which is 1.8 times the cumulative growth in electricity consumption in the Reference case over the same time period.

For the whole nation, the potential electricity savings from residential policies is $260 \mathrm{TWh}(16.1 \%$ of Reference case consumption) in 2035. The cumulative savings residential electricity demand is 4,205 TWh from 2011 to 2035 . In the last year of our projection, the total energy consumption per household decreases from 155 million Btu in the reference case to 135 million Btu in our integrated policy scenario.

\subsubsection{Electricity Savings Potential by End Use}

Most of the potential electricity savings in residential buildings comes from space cooling (46\%) and water heating (36\%). Space heating has the third highest electricity savings potential, accounting for $9 \%$ of electricity savings. Table 3.9 illustrates the potential electricity savings from residential policies by end-use, which shows that refrigeration, dishwashers and other enduses are able to generate small amount of electricity savings (2-4\%) in the nation. 
Table 3.9 Electricity Savings Potential by End-use in the US

\begin{tabular}{l|rrrr|rr}
\hline \multirow{2}{*}{ End-use } & \multicolumn{4}{|c|}{ Annual Savings (TWh) } & \multicolumn{2}{c}{ Cumulative Savings } \\
\cline { 2 - 7 } & $\mathbf{2 0 2 0}$ & $\mathbf{2 0 2 5}$ & $\mathbf{2 0 3 0}$ & $\mathbf{2 0 3 5}$ & \multicolumn{1}{c}{ TWh } & \multicolumn{1}{c}{$\%$} \\
\hline Space Heating & 13.0 & 17.7 & 21.8 & 25.2 & 384.2 & $9 \%$ \\
Space Cooling & 69.0 & 92.5 & 108.4 & 119.3 & $1,923.2$ & $46 \%$ \\
Water Heating & 55.0 & 77.2 & 88.5 & 90.8 & $1,531.2$ & $36 \%$ \\
Refrigeration & 3.0 & 3.3 & 3.3 & 3.2 & 71.5 & $2 \%$ \\
Dishwashers & 5.8 & 9.2 & 11.3 & 12.0 & 176.8 & $4 \%$ \\
Other uses & 3.2 & 5.4 & 7.1 & 9.2 & 118.9 & $3 \%$ \\
\hline Total & 149.0 & 205.3 & 240.4 & 259.7 & 4205.8 & -- \\
\hline
\end{tabular}

The large electricity savings from space cooling and water heating is not driven by technology demand shift between equipment classes, but rather from the shift of different equipment types with different efficiencies within the same equipment class. Table 3.10 shows the technology demand shift of equipment classes in the Eastern Interconnection. There is no significant shift between equipment classes since technology demand stays almost the same in the Reference case and the residential policy bundle.

Table 3.10 Technology Demand Shift from Residential Policies in the Eastern Interconnection

\begin{tabular}{l|l|rrr|rrr}
\hline \multirow{2}{*}{$\begin{array}{l}\text { End- } \\
\text { use }\end{array}$} & \multicolumn{1}{|c|}{ Equipment class } & $\mathbf{2 0 1 5}$ & $\mathbf{2 0 2 5}$ & $\mathbf{2 0 3 5}$ & $\mathbf{2 0 1 5}$ & $\mathbf{2 0 2 5}$ & $\mathbf{2 0 3 5}$ \\
\cline { 3 - 7 } & Central A/C & $47 \%$ & $50 \%$ & $52 \%$ & $47 \%$ & $48 \%$ & $51 \%$ \\
& Electric Heat Pump & $11 \%$ & $12 \%$ & $13 \%$ & $11 \%$ & $13 \%$ & $13 \%$ \\
& Geothermal Heat Pump & $1 \%$ & $1 \%$ & $2 \%$ & $1 \%$ & $1 \%$ & $2 \%$ \\
Space & Natural Gas Heat Pump & $0 \%$ & $0 \%$ & $0 \%$ & $0 \%$ & $0 \%$ & $0 \%$ \\
cooling & Room A/C & $41 \%$ & $37 \%$ & $33 \%$ & $41 \%$ & $37 \%$ & $34 \%$ \\
\hline & Distillate Fuel Oil Water Heater & $3 \%$ & $2 \%$ & $2 \%$ & $4 \%$ & $3 \%$ & $3 \%$ \\
& Electric Water Heater & $47 \%$ & $49 \%$ & $50 \%$ & $47 \%$ & $49 \%$ & $49 \%$ \\
& LPG Water Heater & $2 \%$ & $1 \%$ & $1 \%$ & $2 \%$ & $2 \%$ & $2 \%$ \\
Water & Natural Gas Water Heater & $47 \%$ & $47 \%$ & $47 \%$ & $47 \%$ & $45 \%$ & $46 \%$ \\
heating & Solar Water Heater & $0 \%$ & $0 \%$ & $0 \%$ & $0 \%$ & $0 \%$ & $0 \%$ \\
\hline
\end{tabular}

However, technology shifts dramatically among equipment types within the same equipment class. Table 3.11 illustrates the demand shift between four types of electric heat pumps in the Eastern Interconnection. Type 1 and 2 has relatively low efficiencies, while type 4 represents high efficient electric heat pumps. Most of the purchases (about 90\%) go to type 1 and 2 in the reference case since they have relatively low costs. However, in the integrated policy case, we offer subsidies, no-interest loans, and market priming programs for the most efficient electric heat pumps, type 4 . The result is that, over $95 \%$ of the purchase goes to type 4 instead of type $1 \& 2$ in the policy bundle scenario. It is clear that the efficient equipment types dominant the market, offering great electricity savings in residential buildings. 
Table 3.11 Demand share of Electric Heat Pumps for Cooling in the Eastern Interconnection

\begin{tabular}{l|r|rrr|rrr}
\hline & & \multicolumn{3}{|c|}{ Reference Case } & \multicolumn{3}{c}{ Policy Bundle } \\
\cline { 3 - 8 } & Efficiency & $\mathbf{2 0 1 5}$ & $\mathbf{2 0 2 5}$ & $\mathbf{2 0 3 5}$ & $\mathbf{2 0 1 5}$ & $\mathbf{2 0 2 5}$ & $\mathbf{2 0 3 5}$ \\
\hline Type 1 & $2.26-2.40$ & $67 \%$ & $70 \%$ & $69 \%$ & $0 \%$ & $5 \%$ & $2 \%$ \\
Type 2 & $2.40-2.58$ & $22 \%$ & $20 \%$ & $20 \%$ & $1 \%$ & $0 \%$ & $0 \%$ \\
Type 3 & $2.75-2.80$ & $9 \%$ & $8 \%$ & $9 \%$ & $1 \%$ & $0 \%$ & $0 \%$ \\
Type 4 & $3.11-3.19$ & $2 \%$ & $2 \%$ & $2 \%$ & $98 \%$ & $95 \%$ & $97 \%$ \\
\hline
\end{tabular}

\subsubsection{Potential for Natural Gas Saving and Carbon Dioxide Emission Reductions}

In addition to reducing the demand for electricity, the residential policies are also able to generate significant savings in natural gas and other fuel types. With the policy bundle, the natural gas savings reach $621 \mathrm{TBtu}$ in the Eastern Interconnection, while savings in total energy consumption reach 1,291 TBtu in the region (Table 3.12). The savings in the Eastern Interconnection represents $63 \%$ of national savings.

Table 3.12 Potential savings of natural gas and total energy in the Eastern Interconnection

\begin{tabular}{l|cccc|cccc}
\hline & \multicolumn{4}{|c|}{ Natural gas savings (TBtu) } & \multicolumn{4}{c}{ Total Energy Savings (TBtu) } \\
\cline { 2 - 9 } & $\mathbf{2 0 2 0}$ & $\mathbf{2 0 2 5}$ & $\mathbf{2 0 3 0}$ & $\mathbf{2 0 3 5}$ & $\mathbf{2 0 2 0}$ & $\mathbf{2 0 2 5}$ & $\mathbf{2 0 3 0}$ & $\mathbf{2 0 3 5}$ \\
\hline EI & 390 & 515 & 587 & 621 & 761 & 1,039 & 1,204 & 1,291 \\
US & 668 & 870 & 995 & 1,069 & 1,220 & 1,630 & 1,880 & 2,040 \\
\hline
\end{tabular}

Carbon emissions from the consumption of electricity and other fuels will be reduced since the demand of primary energy drops in the integrated policy scenario. Cumulatively, the reduction in carbon emission from electricity consumption is 1,136 million tonnes in the Eastern Interconnection from 2012 to 2035, while total reduction in emission from primary energy is 1,727 million tonnes in the region (Table 3.13). This represents about $66 \%$ of total emission reductions in the nation.

Table 3.13 Potential Reduction in $\mathrm{CO}_{2}$ Emissions from Residential Policies

\begin{tabular}{c|cccc|cccc}
\hline & \multicolumn{8}{|c}{ Carbon Emission Reduction (Million Tonnes) } \\
\cline { 2 - 9 } & \multicolumn{4}{|c|}{ From electricity } & \multicolumn{5}{c}{ From primary energy } \\
\cline { 2 - 9 } & $\mathbf{2 0 2 0}$ & $\mathbf{2 0 2 5}$ & $\mathbf{2 0 3 0}$ & $\mathbf{2 0 3 5}$ & $\mathbf{2 0 2 0}$ & $\mathbf{2 0 2 5}$ & $\mathbf{2 0 3 0}$ & $\mathbf{2 0 3 5}$ \\
\hline EI & 39 & 57 & 67 & 72 & 60 & 86 & 100 & 107 \\
US & 56 & 80 & 93 & 100 & 93 & 127 & 148 & 159 \\
\hline
\end{tabular}

Note: Primary energy includes all fuel types.

\subsubsection{Additive Effects of the Residential Policy Bundle}

Based on the integrated policy scenario, each of the five residential policies was taken out of the integrated policy scenario one-at-a-time to examine their contribution to the estimate of 
efficiency potential, assuming that the policy environment already has implemented the other residential policies. It is plausible that, when only one policy is implemented, the estimate of potential savings will be greater than when it is analyzed using this "one-off" approach. This is because there are overlapped focuses among the policies, and when they interact with each other, the synergetic effect would result in a smaller energy savings than just simple addition of savings from individual policies. If this is true, then the electricity savings potential estimated by the integrated GT-NEMS analysis would be lower than the sum of the savings from the individual policies. For example, because the estimated savings are significantly higher in the policy bundle, the rebound effect will likely be higher as well, since energy efficiency policies tend to lower electricity prices, which prompt a rebound in overall consumption. In addition, the potential represented by the various policies may be duplicative. This duplication is a function of overlap in the end uses and market segments that the policies target.

Table 3.14 shows the impact of each policy when they are taken out of the integration one-at-atime, compared with the impact when only one of the policies is implemented.

Table 3.14 Comparison of Policy Impacts in the Eastern Interconnection

\begin{tabular}{l|rrrr|rrrr}
\hline \multirow{3}{*}{ Policy } & \multicolumn{3}{|c|}{$\begin{array}{c}\text { Electricity savings from } \\
\text { individual policies (TWh) }\end{array}$} & \multicolumn{3}{c}{$\begin{array}{c}\text { Reduction in electricity savings } \\
\text { from policy bundle (TWh) }\end{array}$} \\
\cline { 2 - 9 } & 2020 & 2025 & 2030 & 2035 & 2020 & 2025 & 2030 & 2035 \\
\hline Appliance Incentives & 12.7 & 19.0 & 23.0 & 25.6 & 6.8 & 11.5 & 14.3 & 16.2 \\
Building Codes & 7.9 & 11.8 & 15.7 & 19.0 & 3.0 & 3.7 & 4.5 & 5.2 \\
On-bill Financing & 13.5 & 17.6 & 20.6 & 22.4 & 3.9 & 2.7 & 1.8 & 1.5 \\
Aggressive Appliance Policy & 16.0 & 25.6 & 34.3 & 40.3 & 6.2 & 13.1 & 20.3 & 27.3 \\
Market Priming & 99.8 & 113.9 & 117.0 & 118.8 & 62.0 & 81.2 & 87.0 & 83.4 \\
\hline
\end{tabular}

Note: the reduction in electricity savings from integration by each policy is the decrease of savings by turning one policy off, compared with the full integration scenario.

It is clear that the significance of individual policy diminishes when integrated into the integrated residential policy scenario. For example, Appliance Incentives alone can save the region 25.6 TWh of electricity in 2035. But, the all-but-Appliance Incentives scenario only indicates 16.2 TWh savings in 2035. The amount of potential savings from each of the five policies when they are taken out from integration is 30-93\% lower than the potential savings from each individual policy scenarios. The potential of On-bill Financing would diminish the most, while Market Priming is successful in retaining $70 \%$ of the potential from its individual policy scenario.

\subsection{Summary and Discussion}

The five polices selected in this chapter target the potential to improve the efficiency of energy use in residential buildings. A combination of the five policies can generate significant savings, more than offsetting the growth in electricity demand between 2012 and 2035. Each of these policies is associated with relatively low levelized costs, ranging from $0.011 / \mathrm{kWh}$ for Market Priming, to $\$ 0.137 / \mathrm{kWh}$ for On-bill Financing. Three of the policies have LCOEs that are lower than the retail electricity price for the residential sector.

In addition to the electricity savings, the policies also produce spillover benefits of large savings of natural gas and other fuels. The savings are not distributed in the Eastern Interconnection 
proportionally to area or population. But rather, local situations, such as current state policies and energy consumption, influence the local savings potential.

Our estimate of electricity efficiency potential is in the middle of the range of potential assessments from a broad set of studies summarized in our review of the previous literature. It should also be acknowledged that our estimation is the achievable potential driven by possible future energy policies, making it smaller than assessments of technical or economic potential.

Potential estimation in this study is based on GT-NEMS forecast of future energy consumption in the U.S. Our estimation is limited by the GT-NEMS characterization of the U.S. energy market, especially the residential building sector. In fact, GT-NEMS modeling of residential buildings is rather constrained by a limited number of technology choices, GT-NEMS characterization of market penetration rates for home appliances and equipment, and other model limitations. The decision-making process in GT-NEMS mimics rational choices based on benefit-cost analysis, but it has limited modeling power to reflect behavioral constraints and suboptimal rationality.

Although estimation is limited by the chosen modeling tool, electricity savings estimated in this study provides a reliable and illustrative assessment of the achievable potential, with some analysis of regional impacts, impacts on other fuels and carbon emissions. Findings in this study are able to assist policy-makers with detailed information about policy options available for promoting electricity end-use efficiency in the Eastern Interconnection. 


\section{ENERGY-EFFICIENCY POTENTIAL IN COMMERCIAL BUILDINGS}

In 2010, the commercial sector in the Eastern Interconnection consumed $945 \mathrm{TWh}$, which was $71.1 \%$ of national electricity consumption in commercial buildings (compared with $68.6 \%$ of the national population). The 2009 consumption level was slightly lower, at $923 \mathrm{TWh}$, due to the country's economic downturn. Delivered electricity consumption (at 25\%) combined with electric system energy losses (at 51\%) make electricity responsible for $76 \%$ of the total energy consumption attributed to the commercial buildings sector in the Eastern Interconnection in 2009 (12,900 TBtu) (Fig 4.1).

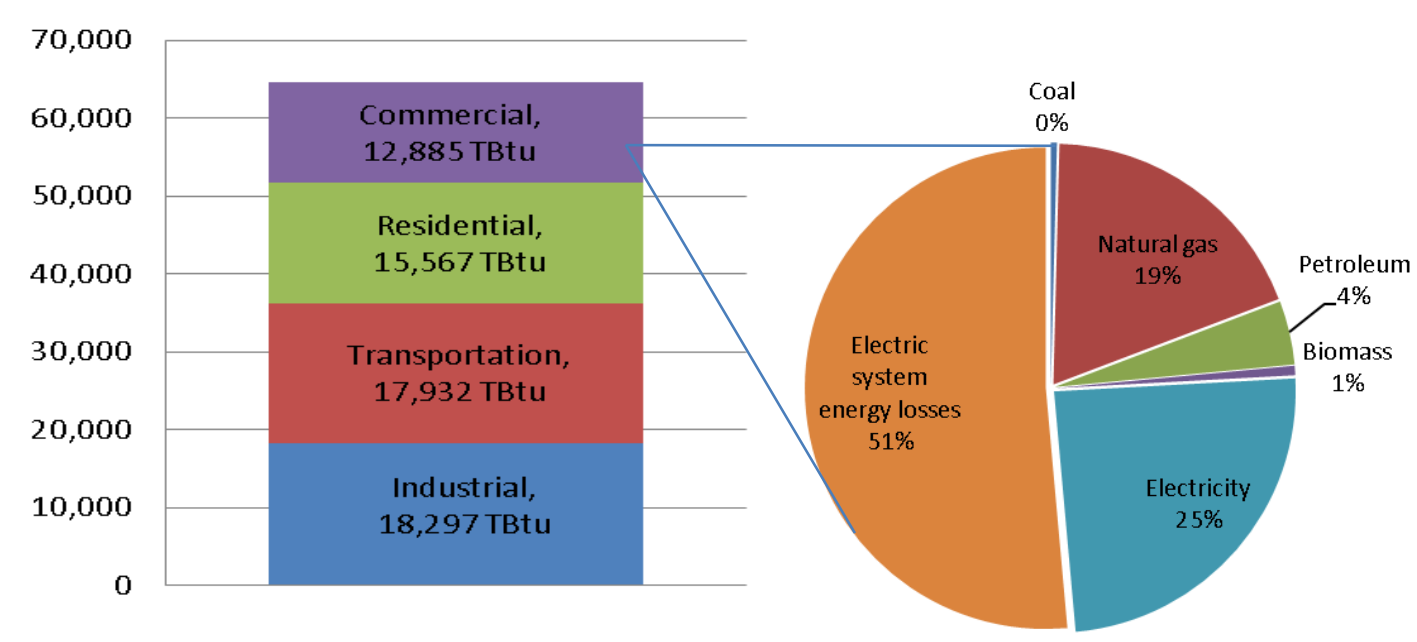

Figure 4.1 Commercial Energy Consumption in the Eastern Interconnection (Source: EIA, SEDS, 2010)

According to the forecast of the Annual Energy Outlook 2011 by EIA (2011), commercial electricity consumption in the Eastern Interconnection will grow steadily at the rate of about $1.3 \%$ annually. In 2035, EIA forecasts the commercial electricity demand is 1,337 TWh in the region, $41 \%$ higher than the 2010 level (Figure 4.2). 


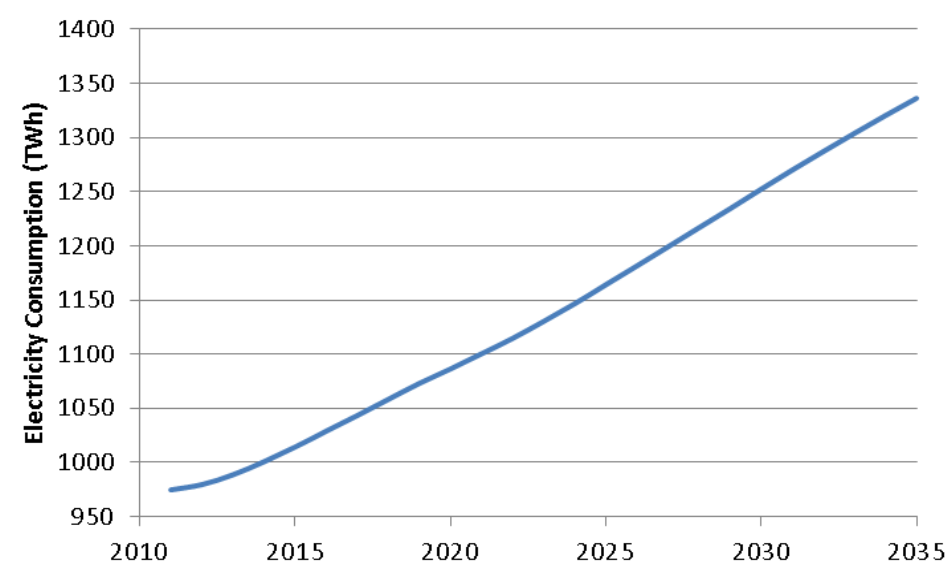

Figure 4.2 Reference Case Forecast of Commercial Electricity Consumption in the Eastern Interconnection (Source: EIA, AEO 2011)

This chapter examines the achievable potential of energy efficiency from selected policies addressing both existing commercial buildings and new construction. The chapter explores the electricity savings from these policies and examines the regional distribution of the estimated savings potential. The other benefits from the energy-efficiency policies, such as natural gas savings, are also investigated. The last section of this chapter tests the effects and potentials of integrating all commercial policies together.

\subsection{Overview of Previous Literature on the Energy-Efficiency Potential of Commercial Buildings}

Evaluations of energy efficiency potential have been done by studies across multiple scales and time frames. McKinsey (Granade, et al., 2009) estimates that the NPV-positive potential for efficiency savings in the commercial sector is $29 \%$ in end-use energy, which sums up to $\$ 290$ billion of total energy savings from 2009-2020. A state-level study of state and local programs in Arkansas estimated the total energy-efficiency potential to be $15 \%$ of electricity demand, $14 \%$ of natural gas demand, and $20 \%$ of peak demand by 2025 . The study focused on cost-effective resources, forecasted to produce $4,700 \mathrm{BBtu}(9 \%)$ of electricity savings and $12,800(8 \%)$ of natural gas savings by 2025 in the commercial sector. The projected potential can be achieved at a relatively low cost where the estimated levelized cost of electricity is only $\$ 0.02 / \mathrm{kWh}$ (Neubauer et al, 2011). Another state-level study, however, examines the energy efficiency in residential and non-profit buildings in Cincinnati (Mackres, et al, 2011). This study finds that the potential energy savings associated with current efficiency programs is $2.8 \%$ of electricity demand and $6.9 \%$ of natural gas demand in 2030 .

Many researchers also study energy-efficiency measures applied to the building sector. A simulation of 12 prototypical buildings in 16 cities provides the basis for assessing the energy efficiency potential in commercial buildings, with cost-effective estimates of $20-30 \%$ on average for new buildings and up to over $40 \%$ for some building types and locations (Kneifel, 2010).

These studies present a wide range of energy-efficiency potentials due to differences in time frames and forecasting methods. State-level estimates tend to generate projections slightly 
smaller than national-level studies. The difference calls for paying attention to the choice of forecasting approaches and potential-type for evaluation (technical, economic, or achievable).

\subsection{Commercial Efficiency Policy Options and Modeling Approach}

Energy consumption in commercial buildings comes from space heating and cooling, water heating, lighting and other end-uses, which are closely related to the efficiency of building shell, HVAC equipment and other appliances. Many state, local, and utility-level programs and policies are designed to improve energy efficiency in commercial buildings. To assess the electricity saving potential from all building components, a policy bundle of three efficiency policies was designed, including: Benchmarking (an information policy), Flexible Innovative Financing (a financing policy), and National Building Codes (a regulatory policy). Table 4.1 summarizes each of these policy scenarios, along with the GT-NEMS levers used to model it. Further details are provided in Appendix B.

Table 4.1 GT-NEMS Levers for Commercial Energy Efficiency Policies

\begin{tabular}{l|l|l|l}
\hline Policy type & Policy & Scenario description & $\begin{array}{l}\text { GT-NEMS } \\
\text { Lever }\end{array}$ \\
\hline Information & Benchmarking & $\begin{array}{l}\text { Lower the time preference premium for } \\
\text { commercial technologies. }\end{array}$ & Kprem.txt \\
\hline Financial & $\begin{array}{l}\text { Flexible } \\
\text { Innovative } \\
\text { Financing }\end{array}$ & $\begin{array}{l}\text { A 30\% subsidy was applied to the capital costs of } \\
\text { the winning technologies under Carbon Tax }\end{array}$ & Ktek.xml \\
\hline Regulatory & $\begin{array}{l}\text { National } \\
\text { Building } \\
\text { Codes }\end{array}$ & $\begin{array}{l}\text { Revised factor of efficiency improvement in } \\
\text { 2035 for new buildings and major renovations }\end{array}$ & $\begin{array}{l}\text { KSHEFF.txt } \\
\text { Ktek.xml }\end{array}$ \\
\hline
\end{tabular}

The Benchmarking policy focuses on giving building owners in the country access to baseline information on their building's energy consumption, as described in Cox, Brown, and Sun (2012). This could be accomplished by requiring utilities to submit energy data in a standard format to a widely used database, such as Portfolio Manager, which currently maintains information on hundreds of thousands of buildings in the U.S., submitted by building owners, managers, and utilities. Using existing software packages, combining the meter data, tenants within a building could provide a "virtual building meter," allowing for building-wide analysis. The data would then be available to the building owner and the utility and maintained by the Environmental Protection Agency (EPA).

Benchmarking helps building owners and tenants focus awareness on poor-performing buildings and subsystems, and enables high-performing buildings to participate in various certification programs that can lead to higher occupancy rates, rents, and property values. It requires an expenditure of time and effort, but this can be minimized by using Portfolio Manager as the benchmarking tool. In fact, every one of the existing programs, including the international effort between the U.S. and Canada, uses Portfolio Manager (Figure 4.3). The Institute for Market Transformation summarized the recent experiences of nine current U.S. programs (Burr, Keicher, 
and Leipziger, 2011). As a result of program reviews and in-depth stakeholder discussions, a series of best practices were recommended for outreach and education, benchmarking, compliance, data quality, energy consumption data, and disclosure. For benchmarking, the main recommendation is to follow EPA guidelines surrounding the use of Portfolio Manager.

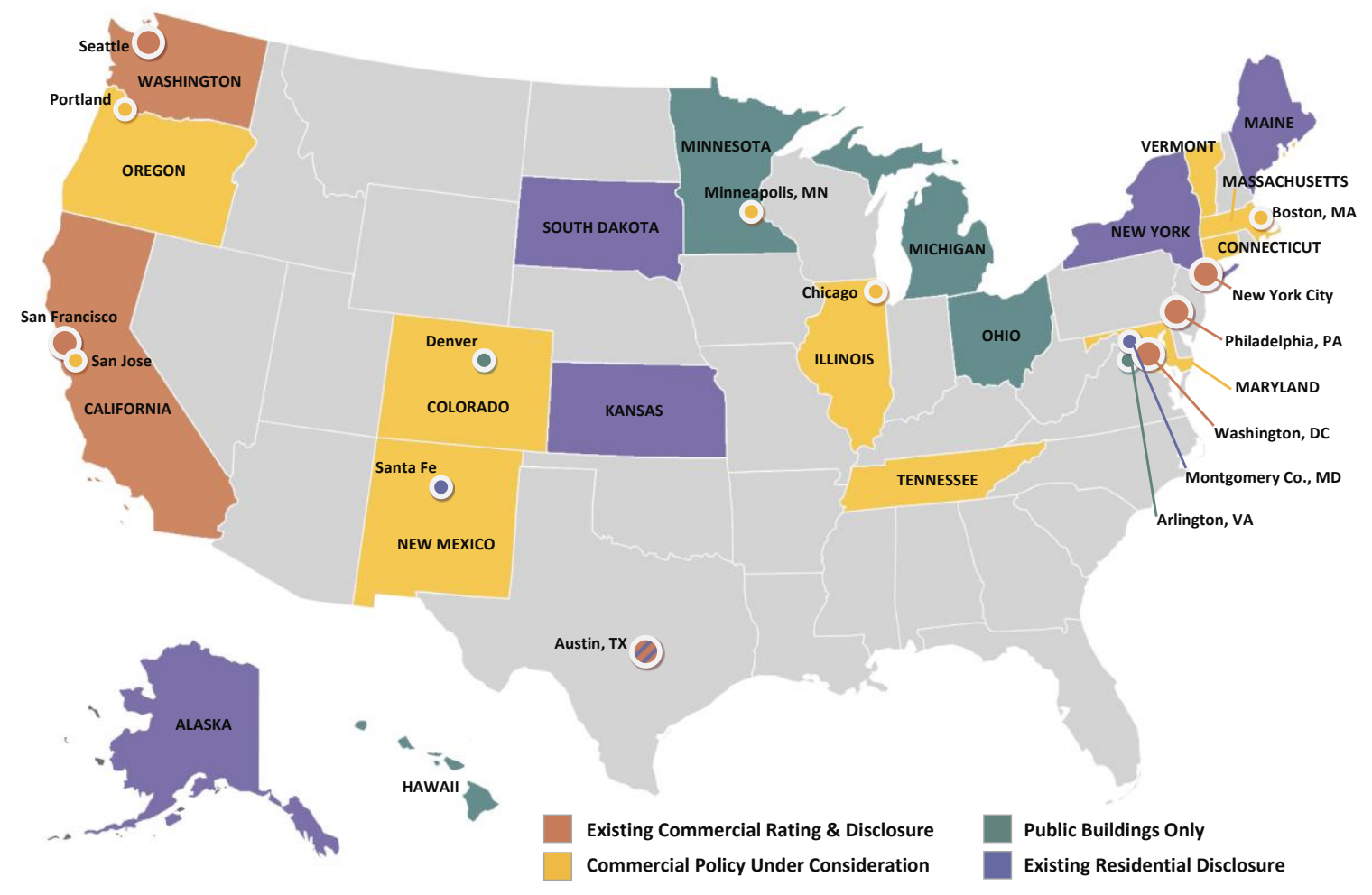

Figure 4.3 Mandated Disclosure and Benchmarking Efforts in the United States

Source: www.IMT.org

Benchmarking has the potential to reduce or eliminate information asymmetries in the marketplace and to reduce the discount rates used by consumers in the sector. Thus, we model this policy by lowering the time preference premium for energy-efficient commercial technologies, as described in Appendix B.

Flexible Innovative Financing is a federal policy that would support state and local initiatives via the financially sustainable mechanisms of loan loss reserves, property assessed clean energy (PACE) tax liens, revolving loans, performance contracts, and on-bill programs, as described in Deitchman, Brown, and Wang (2012). The lack of attractive financing options remains one of the most significant barriers to deep energy efficiency upgrades in private commercial buildings (Prindle, 2010; Johnson Controls/IFMA, 2010; Kammen, 2009). Recognizing this barrier to energy efficiency investments, many states passed legislation enabling the creation of PACE districts between 2008 and 2010, as shown in Figure 4.4. 


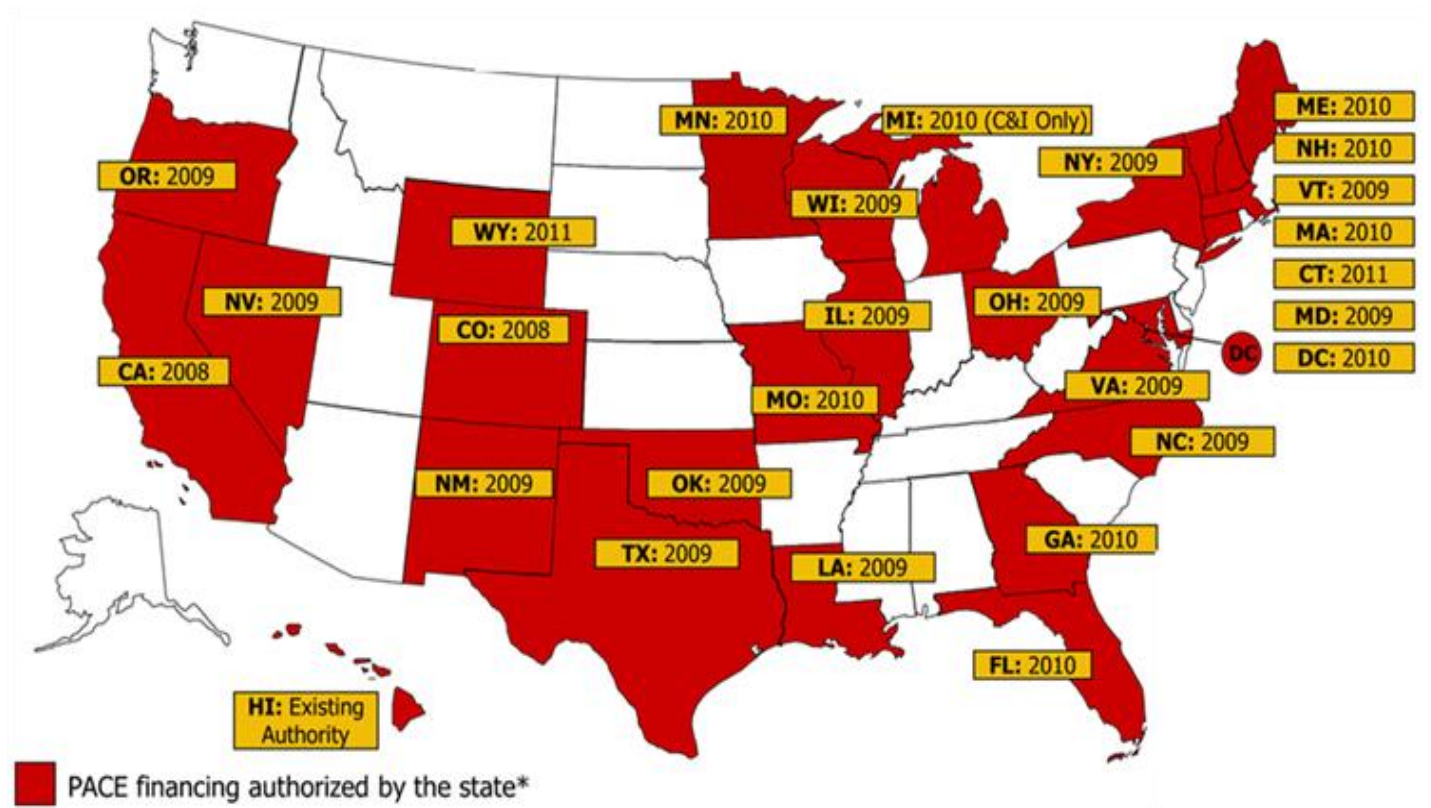

Figure 4.4. PACE-Enabled States

Source: DSIRE (2012)

A fundamental assumption of this analysis is that flexible innovative financing could be modeled as a subsidy on the first costs of energy-efficient technologies as firms consider the net present value of an investment. Reducing interest rates, entering into ESPCs, or financing through the other mechanisms have the long-term impact of making upfront investments more economically attractive. We use the results of Brown, Cox, and Sun (2012) to identify the subset of 350 technologies characterized in the GT-NEMS commercial module that would be modeled with a $30 \%$ subsidy. Specifically, we subsidize the 107 technologies that attract greater energy service demand following the introduction of a Carbon Tax. This set of 107 technologies draws on the suite of technologies from EIA's "High Tech" side case that assumes higher efficiencies for equipment, and earlier availability of some advanced equipment. Use of the high-technology equipment menu in GT-NEMS is predicated on the presumption that creating flexible innovative financing would facilitate research, development, and the demand for better-than-baseline technologies. These technologies are listed in Table B.3.

The National Building Codes policy for commercial buildings would set higher building shell efficiency requirements and more stringent energy efficiency standards for space heating and cooling technologies in both new construction and existing buildings that undergo major modifications, It is modeled after the aggressive building codes policy described in Sun, Brown, Jackson, and Cox (2012), but it does not include requirements for improved lighting and water heating. To maximize code adoption and compliance, DOE would facilitate the establishment of building code compliance assistance programs at the state and local level to help developers and builders analyze and comprehend the code, train code officials and inspectors to oversee the code compliance, provide information and training opportunities to parties involved in the building industry, and engage utilities to promote the adoption and compliance of the codes. The policy would also encourage establishing a building code liability structure under which relevant parties including developers, design companies, builders, building owners, and others have the 
responsibility to ensure their project is in compliance with the building code. Code officials and inspectors at the state and local level would be able to exercise their authority established by law to enforce the codes and hold the relevant parties accountable in case of non-compliance.

Unlike the commercial end-use technologies that have detailed characteristics profiles, GTNEMS does not include a building shell technology profile. Instead, the shell efficiency improvement over time is indexed by a set of efficiency factors that represent the overall shell efficiency improvement of the U.S. commercial building stock in 2035 over the 2003 level. Table B.2 summarizes the building shell efficiency assumptions of the reference case with the National Building Code policy case examined here.

\subsection{Modeling Results for Individual Commercial Building Policies}

The energy consumption forecasts of the policy cases were compared with the reference case forecast, and the differences represent the achievable energy efficiency potential. Figure 4.5 shows the estimated potential of each policy. The percentage number is the reduction in electricity demand as a percentage of the reference case forecast in each year.

In 2035, the electricity savings from these four policies in the Eastern Interconnection is 3.4 $76.8 \mathrm{TWh}(0.3 \%-5.8 \%$ of reference case consumption), while the total electricity savings in the nation is $5.0-107.0 \mathrm{TWh}(0.3 \%-5.7 \%$ of Reference case consumption).

The Benchmarking policy generates the highest level of electricity savings among all four commercial policies. Flexible Innovative Financing also generates significant savings. The deployment of commercial CHP systems, on the other hand, indicates less potential for energy saving, due partly to the slow penetration of CHP facilities in commercial buildings.

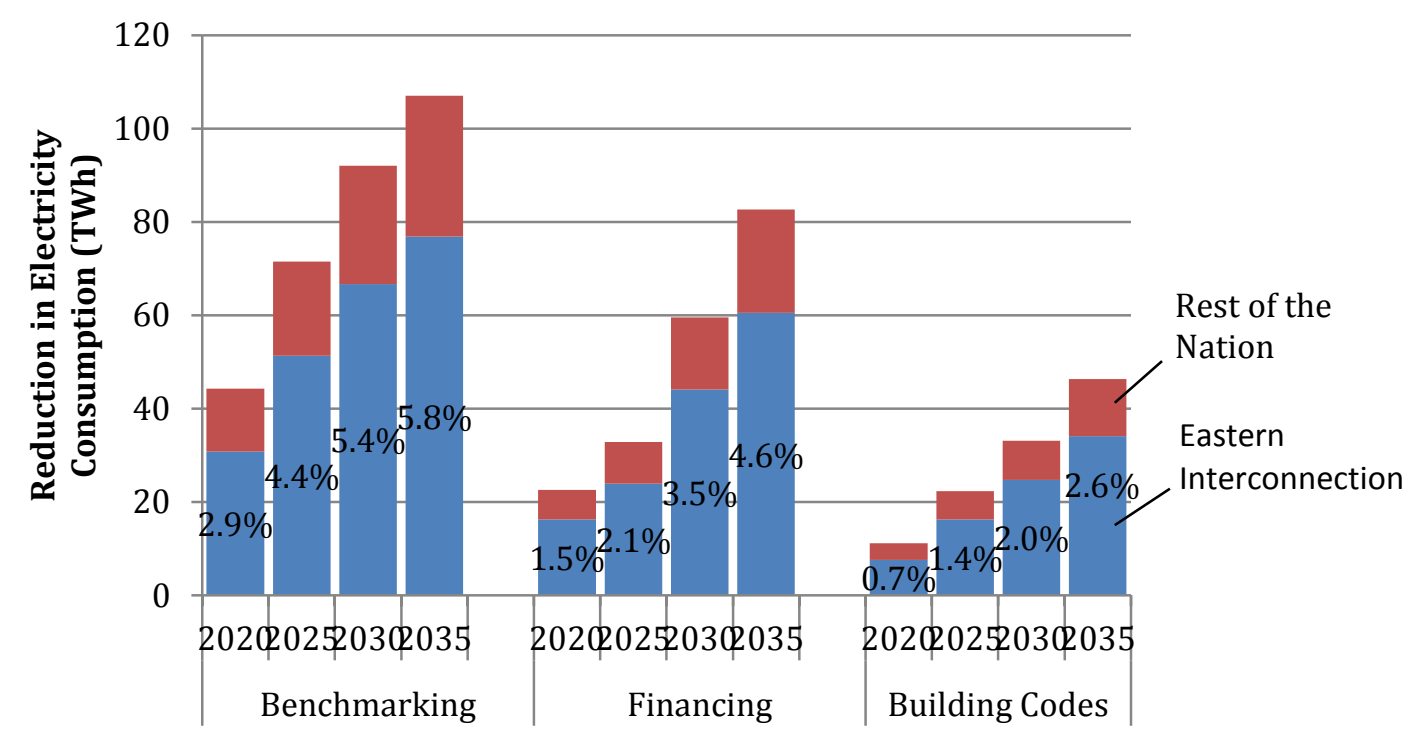

Figure 4.5 Estimated Reductions in Electricity Demand by Individual Policies (Percentages of Commercial Buildings Electricity Consumption) 


\subsubsection{Regional Differences}

Within the Eastern Interconnection, the policies generate different impacts in different census divisions. It is notable that Benchmarking and Flexible and Innovative Financing have a large portion of savings in South Atlantic, East North Central and Middle Atlantic regions. But it is different for Commercial CHP in the pattern of benefit distribution among regions. The largest proportion of electricity savings goes to the Middle Atlantic and East North Central regions (Figure 4.6).
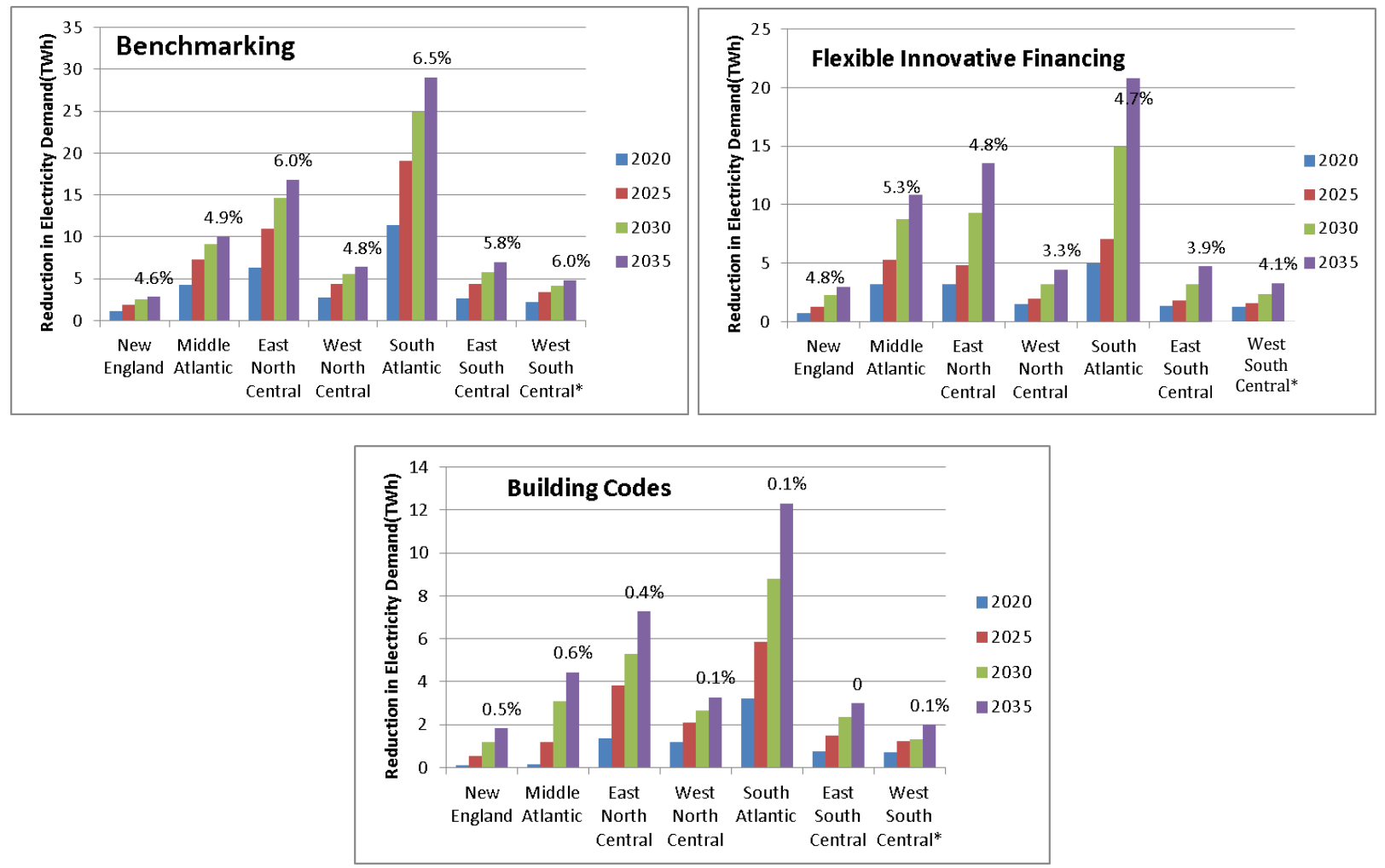

Figure 4.6 Electricity Savings by Census Division for Individual Policies (*West South Central Excluding Texas)

\subsubsection{Spillover Benefits}

All selected policies aim to promote efficiency in commercial buildings, including the efficient use of electricity and other fuel types. Table 4.2 illustrates the reduction in natural gas consumption that is estimated to result from each individual policy.

Different from the policy-specific estimates of electricity-savings potential where Benchmarking dominated, National Building Codes is the commercial policy with the largest natural gas savings potentials in the Eastern Interconnection and in the whole nation. The financing policy is similar to the benchmarking policy in its natural gas savings in 2035, but its cumulative savings are greater because its impact is more significant in earlier years. 
Table 4.2 Natural Gas Savings from Individual Policies

\begin{tabular}{l|l|c|c|c|c}
\hline \multicolumn{2}{c|}{} & \multirow{2}{*}{$\begin{array}{c}\text { Reference Demand } \\
\text { Forecast (TBtu) }\end{array}$} & \multicolumn{3}{|c}{ Natural Gas Savings (TBtu) } \\
\cline { 4 - 6 } \multicolumn{2}{c|}{} & & Benchmarking & Financing & Building Codes \\
\hline \multirow{2}{*}{2020} & EI & 2,708 & 60 & 106 & 125 \\
\cline { 2 - 6 } & US & 3,594 & 75 & 134 & 156 \\
\hline 2025 & EI & 2,755 & 82 & 112 & 149 \\
\cline { 2 - 6 } & US & 3,661 & 104 & 145 & 189 \\
\hline 2030 & EI & 2,838 & 95 & 105 & 165 \\
\cline { 2 - 6 } & US & 3,775 & 120 & 139 & 208 \\
\hline 2035 & EI & 2,946 & 116 & 103 & 183 \\
\cline { 2 - 6 } & US & 3,919 & 146 & 135 & 230 \\
\hline
\end{tabular}

The policies are also able to generate savings in fuels other than electricity and natural gas, such as fuel oil, diesel, and propane. Table 4.3 shows the potential savings in total energy, which is the projected reduction in total commercial energy consumption. These savings were calculated without including the avoided electricity related losses. In terms of total energy savings, Benchmarking has the greatest potential. Benchmarking also exerts a bigger push for energy efficiency from the beginning of the program, while for National Building Codes, energy savings start slowly but grow steadily over time.

Table 4.3 Total Energy Savings from Individual Policies

\begin{tabular}{l|l|c|r|r|r}
\hline \multicolumn{2}{c|}{} & Reference Demand & \multicolumn{3}{|c}{ Total Energy Savings (TBtu) } \\
\cline { 4 - 6 } \multicolumn{2}{c}{} & Forecast (TBtu) & Benchmarking & Financing & Building Codes \\
\hline \multirow{2}{*}{2020} & EI & 14,372 & 447 & 354 & 280 \\
\cline { 2 - 6 } & US & 20,300 & 610 & 450 & 360 \\
\hline 2025 & EI & 15,220 & 604 & 401 & 395 \\
\cline { 2 - 6 } & US & 21,460 & 880 & 540 & 520 \\
\hline 2030 & EI & 16,020 & 720 & 515 & 433 \\
\cline { 2 - 6 } & US & 22,720 & 1,060 & 740 & 600 \\
\hline \multirow{2}{*}{2035} & EI & 16,903 & 857 & 687 & 537 \\
\cline { 2 - 6 } & US & 24,000 & 1,220 & 960 & 730 \\
\hline
\end{tabular}

\subsubsection{Cost Estimation}

The Benchmarking policy lowers the hurdle rate used by consumers in their equipmentpurchasing decisions. Private investment is the expenditure for purchasing equipment. There is no public cost except for program administrative costs, estimated as $\$ 0.13 / \mathrm{MMBtu}$ energy saved. The LCOE in this policy case is estimated to be $0.7-1.2$ cent $/ \mathrm{kWh}$. Details of the cost estimations associated with Benchmarking are shown in Table 4.4. 
Table 4.4 Cost Estimations from Benchmarking

\begin{tabular}{c|cccc}
\hline Cost $($ Billion $\$ 2009)$ & 2020 & 2025 & 2030 & 2035 \\
\hline Private Cost & 0.93 & 0.85 & 0.85 & 0.82 \\
Compliance Cost & -0.001 & -0.001 & -0.001 & -0.001 \\
Total & 0.92 & 0.85 & 0.84 & 0.82 \\
\hline LCOE $($ cent $/ \mathrm{kWh})$ & \multicolumn{4}{|c}{$0.7-1.2^{\mathrm{b}}$} \\
\hline
\end{tabular}

a. Private cost was discounted at 7\%, and public cost was discounted at 3\%.

b. Levelized cost calculated in a sensitivity when all costs were discounted at 3\%.

In the Financing case, private investment is the expenditure for purchasing equipment. Total cost was estimated to be the sum of private cost, the cost of subsidizing the most efficient technologies, and program administrative costs, estimated as $\$ 0.13 / \mathrm{MMBtu}$ energy saved. The LCOE in this policy case is estimated to be 6.4-6.6 cent $/ \mathrm{kWh}$. Details of cost estimations associated with Appliance Incentives are shown in Table 4.5.

Table 4.5 Cost Estimations from Financing

\begin{tabular}{|c|c|c|c|c|}
\hline Cost (Billion \$2009) ${ }^{\mathrm{a}}$ & 2020 & 2025 & 2030 & 2035 \\
\hline Private Cost & 0.71 & 0.58 & 0.49 & 0.44 \\
\hline Subsidy Cost & 9.17 & 8.07 & 9.07 & 8.64 \\
\hline Administration Cost & 0.06 & 0.06 & 0.07 & 0.06 \\
\hline Total & 9.94 & 8.71 & 9.64 & 9.14 \\
\hline LCOE (cent/kWh) & \multicolumn{4}{|c|}{$6.4-6.6^{b}$} \\
\hline
\end{tabular}

a. Private cost was discounted at 7\%, and public cost was discounted at $3 \%$.

b. Levelized cost calculated in a sensitivity when all costs were discounted at 3\%.

For Building Codes, private investment is the incremental cost of equipment and building envelope expenditures to meet new building codes. There is no public cost except for program administration. This policy assumes costs associated with building code enforcement carried out by state building code officials and inspectors. The administrative costs are based on each state's adding one administrative office, operated for $\$ 150,000$ per annum, and one code official at $\$ 75,000$ salary per annum. It also includes two additional building code inspectors for the verification of every 100 million square feet in the state at $\$ 75,000$ per year (Brown, et al., 2009). The LCOE in this policy case is estimated to be 3.5-4.6 cent/kWh. Details of cost estimations associated with Building Codes are shown in Table 4.6.

Table 4.6 Cost Estimations from Building Codes

\begin{tabular}{c|cccc}
\hline Cost $(\text { Billion } \$ 2009)^{\mathrm{a}}$ & 2020 & 2025 & 2030 & 2035 \\
\hline Private Cost & 1.08 & -1.91 & 0.39 & 0.25 \\
Shell Improvement Cost & 0.07 & -0.15 & 0.05 & 0.03 \\
Administration Cost & 0.04 & -0.10 & 0.04 & 0.03 \\
Total & 1.19 & -2.16 & 0.48 & 0.31 \\
\hline LCOE (cent $/ \mathrm{kWh})$ & \multicolumn{4}{|c}{$3.5-4.6^{\mathrm{b}}$} \\
\hline
\end{tabular}

a. Private cost was discounted at 7\%, and public cost was discounted at $3 \%$.

b. Levelized cost calculated in a sensitivity when all costs were discounted at $3 \%$. 


\subsection{Integrated Commercial Policy Bundle}

The projected savings change when the commercial policies are evaluated as one policy bundle. Figure 4.7 shows the efficiency potential resulting from the integrated commercial policy case. The savings potential from the integrated policy scenario is $40 \mathrm{TWh}$ in 2020, expanding to 153 TWh (8.4\% of reference consumption) in 2035 in the Eastern Interconnection.

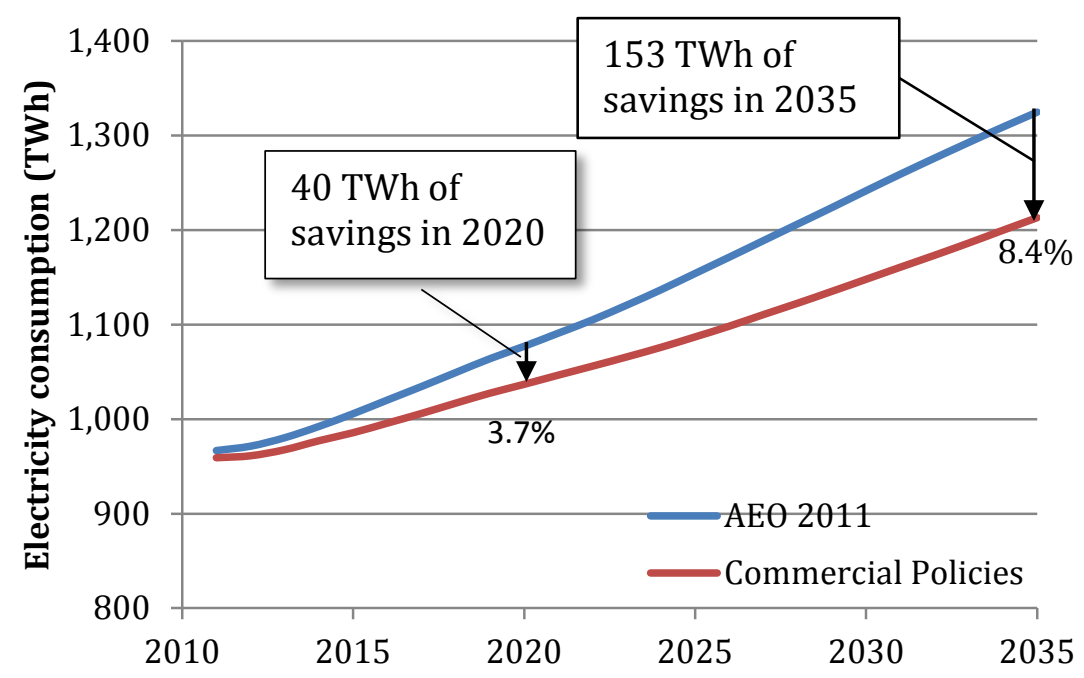

\section{Figure 4.7 Commercial Electricity Savings Potential in the Eastern Interconnection}

\subsubsection{Electricity Savings Potential By End Use}

Electricity consumption by space cooling, space heating, and ventilation would be reduced significantly by the Commercial Policies bundle (Table 4.7). However, electricity consumption by "other" end-uses services has increased in the Commercial Policies case; these represent an array of miscellaneous "plug loads" that are not targeted by any of our commercial building energy policies. 
Table 4.7 Electricity-Savings Potential by End-Use in the US

\begin{tabular}{|c|c|c|c|c|c|c|c|c|c|}
\hline \multirow[b]{2}{*}{ End Use } & \multirow{2}{*}{\begin{tabular}{|c|}
2010 \\
Reference
\end{tabular}} & \multicolumn{4}{|c|}{2020} & \multicolumn{4}{|c|}{2035} \\
\hline & & Reference & $\begin{array}{c}\text { Policy } \\
\text { Case }\end{array}$ & $\begin{array}{l}\text { Annual } \\
\text { Savings }\end{array}$ & $\begin{array}{l}\text { Percent } \\
\text { Savings } \\
\end{array}$ & Reference & Policy Case & $\begin{array}{l}\text { Annual } \\
\text { Savings }\end{array}$ & $\begin{array}{l}\text { Percent } \\
\text { Savings }\end{array}$ \\
\hline Space Heating & 51 & 50 & 43 & 7 & $15 \%$ & 52 & 42 & 10 & $18 \%$ \\
\hline Space Cooling & 170 & 160 & 137 & 23 & $14 \%$ & 180 & 141 & 39 & $22 \%$ \\
\hline Water Heating & 27 & 28 & 27 & 1 & $4 \%$ & 28 & 25 & 3 & $10 \%$ \\
\hline Ventilation & 150 & 176 & 102 & 74 & $42 \%$ & 209 & 107 & 102 & $49 \%$ \\
\hline Lighting & 300 & 321 & 311 & 10 & $3 \%$ & 365 & 303 & 62 & $17 \%$ \\
\hline Refrigeration & 115 & 105 & 100 & 5 & $5 \%$ & 114 & 105 & 9 & $8 \%$ \\
\hline $\begin{array}{l}\text { Personal } \\
\text { Computer }\end{array}$ & 62 & 56 & 56 & 0 & $0 \%$ & 62 & 62 & 0 & $0 \%$ \\
\hline $\begin{array}{l}\text { Other Office } \\
\text { Equipment }\end{array}$ & 77 & 108 & 108 & 0 & $0 \%$ & 137 & 137 & 0 & $0 \%$ \\
\hline Other Uses & 391 & 518 & 578 & -60 & $-11 \%$ & 730 & 802 & -72 & $-10 \%$ \\
\hline Total & 1343 & 1522 & 1462 & 60 & $3.9 \%$ & 1877 & 1724 & 153 & $8.2 \%$ \\
\hline
\end{tabular}

\subsubsection{Potential for Natural Gas Savings and Carbon Dioxide Emission Reductions}

The commercial policies are also able to generate significant savings in natural gas and other fuel types. In the integrated policy scenario, the natural gas savings reach 368 TBtu in the Eastern Interconnection, while savings in total energy consumption reach 1,930 TBtu in the region (Table 4.8).

Table 4.8 Potential Savings of Natural Gas and Total Energy

\begin{tabular}{l|cccc|cccc}
\hline & \multicolumn{4}{|c|}{ Natural gas savings (TBtu) } & \multicolumn{4}{c}{ Total Energy Savings (TBtu) } \\
\cline { 2 - 9 } & $\mathbf{2 0 2 0}$ & $\mathbf{2 0 2 5}$ & $\mathbf{2 0 3 0}$ & $\mathbf{2 0 3 5}$ & $\mathbf{2 0 2 0}$ & $\mathbf{2 0 2 5}$ & $\mathbf{2 0 3 0}$ & $\mathbf{2 0 3 5}$ \\
\hline EI & 187 & 222 & 253 & 288 & 681 & 939 & 1,167 & 1,375 \\
US & 236 & 283 & 324 & 368 & 900 & 1,300 & 1,640 & 1,930 \\
\hline
\end{tabular}

In addition, carbon emissions from the consumption of electricity and other fuels would be reduced since the demand for primary energy drops in the Integrated Policy scenario (Table 4.9).

Table 4.9 Potential Reduction in $\mathrm{CO}_{2}$ Emissions from Commercial Policies

\begin{tabular}{l|rrrr|rrrr}
\hline & \multicolumn{8}{|c}{ Carbon Emission Reduction (Million Tonnes) } \\
\cline { 2 - 9 } & \multicolumn{4}{|c}{ From electricity } & \multicolumn{5}{c}{ From primary energy } \\
\cline { 2 - 9 } & $\mathbf{2 0 2 0}$ & $\mathbf{2 0 2 5}$ & $\mathbf{2 0 3 0}$ & $\mathbf{2 0 3 5}$ & $\mathbf{2 0 2 0}$ & $\mathbf{2 0 2 5}$ & $\mathbf{2 0 3 0}$ & $\mathbf{2 0 3 5}$ \\
\hline EI & 31 & 44 & 55 & 64 & 42 & 57 & 70 & 81 \\
US & 40 & 56 & 83 & 83 & 54 & 72 & 89 & 103 \\
\hline
\end{tabular}

\subsection{Conclusion and Discussion}


The three polices examined in this chapter target the electricity efficiency potential in commercial buildings. A combination of the policies can generate significant savings, more than offsetting the growth in electricity demand between 2012 and 2035. Each of these policies is associated with relatively low levelized costs, ranging from $\$ 0.017 / \mathrm{kWh}$ for Benchmarking, to $\$ 0.104 / \mathrm{kWh}$ for Flexible Innovative Financing. All three policies have LCOEs that are lower than the retail electricity price for the commercial buildings sector.

These electricity savings are not distributed in the Eastern Interconnection proportionally to area or population. Rather, local situations, such as state policies and energy consumption, influence the local savings potential.

Our estimate of electricity efficiency potential is in the middle of the range of potential assessments from a broad set of studies summarized in our review of the previous literature. It should also be acknowledged that our estimate is the achievable potential driven by selected policies, making it different from assessments of technical or economic potential.

In addition to saving electricity, the policies also produce spillover benefits of large savings of natural gas and other fuels.

The potential estimation in this study is based on GT-NEMS forecast of future energy consumption in the U.S. Our estimation is limited by the GT-NEMS characterization of the U.S. energy market and the commercial building sector. In fact, GT-NEMS's modeling of commercial buildings is enhanced by a sizeable number of technology choices. The decision-making process in GT-NEMS mimics rational choices based on benefit-cost analysis, but it has limited modeling power to reflect behavioral constraints and sub-optimal rationality. 


\section{ENERgy EFficiency Potential in Industrial Sector}

In 2010, the industrial sector in the Eastern Interconnection consumed 700 TWh of electricity, which was $72.1 \%$ of national industrial electricity consumption (compared with $68.6 \%$ of the national population). The 2009 consumption level was higher, indicating the continued impacts of the country's economic downturn on U.S. manufacturing. Delivered electricity consumption (at 12\% of total industrial energy use in the region) combined with electric system energy losses (at 26\%) make electricity responsible for 38\% of the total energy consumption attributed to the industry in the Eastern Interconnection in 2009 (18,300 TBtu) (Fig 5.1).

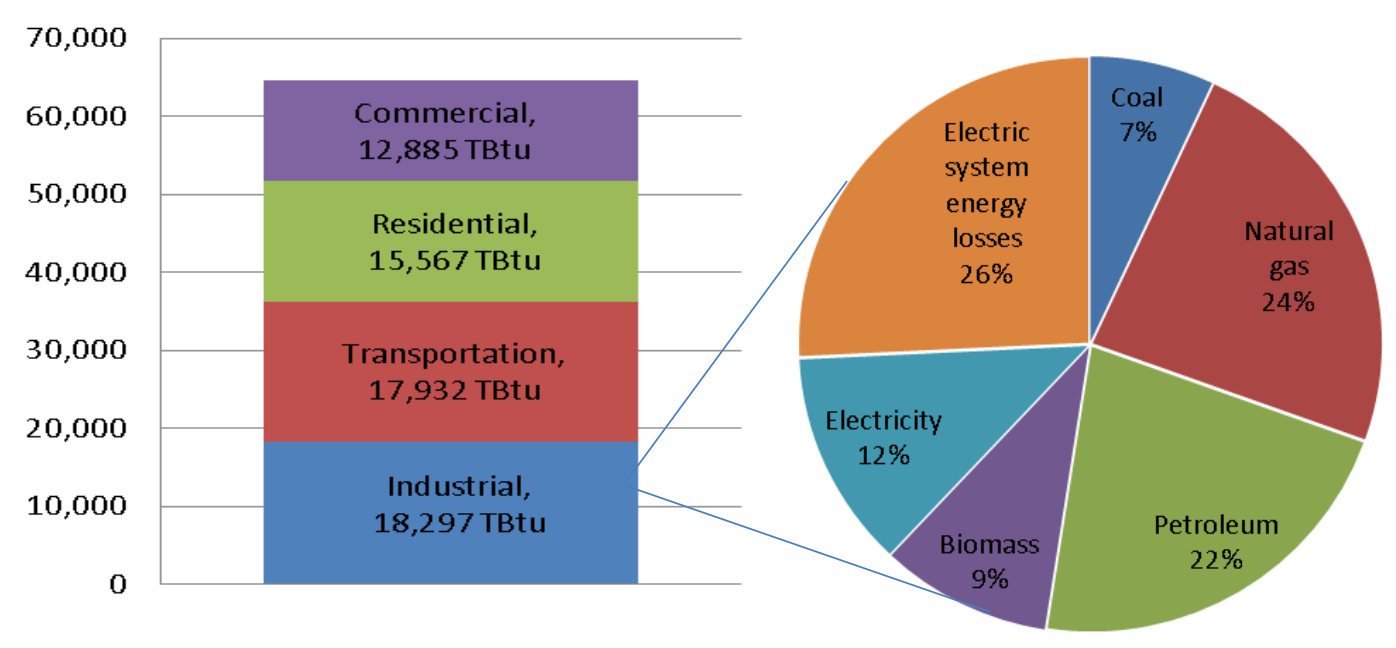

Figure 5.1 Industrial Energy Consumption in the Eastern Interconnection (Source: EIA, SEDS, 2010)

The U.S. industrial sector, which encompasses diverse manufacturing and non-manufacturing activities, has energy requirements for all kinds of fuel types. As the most diversified economic sector, the industrial sector includes manufacturing, agriculture, mining, and construction. Manufacturing industries dominate industrial energy demand. Petroleum and coal products (at $27 \%$ ) and chemicals (at 23\%) are the two most energy-consuming manufacturing industries in terms of primary energy consumption (Figure 5.2), but these same two industries account for lower proportions of manufacturing's total value of production (at $11 \%$ and $13 \%$, respectively) (Figure 5.3). 


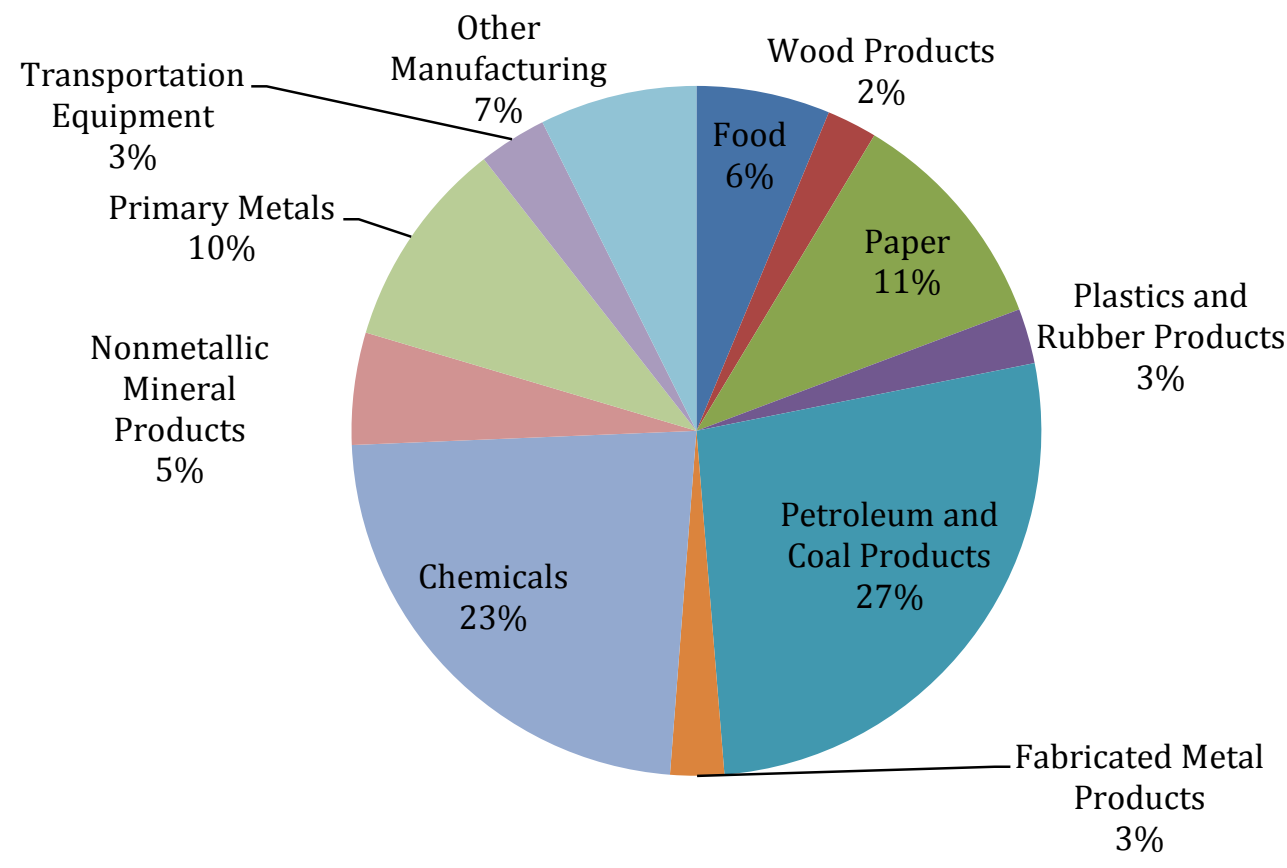

Figure 5.2 Primary Energy Consumption by Manufacturing Industries in 2006, Nationwide (Source: MECS, 2006)

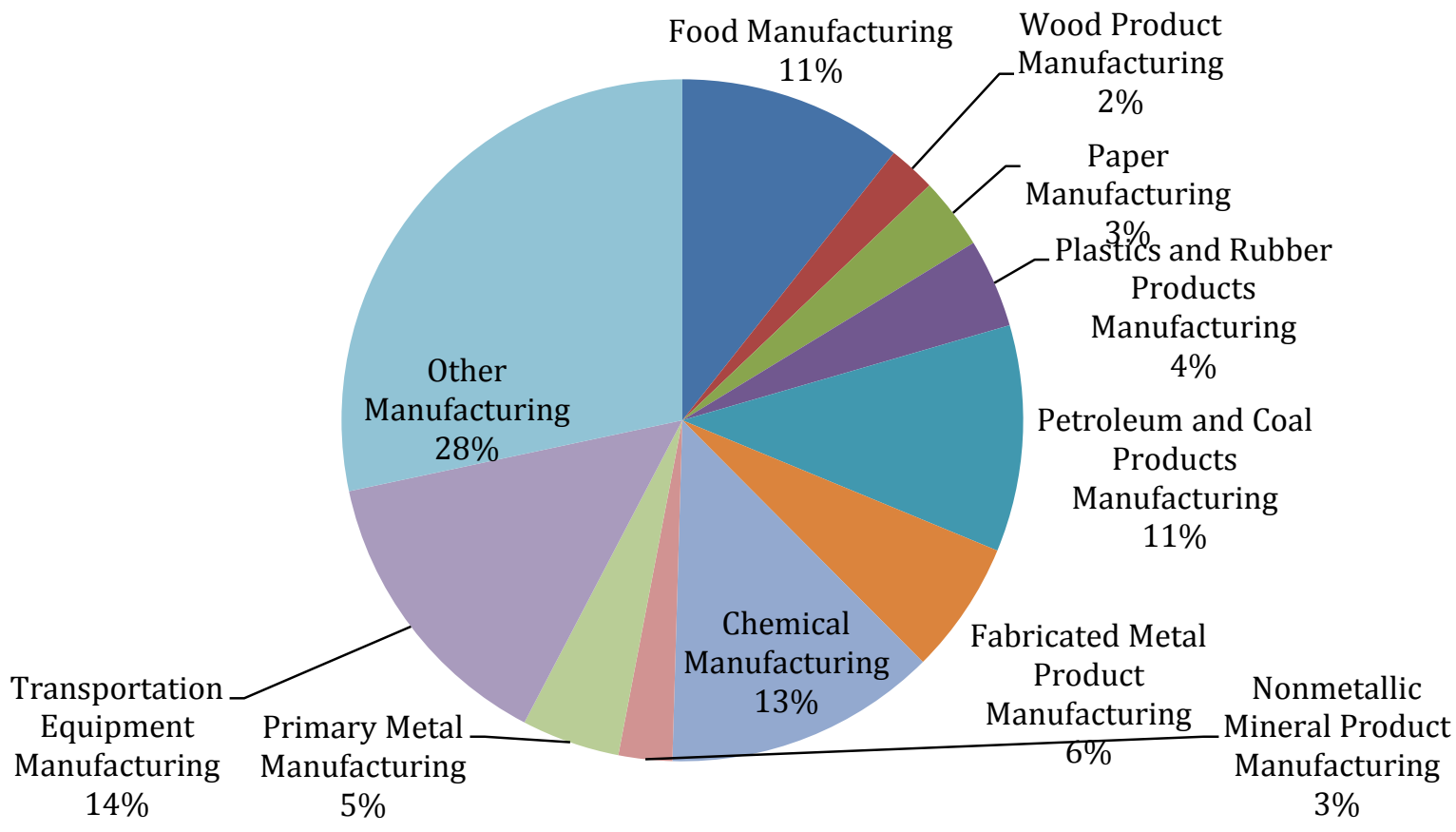

Figure 5.3 Gross Output by Manufacturing Industries in 2006

(Source: DOC, Gross Domestic Product by Industry 1998-2007, 2009) 
According to the forecast of future electricity demand in the industrial sector provided by the Annual Energy Outlook 2011, industry reaches a peak in 2021, rising to about 771 TWh in the Eastern Interconnection. The industrial electricity consumption decreases steadily after 2021 (Figure 5.4). The U.S. as a whole has similar trends as the Eastern Interconnection. The declining demand in the later years of projection is due to the increasing energy efficiency, when electricity requirement for industrial activities drops from 443 Btu/dollar in 2021 to 352 Btu/dollar in 2035 (EIA, 2011).

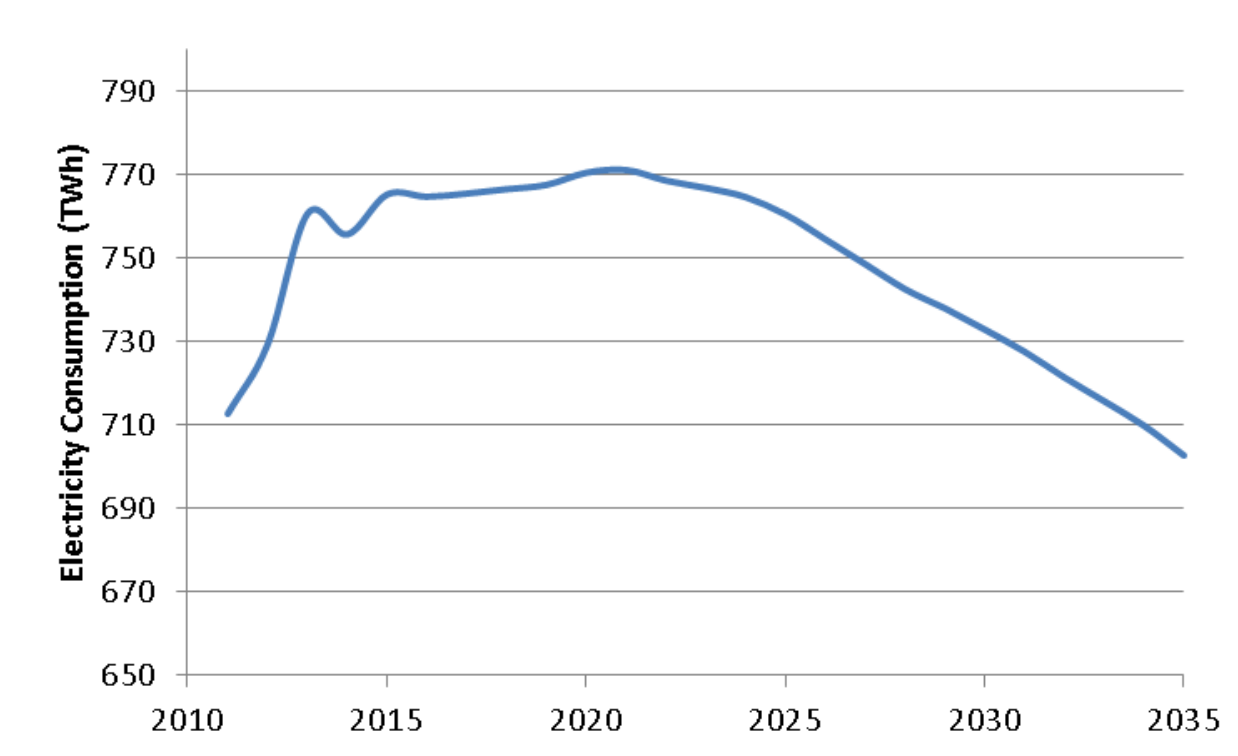

\section{Figure 5.4 Reference Case Forecast of Industrial Electricity Consumption in the Eastern Interconnection (Source: EIA, 2011)}

This chapter examines the achievable potential of energy efficiency from selected policies that promote technology advancement and improved energy management practices in industry. The chapter explores the electricity savings from these policies and examines how the savings are distributed among regions. The other benefits from the energy-efficiency policies, such as natural gas savings, are also investigated. The last section of this chapter explores the effects and potentials of concurrently implementing the entire industrial policy bundle.

\subsection{Overview of Previous Literature on the Energy-Efficiency Potential of Industry}

A long-term efficiency potential assessment done by a recent ACEEE study indicates a 33\% electricity-savings potential in the industrial sector in 2050 (Laitner, et al, 2012). This potential can be reached by a set of efficiency improvements and technology advancement in the industrial sector, including recycled feedstock and materials substitution, transformative processes, and smart manufacturing, and supply chain integration.

The McKinsey report estimates the potential of electricity savings in the industrial sector to be about $190 \mathrm{TWh}$ (18\% of baseline demand) in 2020 provided by a combination of energy efficiency programs (Granade, et al., 2009). The industries have great opportunities in various energy-efficiency initiatives and CHP deployment, which are able to generate cost-effective 
energy savings. This study found that $33 \%$ of the potential comes from cross-cutting energy support systems (such as steam systems, motors, and buildings), and the rest resides in the process and assembly steps of industry subsector. It is also found that $61 \%$ of the potential can be realized in energy-intensive industries.

Brown et al. (2011) evaluated seven industrial policies at the national scale. The three policies with the greatest energy savings potential were Output-Based Emissions Standards (3.4\% savings in 2020 rising to $9.0 \%$ savings in 2035), the Superior Energy Performance program (2.2\% savings in 2020 rising to $7.7 \%$ savings in 2035), and a 30\% Investment Tax Credit for CHP (2.3\% savings in 2020 rising to 5.6\% savings in 2035). These savings are not additive because the policies overlap in their targeted markets, but each of these policies when examined individually was highly cost-effective.

A state-level study done in Arkansas estimates the total electric efficiency potential in the industrial sector to be $2,880 \mathrm{GWh}$ ( $16 \%$ of baseline consumption) in 2025 at a levelized cost of about $\$ 0.02 / \mathrm{kWh}$ (Neubauer et al, 2011). However, the study only estimates the electric efficiency potential for cross-cutting measures, excluding the efficiency opportunities of processspecific measures. As a result, the percentage potential from the study is lower than the other two nation-level assessments mentioned above.

A meta-review done by Nadel et al (2004) reviews eleven energy-efficiency potential studies and summarizes them by type of potential (technical, economic, and achievable) and by sector (residential, commercial and industrial). It concludes that the median achievable potential for electricity savings in the industrial sector is about $14 \%$.

The America's Energy Future study by the National Academy of Sciences (2009) examined the potential for increasing efficiency, and estimated the potential to generate $14-20 \%$ of energy savings by 2020 using financially attractive technologies. The study also forecasted that industrial CHP could cost-effectively save approximately 4.4 to 6.8 quadrillion Btu of energy by 2020 (National Academy of Sciences, 2009, Table 4.4).

Studies on specific industry subsectors have shown wide ranges of savings potentials. A study of the pulp and paper industry (Fleiter, et al, 2012) estimated the savings due to 17 process technologies for improving energy efficiency up to 2035. The economic potential assessed is $16 \%$ for electricity and 21\% for all fuels. An assessment based on Best Practice Technology in the chemical and petrochemical industry estimate the potential energy savings for the U.S. to be about $24 \%$ with top-down approach and about $10.9 \%$ with bottom-up approach (Saygin, et al, 2011). The energy efficiency for industrial motor systems is estimated for both cost-effective and technical potential in McKane and Hasanbeigi (2011)'s study. The assessment is 14-49\% as the economic potential, and $27-57 \%$ as the technical potential.

These assessments are relatively aggressive comparing with an earlier work, which estimates the achievable potential for industry to be $7-17 \%$ by 2020 from different policy scenarios (Worrell \& Price, 2001). A review of assessment studies on the U.S. industrial sector shows a wide range of estimates of energy efficiency potential within and across industries: 3-18\% savings for chemical industry, 5-23\% for petroleum refining industry, and 6-37\% for pulp and paper industry in 2020 (Brown, Cox, \& Cortes, 2010). 


\subsection{Industrial Efficiency Policy Options and Modeling Approach}

Energy consumption in the industrial sector comes from all kinds of process-specific technologies and cross-cutting systems. A policy bundle of four efficiency policies were designed to tackle the efficiency potential of industrial processes, motors, and buildings. The industrial policy bundle includes Motor Standards, Motor Rebate, Advanced Manufacturing Initiative, and CHP Incentives.

Approximately two-thirds of industrial electricity consumption is used to operate motors. As a result, two of our four industrial policies are designed to improve the efficiency of industrial motor systems. Over the life of a motor $96 \%$ of the expenditure is for electricity, with initial purchase and equipment maintenance accounting for a small fraction of the cost (DOE/ITP, 2008). Motor replacement is a long-term endeavor, with an estimated time frame of 15 to 20 years for a 90\% turnover in the market (Xnergy Inc., 2002).

The Motor Rebate is a financial policy for promoting the deployment of premium motors that satisfy the efficiency requirement of the Energy Independence and Security Act (EISA) of 2007. EISA upgraded standards on all new motors sold in the U.S. from requirements laid out in the Energy Policy Act of 1992 (EPACT-92) to National Electrical Manufacturers Association (NEMA) Premium ${ }^{\circledR}$ certified levels, but does not offer incentives to encourage firms to replace functional motors that predate EPACT-92 standards with more efficient models. In fact, an unintended consequence of the new standards policy could be that industrial firms choose to repair instead of replace older, inefficient motors rather than pay the additional costs of new motors under the new regulations (Elliot, 2007).

This policy would provide industrial firms with rebates for purchases of certified high-efficiency motors of 25 to 500 horsepower. It is similar to the Motor Efficiency Rebate Program authorized in Section 245 of the American Clean Energy and Security (ACES) Act, as passed in the House of Representatives, which would operate for five years. It is modeled here as a $30 \%$ subsidy to reduce the capital costs of premium motors and to facilitate the removal of the most inefficient motors.

A Motor Standard is another policy targeting motor systems in industries, which assumes a new motor standard comes into performance 10 years after EISA 2007, requiring efficiency improvement for premium motors. Also, for systems that use motors, this new motor standard would require higher efficiency, which allows energy usage of these systems to be reduced by $25 \%$. This policy should encourage the development and production of a next generation of premium electric motors.

The Advanced Manufacturing Initiative is a combined program of R\&D and technology demonstration, which aims at identifying the most promising opportunities associated with new technologies. This policy can be applied to various industrial processes and sectors, including advanced robotics, nano-electronics, materials by design, and biomanufacturing. An assessment for plant utility upgrades for efficiency potential was derived from the Industrial Assessment Centers (IAC) database (see Table C.1 for details). Potential energy savings (both electricity and natural gas savings) from this dataset was modeled in GT-NEMS to forecast the influence of this policy on industrial electricity demand. 
The CHP Incentive tries to promote the deployment of CHP systems by offering a 30\% Investment Tax Credit (ITC) for 10 years across all type of systems (unlike the current expiring ITC that applies only to systems up to $50 \mathrm{MW}$ in capacity). This policy aims at decreasing the up-front capital costs of CHP equipment, which is more electric efficient by using waste heat to generate on-site electricity. If the electricity generated by CHP systems exceeds the demand from equipment owners, the excess electricity is allowed to be sold back to the grid, which generates an extra stream of revenue for equipment owners. With a large potential as a distributed generation resource, CHP is identified as one of the most important clean resources in the most recent proposal of the Clean Energy Standard Act of 2012 (Bingaman Bill, 2012).

Table 5.1 GT-NEMS Levers for Indusial Efficiency Policies

\begin{tabular}{l|l|l|l}
\hline Policy type & Policy & Scenario Description & $\begin{array}{l}\text { GT-NEMS } \\
\text { Lever }\end{array}$ \\
\hline Financial & Motor rebate & $\begin{array}{l}\text { A 30\% subsidy for premium motors } \\
\text { which satisfies the minimum efficiency } \\
\text { requirement of EISA 2007 }\end{array}$ & Indmotor.xml \\
\hline Regulatory & $\begin{array}{l}\text { Motor } \\
\text { standard }\end{array}$ & $\begin{array}{l}\text { New motor standard at 2017 which has } \\
\text { efficiency improvement for premium } \\
\text { motor and system savings increase by } \\
\text { 25\%. Systems include fans, pumps, and } \\
\text { compressed air. }\end{array}$ & Source code \\
\hline $\begin{array}{l}\text { R\&D and } \\
\text { Promonstration }\end{array}$ & $\begin{array}{l}\text { Advanced } \\
\text { Initiative }\end{array}$ & $\begin{array}{l}\text { Assessments for Plant Utility Upgrades } \\
\text { for efficiency opportunities. Energy } \\
\text { savings potential are based on audit } \\
\text { information in the Industrial Assessment } \\
\text { Centers (IAC) dataset. }\end{array}$ & itech.txt \\
\hline Financial & CHP Incentive & $\begin{array}{l}\text { A 30\% ITC for industrial CHP for 10 } \\
\text { years }\end{array}$ & indcogen.xml \\
\hline
\end{tabular}

The GT-NEMS modeling levers for these four policies were purposely chosen to generate separate policy impacts (Table 5.1). The Industrial CHP Incentive is modeled in the cogeneration profile of GT-NEMS, where we add a 30\% ITC for 10 years for CHP starting in 2015. The modeling of Motor Rebate was done by changing the deal rebate variable for premium motors in the motor profile. Within the same profile, the Motor Standard policy was modeled by modifying two other variables, the efficiency for premium motors by system size, and system savings. These modifications were combined with source code changes to reflect the correct history. To model the Advanced Manufacturing Initiative, the technology profile from the Reference case was modified to change the Unit Energy Consumption (UEC) for industry subsector in different census divisions to reflect the potential energy savings based on the IAC assessment.

\subsection{Modeling Results for Industry Policies}


The energy consumption forecasts of the policy cases were compared with the reference case forecast, and the differences represent the achievable energy-efficiency potential. Figure 5.5 shows the estimated potential from Motor Rebates, Motor Standards, and the Advanced Manufacturing Initiative. The percentage numbers are the reduction in electricity demand as a percentage of the Reference case forecast in each year.

In 2035, the reduction in electricity consumption from these three policies in the Eastern Interconnection ranges from $1.62 \mathrm{TWh}(0.2 \%$ of reference case consumption) for the Motor rebate policy to $16.4 \mathrm{TWh}(2.3 \%)$ for the Advanced Manufacturing Initiative. For the nation as a whole, the electricity savings range from $2.3-21.7 \mathrm{TWh}(0.3-3.1 \%$ of Reference case consumption).

The Motor Rebate policy is the only policy that does not have an expanding level of energy savings over the 20-year planning horizon. Its decline in energy-savings potential is a function of the 5-year duration of the rebate, which has limited impact in later years.

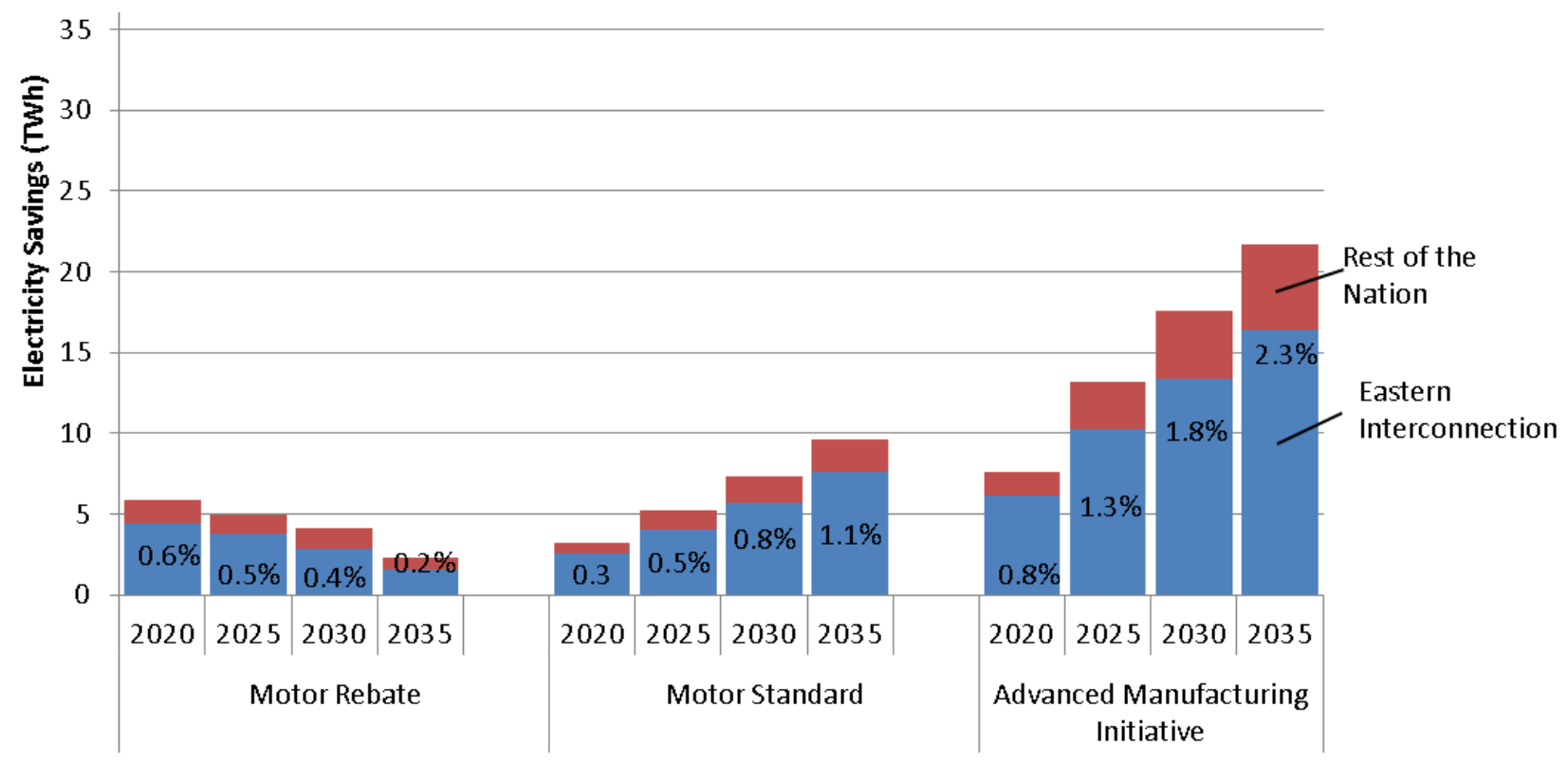

Figure 5.5 Estimated Reductions in Electricity Demand by Individual Policies (Excluding CHP) (Percentages of Industrial Electricity Consumption Savings)

The Reference case forecasts a doubling of the capacity of industrial CHP systems in the Eastern Interconnection from 2012 to 2035. In the Industry CHP scenario, incentives are provided to CHP systems that utilize waste heat to generate electricity for on-site uses and to sell the excess power back to the grid. In addition to the reduction in electricity demand, the contribution of new generation by industrial CHP is significant. Based on our projection, the extended ITC will incentivize 33.8 TWh more generation in 2020, and 39.7 TWh more generation in 2035 in the Eastern Interconnection (Figure 5.6). This represents a 10 to $15 \%$ increase in electricity generating capacity of industrial CHP systems above and beyond the doubling that is forecast to occur without any additional policy intervention (Figure 5.7). 


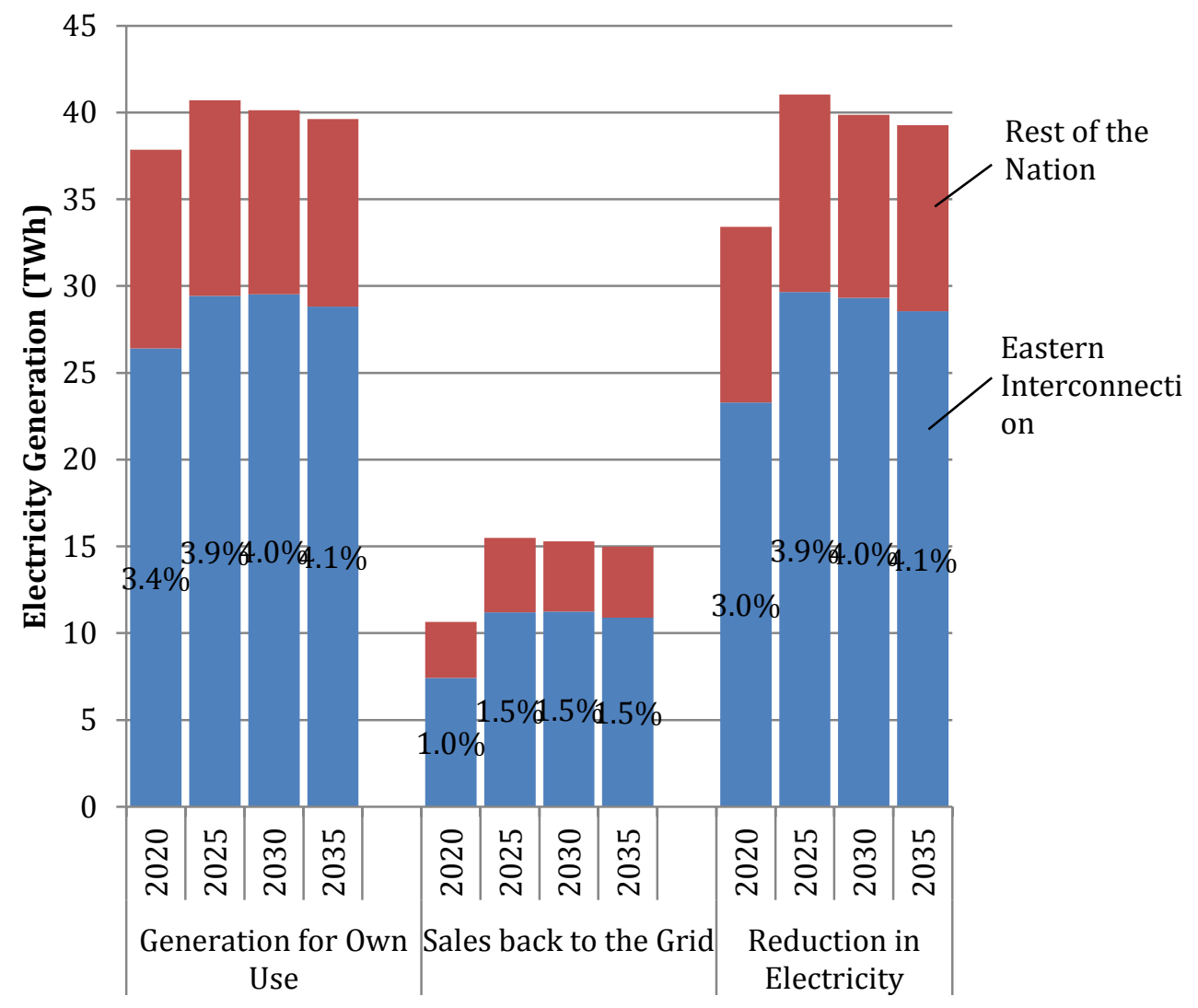

Figure 5.6 CHP Generation and Reduction in Electricity Purchase

(Percentages of Industrial Electricity Consumption Growth and Reduction in Electricity Purchase)

Of the electricity generated by industrial CHP systems in 2020, about $78.1 \%$ is consumed for industry's own use, with the excessive part being sold back to the grid. The percentage of CHP generation sold back to the grid grows to $27.4 \%$ in 2035 and represents a significant new revenue stream for manufacturing facilities. The reduction in electricity purchase is the net reduction from the CHP policy compared to the Reference case. 


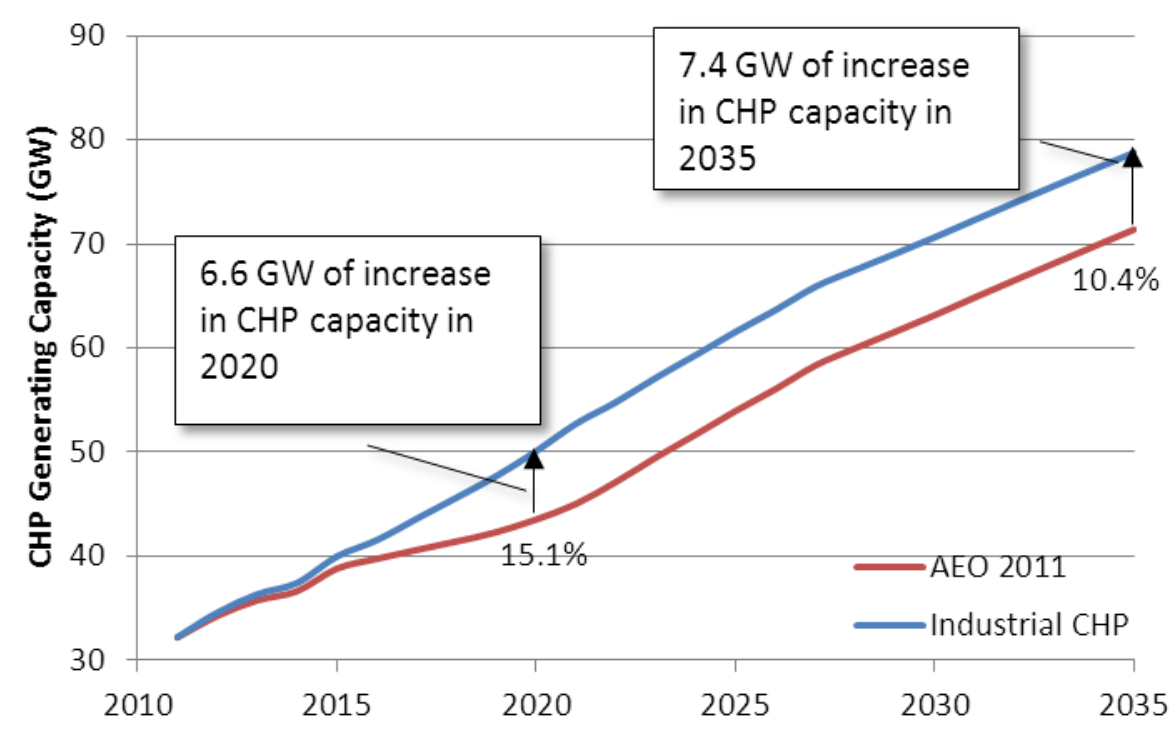

\section{Figure 5.7 Potential for Expanded CHP Generating Capacity in the Eastern Interconnection}

The increase in generation is facilitated by the increased industrial CHP capacity (Figure 5.7). Due to the ITC incentives, the deployment of industrial CHP systems keeps increasing at a steady rate. While more CHP systems are installed in the policy scenario, the consumption of natural gas also increases (Figure 5.8). The usage of natural gas by industrial sector increases by 474 TBtu (22.8\%) in 2035.

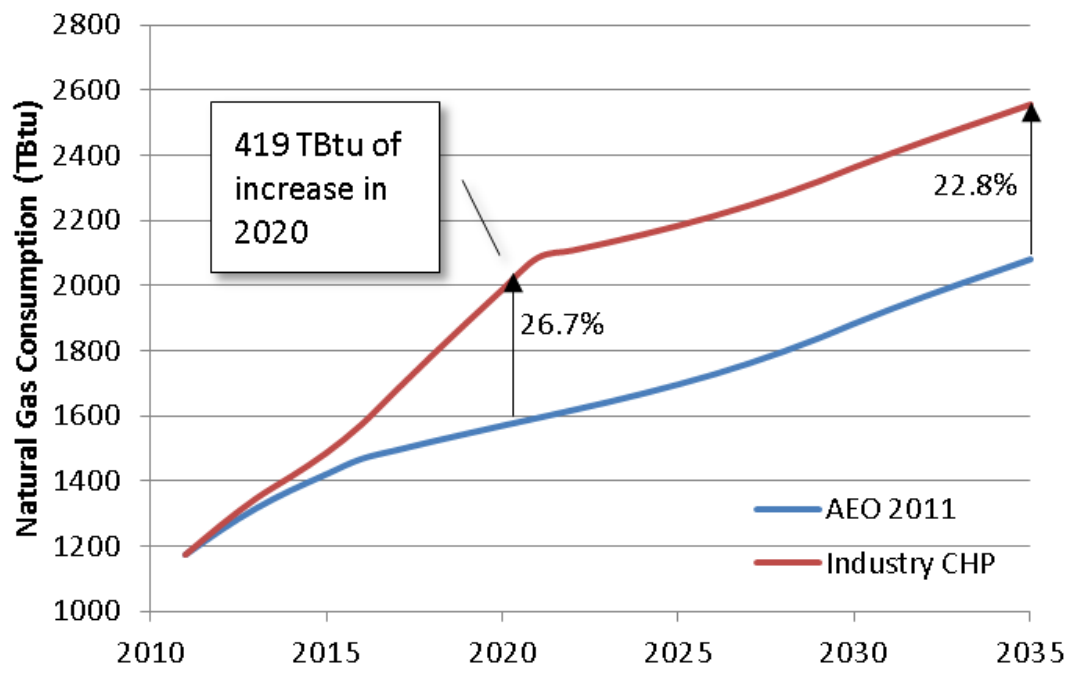

Figure 5.8 Natural Gas Consumption by Industry Sector in the Eastern Interconnection

The majority of electricity is consumed by industry for its own use, with the rest of generated electricity sold back to the grid. In the CHP policy scenario, one-fourth to one-fifth of the on-site generated electricity is sold back to the grid between 2020 and 2035. These shifts are able to motivate a small decrease in electricity retail price in the industrial sector (Figure 5.9). The price reduction ranges from $0.5 \%$ to $1 \%$ across the 20 -year period. 


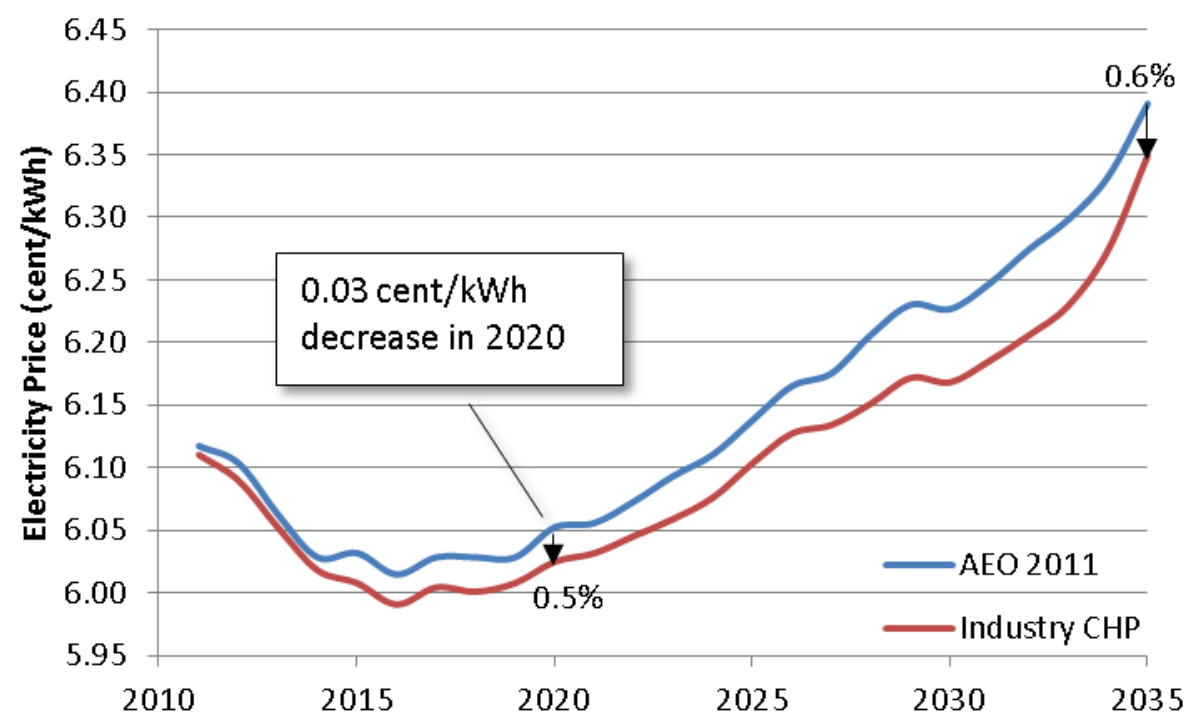

Figure 5.9 Electricity Retail Price in the Industry Sector

\subsubsection{Regional Differences}

The distribution of electricity savings across seven census divisions in the industrial sector is distinct from the pattern of energy-efficiency potential in the residential and commercial sectors. Motor Rebates, Motor Standard, and Advanced Manufacturing Initiative have similar regional distributions. In absolute savings, the East North Central region (ENC includes five states: Indiana, Illinois, Michigan, Ohio, and Wisconsin) enjoys the largest portion of benefits from these three policies (Figure 5.10). These five states produce a total Gross State Product (GSP) of about $14.0 \%$ of the nation's GDP (DOC, 2010). The ENC region is particularly dominant in its potential to reduce electricity consumption via the Advanced Manufacturing Initiative.

The distribution of potential from the CHP Incentive is quite different from the other three industrial policies. The electricity generation and reduction in consumption would mainly occur in the South Atlantic (SA), the ENC and the East South Central (ESC) regions (Figure 5.11). SA and ESC could have $7.5 \%$ of the electricity consumed for manufacturing be generated by CHP facilities in 2035. SA is the largest census division including nine states and generating $18.5 \%$ of the nation's GDP. The five states in ENC and the four states in ESC produce $14.0 \%$ and $4.7 \%$ of the nation's GDP (DOC, 2010). 

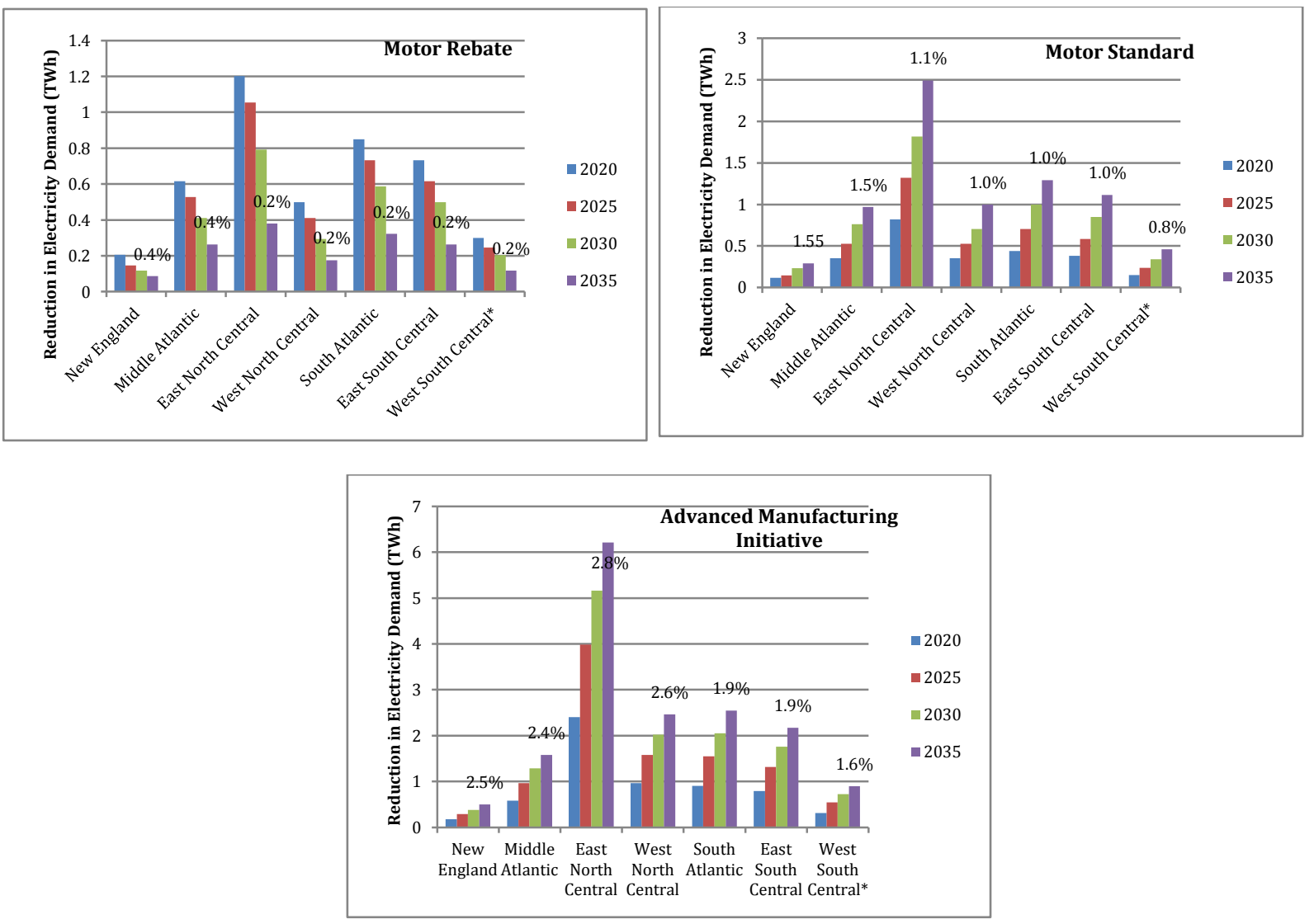

Figure 5.10 Electricity Savings by Census Division from Motor Rebates, Motor Standard, and Advanced Manufacturing Initiative (*West South Central Excluding Texas)
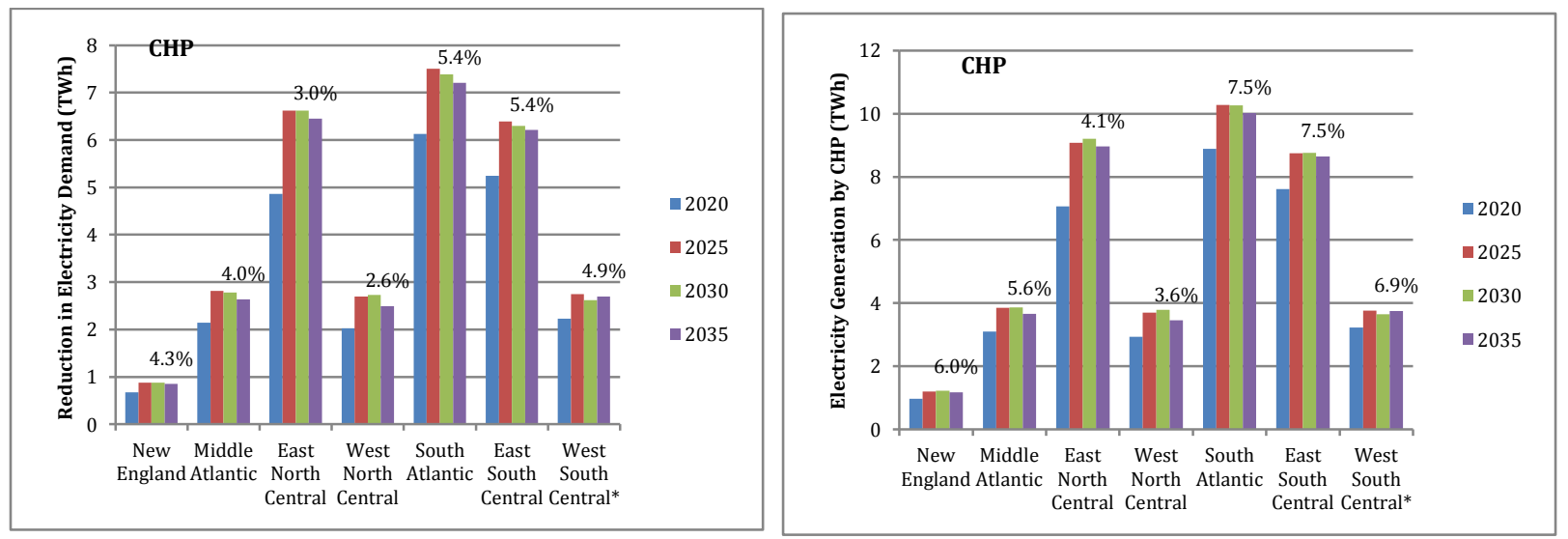

Figure 5.11 Electricity Savings by Census Division from CHP

(*West South Central Excluding Texas) 


\subsubsection{Spillover Benefits}

The policies aim to promote energy efficiency in industry, and each of them improves the efficient use of electricity. Their impact on the use of other fuels is highly variable.

CHP systems utilize waste heat to generate electricity; increasingly these systems are powered by natural gas. As a result, the CHP Incentive policy would produce electricity savings, but natural gas consumption in the industrial sector would increase relative to the reference case.

On the other hand, the two policies promoting premium motors would have minimal influence on natural gas usage since the only fuel used by motors is electricity. In contrast, the Advanced Manufacturing Initiative is able to generate savings in both electricity and natural gas. Table 5.2 shows the significant natural gas savings from this policy.

Table 5.2 Natural Gas Savings from Advanced Manufacturing Initiative

\begin{tabular}{|c|c|c|c|}
\hline & \multirow{2}{*}{$\begin{array}{c}\text { Reference } \\
\text { Forecast for } \\
\text { Eastern } \\
\text { Interconnection } \\
\text { (TBtu) }\end{array}$} & \multicolumn{2}{|c|}{$\begin{array}{c}\text { Natural gas savings } \\
\text { (TBtu) }\end{array}$} \\
\hline & & $\begin{array}{c}\text { Eastern } \\
\text { Interconnection }\end{array}$ & U.S. \\
\hline 2020 & 9,690 & 18 & 20 \\
\hline 2025 & 9,550 & 31 & 40 \\
\hline 2030 & 9,550 & 43 & 50 \\
\hline 2035 & 9,510 & 56 & 60 \\
\hline Total & & 654 & 731 \\
\hline
\end{tabular}

Note: the total number is the cumulative savings from 2012-2035.

\subsubsection{Cost Estimation}

The levelized cost of electricity saved from each industrial energy efficiency policy was calculated to evaluate the cost impacts of these policies. In the Motor Rebate scenario, failed motors can be rewound with relatively low cost or replaced by EISA 2007 premium motors with considerably high costs. A $30 \%$ subsidy was applied to premium efficiency motors to lower the replacement costs. Private investment was calculated based on the cost of rewound motors and replaced motors, while subsidy cost was estimated based on motor replacement. Program Administration Cost is estimated as $2.5 \%$ of subsidy cost. The LCOE in this policy case is estimated to be 9.3-11.5 cent/kWh. Details of cost estimations associated with Motor Rebate are shown in Table 5.3.

Table 5.3 Cost Estimations from Motor Rebate

\begin{tabular}{c|cccc}
\hline Cost $\left(\right.$ Billion \$2009) $^{\mathrm{a}}$ & 2020 & 2025 & 2030 & 2035 \\
\hline Private Cost $_{\text {Subsidy Cost }}$ & 0.45 & 0.34 & 0.25 & 0.19 \\
Administration Cost & 0.01 & 0.35 & 0.31 & 0.29 \\
Total & 0.85 & 0.69 & 0.57 & 0.01 \\
\hline LCOE (cent/kWh) & \multicolumn{5}{|c}{$9.3-11.5^{\mathrm{b}}$} \\
\hline
\end{tabular}


a. Private cost was discounted at $7 \%$, and public cost was discounted at $3 \%$.

b. Levelized cost calculated in a sensitivity when all costs were discounted at $3 \%$.

Similarly, private costs in the Motor Standard case were estimated based on the cost of rewinding and replacing failed motors. However, public cost is only the program administrative cost estimated as \$0.13/MMBtu energy saved. The LCOE in this policy case is estimated to be \$2.4-3.9cent/kWh. Details of cost estimations in Table 5.4 suggest that Motor Standard is able to save industries in equipment expenditure. In the policy case, the portion of failed motors got rewound with relatively low cost are much higher than the portion of rewound motors in the reference case. The new motor standard restrains industries in favoring replacing failed motors with premium motors. By going with the less costly option of rewinding failed motors, the industries are able to save money in equipment expenditure, thus, leading to a negative LCOE for this policy.

Table 5.4 Cost Estimations from Motor Standard

\begin{tabular}{|c|c|c|c|c|}
\hline Cost $(\text { Billion } \$ 2009)^{a}$ & 2020 & 2025 & 2030 & 2035 \\
\hline Private Cost & 0.408 & 0.224 & 0.182 & 0.204 \\
\hline Administration Cost & 0.001 & 0.002 & 0.002 & 0.002 \\
\hline Total & 0.410 & 0.226 & 0.184 & 0.207 \\
\hline LCOE (cent/kWh) & \multicolumn{4}{|c|}{$2.4-3.9^{b}$} \\
\hline
\end{tabular}

a. Private cost was discounted at $7 \%$, and public cost was discounted at $3 \%$.

b. Levelized cost calculated in a sensitivity when all costs were discounted at $3 \%$.

In the CHP Incentive case, private cost is the investment in CHP systems in the private sector. Subsidy cost was estimated based on the amount of incremental cost in CHP investments, while program administrative cost was estimated as $2 \%$ of subsidy cost. The LCOE in this policy case is estimated to be $1.5-2.3$ cent $/ \mathrm{kWh}$. Details of cost estimations associated with CHP Incentive are shown in Table 5.5.

Table 5.5 Cost Estimations from CHP Incentive

\begin{tabular}{c|cccc}
\hline Cost (Billion \$2009) ${ }^{\mathrm{a}}$ & 2020 & 2025 & 2030 & 2035 \\
\hline Increased Natural Gas Expenditure & 1.55 & 1.15 & 0.62 & 0.54 \\
CHP system & 0.25 & -0.02 & -0.01 & 0.00 \\
Subsidy cost & 0.56 & 0.00 & 0.00 & 0.00 \\
Administration cost & 0.01 & 0.00 & 0.00 & 0.00 \\
Total & 2.37 & 1.13 & 0.62 & 0.54 \\
\hline LCOE (cent/kWh) & \multicolumn{5}{|c}{$1.5-2.3^{\mathrm{b}}$} \\
\hline
\end{tabular}

a. Private cost was discounted at $7 \%$, and public cost was discounted at $3 \%$.

b. Levelized cost calculated in a sensitivity when all costs were discounted at $3 \%$.

The Advanced Manufacturing Initiative is a combination of R\&D and demonstration programs, which aims at identifying the most promising opportunities associated with new technologies 
that can be applied to various industrial processes and sectors. This policy is able to stimulate volunteer upgrades in plants and firms.

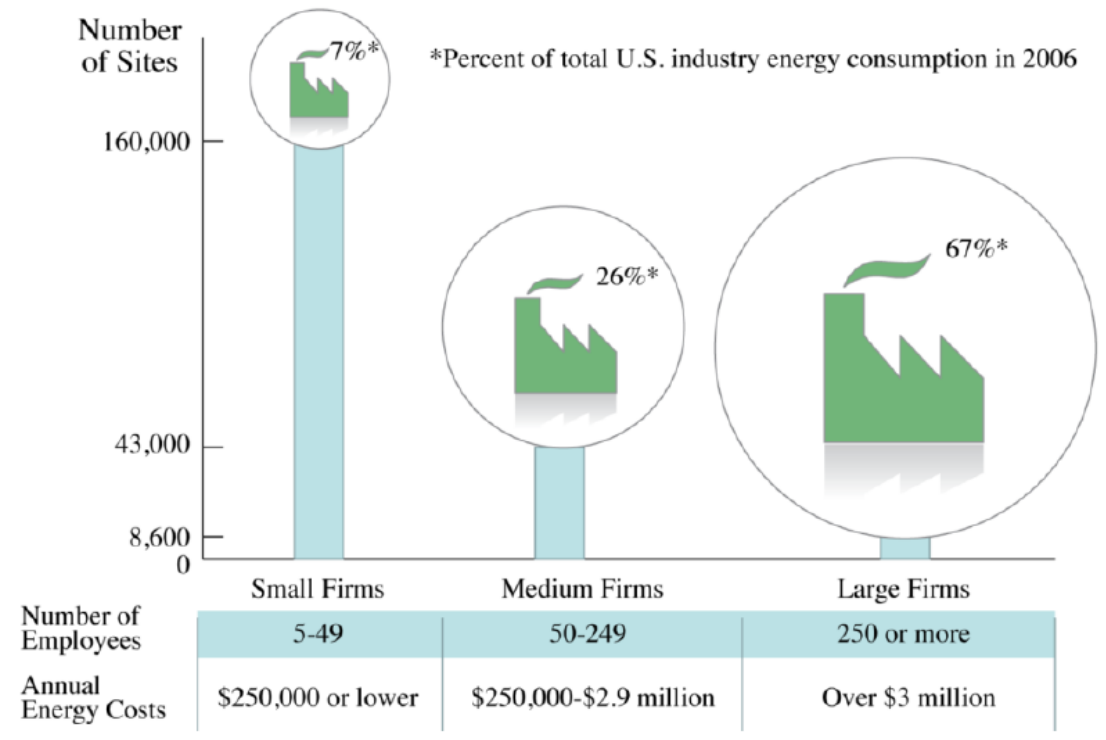

Figure 5.12 U.S. Industrial Consumption by Size of Firm

(Source: Brown, et al., 2011)

To calculate private investment, this study follows the division of industrial plants by Brown et al (2011), grouping firms into small, medium and large firms (Figure 5.12). It is assumed that the private investment is $\$ 14 / \mathrm{MMBtu}$ energy saved for large firms and \$12.6/MMBtu energy saved for small and medium firms (Brown et al., 2011). Public cost includes only the program administrative cost, estimated as $\$ 0.13 / \mathrm{MMBtu}$ energy saved. The LCOE in this policy case is estimated to be 3.0-4.8 cent $/ \mathrm{kWh}$, with investment cost declining from $\$ 1.36$ Billion in 2020 to \$0.97 Billion in 2035 (in 2009 dollar, Table 5.6).

Table 5.6 Cost Estimations from Advanced Manufacturing Initiative

\begin{tabular}{c|cccc}
\hline Cost (2009\$Billion) $^{\mathrm{a}}$ & 2020 & 2025 & 2030 & 2035 \\
\hline Private Cost & 1.34 & 1.26 & 0.89 & 0.94 \\
Public Cost & 0.02 & 0.03 & 0.03 & 0.03 \\
Total & 1.36 & 1.29 & 0.93 & 0.97 \\
\hline LCOE (cent/kWh) & \multicolumn{4}{|c}{$3.0-4.8^{\mathrm{b}}$} \\
\hline
\end{tabular}

a. Private cost was discounted at $7 \%$, and public cost was discounted at $3 \%$.

b. Levelized cost calculated in a sensitivity when all costs were discounted at $3 \%$.

\subsection{Integrated Industrial Policy Bundle}

By evaluating all four industrial energy-efficiency policies as one policy bundle, the electricity consumption by the Eastern Interconnection drops by about 68.3 TWh (9.7\%) in 2035 compared to the Reference case consumption (Figure 5.13). In the integrated policy bundle, the projected level of consumption in 2035 is $9.4 \%$ lower than the current level (700 TWh in 2010). From 
2012 to 2035 , the total reduction in electricity demand is 1,195 TWh in the Eastern Interconnection. In the integrated policy scenario, the electricity consumption in the industrial sector decreases at an annual rate of $0.5 \%$, which is much higher than the annual decrease rate of $0.05 \%$ in the reference case.

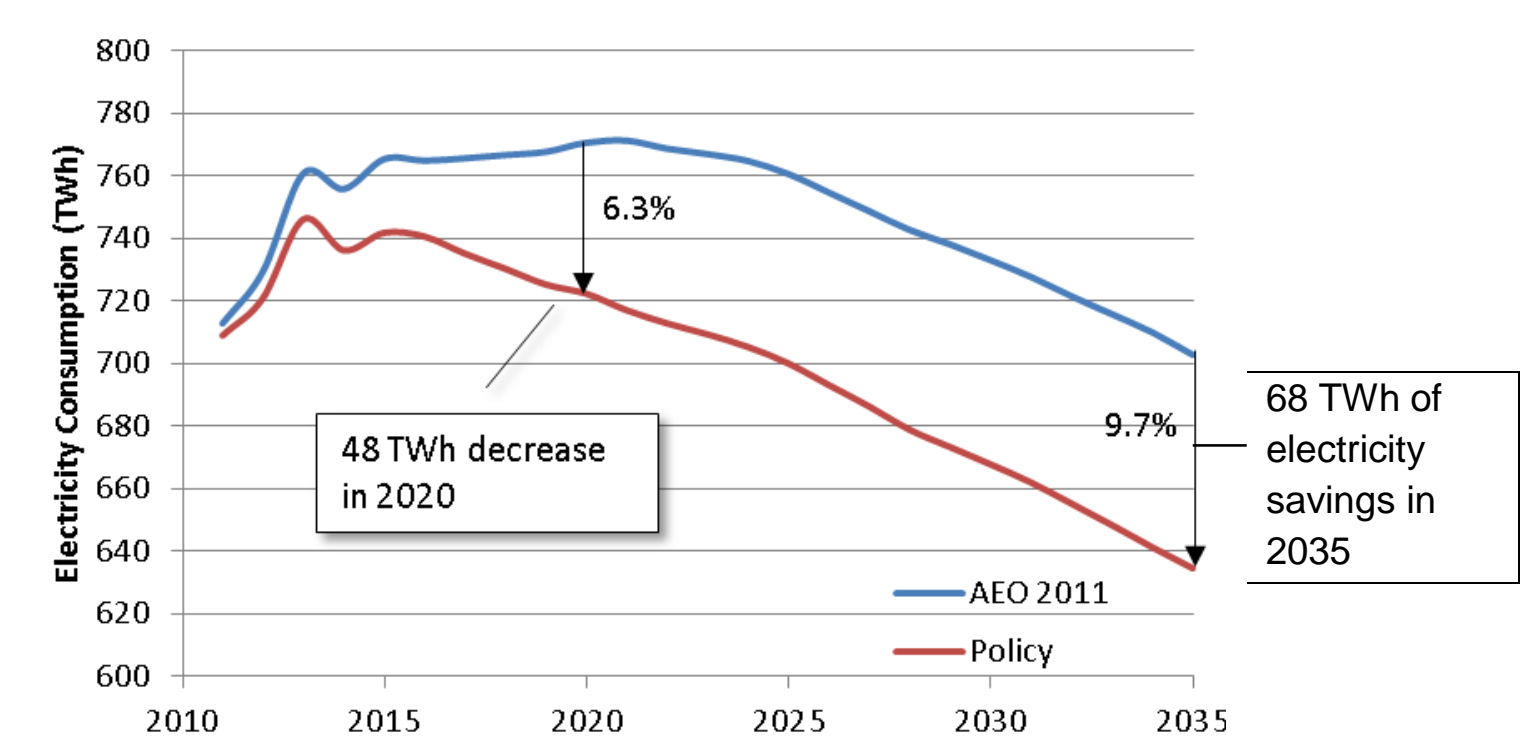

Figure 5.13 Industrial Electricity Savings Potential in the Eastern Interconnection

The majority of electricity savings come from the bulk chemical, food, and paper industries. Mining and iron and steel industries also have the potential to generate significant amount of savings (Figure 5.14). According to ICF International (2010, Table 5) and Brown, Cox and Baer (2012), these same industries have greater opportunities for utilizing waste heat to generate electricity by CHP facilities than other industries.

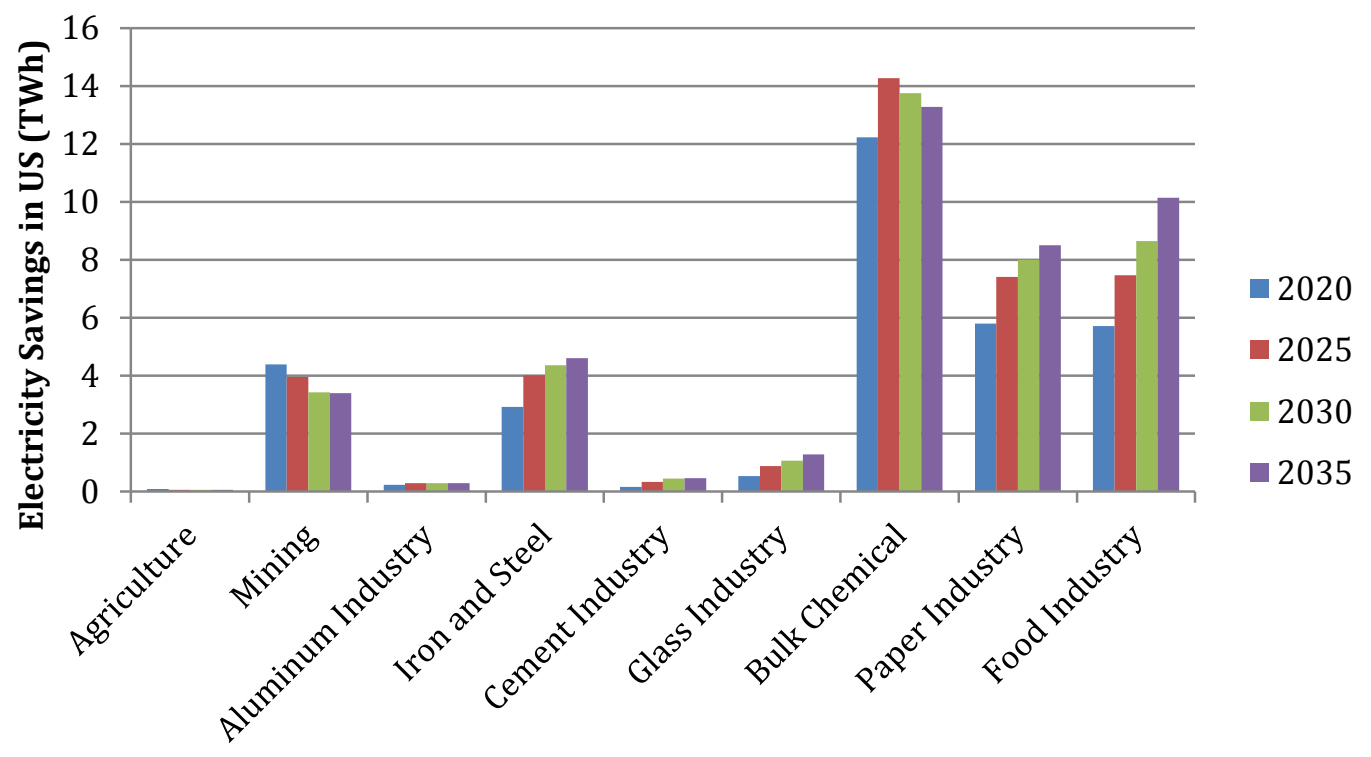

Figure 5.14 Electricity Savings by Industry Subsectors 
Due to the incorporation of CHP incentives into the policy bundle, the electricity generation by industrial CHP also increases. By comparing the generation in the integrated policy case (Figure 5.15) with the stand-alone CHP policy case (Figure 5.6), the amount of increase and the trend over time are almost the same. This result suggests that the CHP incentives do not interact with other industrial policies in terms of generation. This interpretation is plausible since the other three policies do not address distributed generation issues in their policy design.

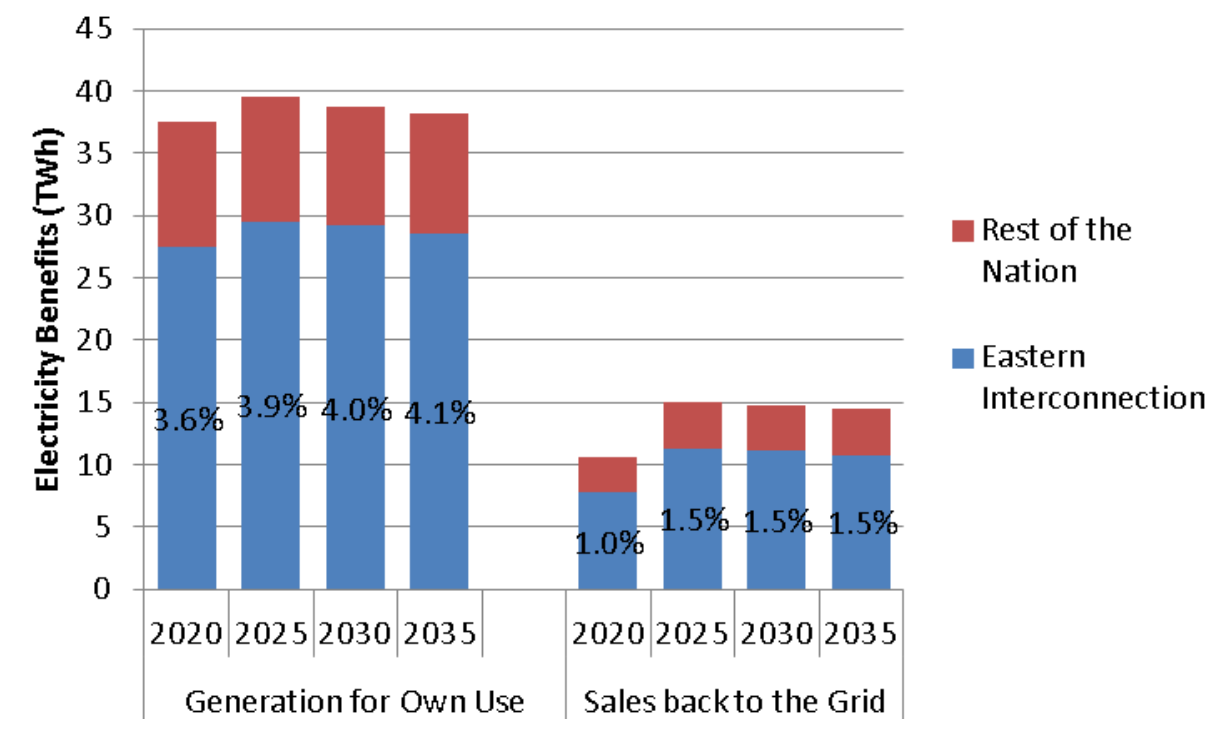

Figure 5.15 Increases in Electricity Generation from Industrial CHP

The increase in CHP capacity precipitates an increase in natural gas consumption in the industrial sector. However, the amount of increase is offset by the significant potential for natural gas savings from the Advanced Manufacturing Initiative. In the year 2035, the natural gas consumption in the integrated policy case increases by only $154 \mathrm{TBtu}(2.8 \%)$, which is significantly less than in the stand-alone CHP policy case (Figure 5.16).

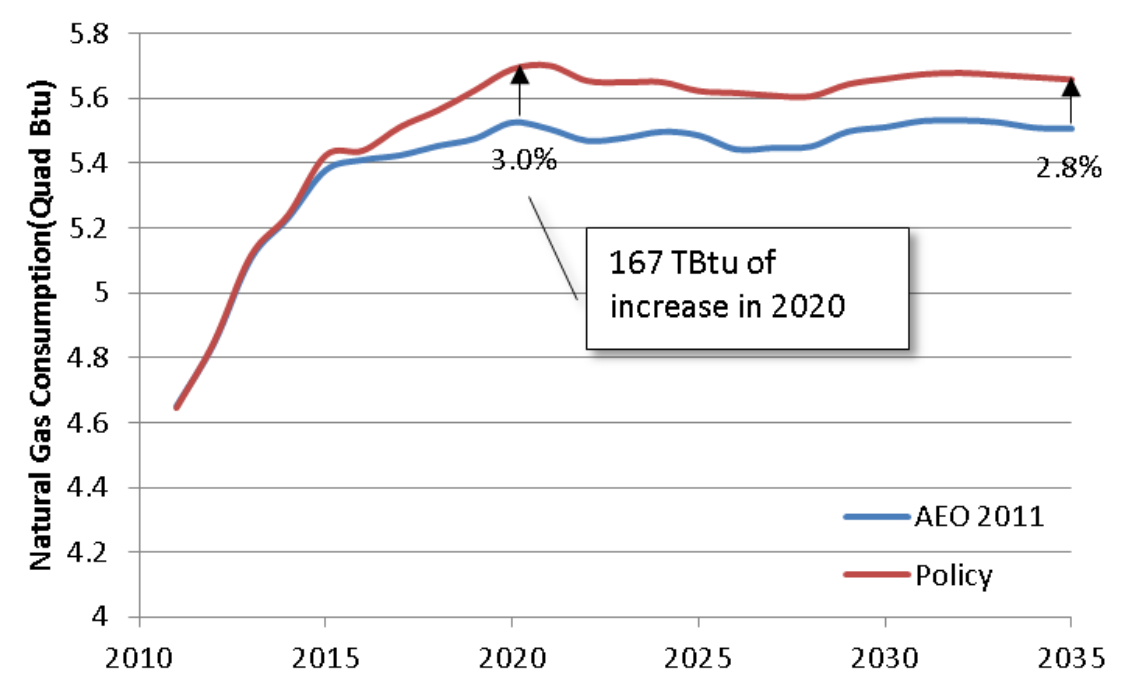

Figure 5.16 Natural Gas Consumption in the Industry Sector 
Similar to the stand-alone CHP incentives case, about one-fifth of the electricity generation (by CHP and other distributed generation technologies) is sold back to the grid each year. Grid sales are able to drive the electricity retail prices down beginning in 2015 (Figure 5.17). However, this price decrease is no bigger than 0.12 cent $/ \mathrm{kWh}$ through 2035 .

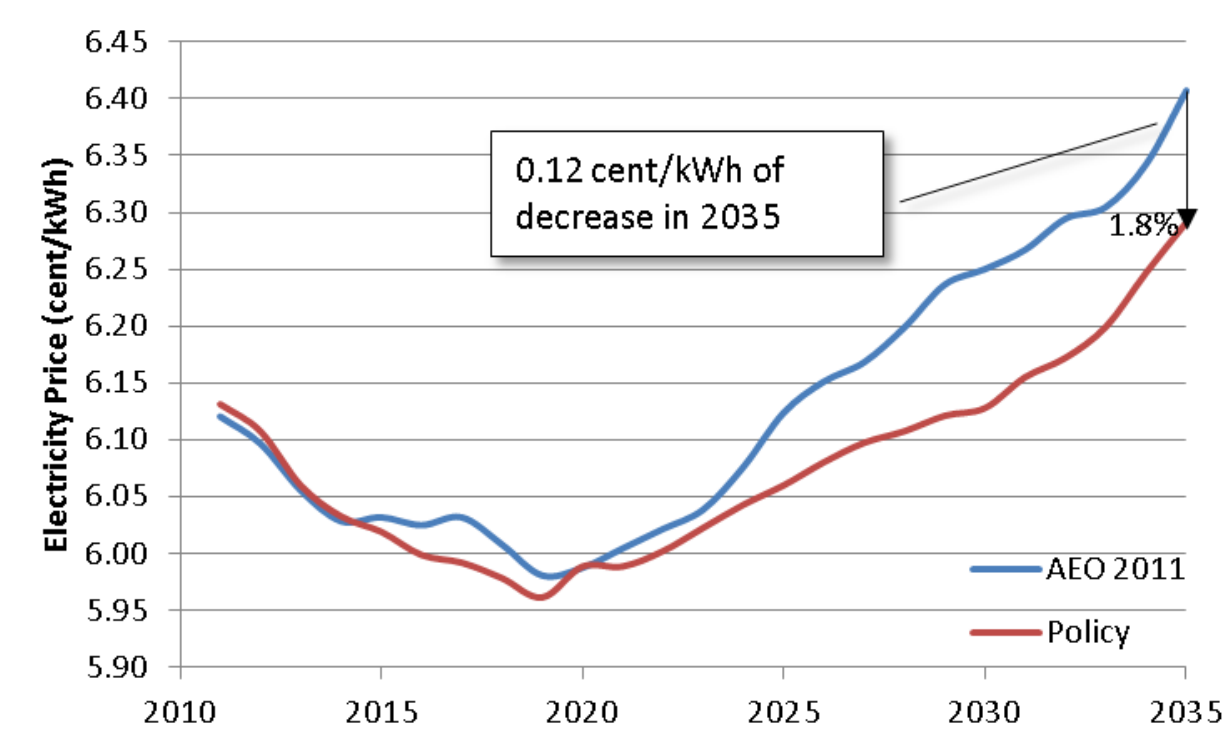

Figure 5.17 Electricity Retail Price in the Industry Sector

The level of carbon dioxide emissions also decreases in the integrated policy case (Table 5.7). U.S. carbon emissions are reduced by 54 million tonnes in 2035 due to the decrease in electricity consumption. However, the slight increase in natural gas consumption makes the emissions reduction from total primary energy consumption slightly lower than the emission reduction from electricity, which is 43 million tonnes in 2035.

Table 5.7 Reductions in Carbon Emissions

\begin{tabular}{l|rrrr|rrrr}
\hline & \multicolumn{6}{|c|}{ Carbon Emission Reduction (Million Tonnes) } \\
\cline { 2 - 9 } & \multicolumn{4}{|c}{ From electricity } & \multicolumn{4}{c}{ From primary energy } \\
\cline { 2 - 9 } & 2020 & 2025 & 2030 & 2035 & 2020 & 2025 & 2030 & 2035 \\
\hline EI & 37 & 41 & 41 & 44 & 30 & 30 & 29 & 34 \\
US & 45 & 50 & 54 & 54 & 31 & 36 & 37 & 43 \\
\hline
\end{tabular}

\subsection{Conclusions and Discussions}

This chapter investigates the energy efficiency potential driven by four industrial policies, including Motor Rebates, Motor Standard, CHP Incentive, and Advanced Manufacturing Initiative. Together these four policies are estimated to generate significant electricity savings potential in the Eastern Interconnection. Each of these policies has levelized costs that are lower than the retail electricity price for industry. CHP Incentive is the industrial policy with the largest electricity-savings potential. This policy also drives up natural gas consumption while lowering 
electricity prices. Other benefits of energy-efficiency policies include climate change impacts; carbon emissions are projected to be reduced significantly in the integrated policy case.

This study focuses on the achievable potential driven by energy efficiency policies. The estimation of achievable potential in this study is slightly lower than the estimates summarized in our review of the previous literature. However, it is in the range of potential savings assessments from real-world practices and programs. Although limited by the modeling tool, this chapter is able to offer reliable assessment of electric end-use efficiency potential and cost estimation of industrial energy-efficiency policies. 


\section{INTEGRATED POLICY CASE}

The previous three chapters examined a suite of twelve energy-efficiency policies, as a means of quantifying the potential for electricity efficiency improvements that are both cost-effective and achievable. The results are summarized in Table 6.1. The estimated electricity savings from individual policies sum up to reach $241 \mathrm{TWh}$ in 2020, which is higher than the estimation from the Integrated Policy case (Figure1). This indicates that part of the policy impacts cancels out when all energy efficiency policies are implemented together. Although modeling levers were chosen purposely to avoid overlap, some of the policies target the same set of technologies. It is quite possible that their ability to promote energy efficiency diminishes when overlapping policies co-exist. A related impact is the rebound effect, where energy usage increases when consumers save more in the Integrated Policy case, because of electricity rate reductions.

Market Priming is the energy efficiency policy with most significant savings potential and relatively low levelized cost. Information-based instruments, such as the mandated disclosure of home energy performance with home ratings, green labeling and leasing, home energy audits, etc., are able to promote inclusion of energy efficiency when selling or renting. Efficiency improvements from these policies can generate noticeable home equity premiums (Nevin \& Watson, 1998). Because of the potential policy impacts on efficiency improvements and equity value, the Federal Office of Management and Budget (OMB) suggests that policies or measures explicitly designed to alleviate asymmetric information should be given preference over other measures, as a general rule-of-thumb (OMB Circular A-4).

To explore the combined effects of these twelve policies, all twelve energy-efficiency options (five from the residential sector, three from the commercial sector, and four from the industrial sector) are modeled in the Integrated Policy scenario. This scenario was prepared to determine whether applying multiple policies at once would enhance or reduce the achievable energysavings potential. On the one hand, the integrated energy-savings potential could be less than the sum of the individual policy savings potentials because the policies target overlapping technologies, barriers, and energy consumers. If the rebound effect is strong, the reduction of electricity rates resulting from reduced energy consumption could cause consumers to take back some of their potential savings by using their bill savings to buy more energy services. On the other hand, synergistic policy combinations could produce greater energy-savings potential. For example, by providing better energy benchmarking data, consumers might be more responsive to an opportunity to secure low-cost financing to invest in more energy-efficient equipment. The results from the Integrated Policy scenario can help us understand the dynamics among the selected policies and their interactive effects on the energy-efficiency potential of the Eastern Interconnection. 
Table 6.1 Savings Potential and Levelized Cost of Electric End-Use Efficiency, by Policy

\begin{tabular}{|c|c|c|c|c|c|}
\hline Sector & Policy Type & Policy & $\begin{array}{c}\text { Electricity } \\
\text { Efficiency } \\
\text { Potential } \\
(\text { TWh) in } \\
2020\end{array}$ & $\begin{array}{c}\text { Electricity } \\
\text { Efficiency } \\
\text { Potential } \\
(\text { TWh) in } \\
2035\end{array}$ & $\begin{array}{l}\text { Levelized Cost } \\
\text { of Electric End- } \\
\text { Use Efficiency } \\
\text { (cent/kWh) }\end{array}$ \\
\hline \multirow[t]{5}{*}{ Residential } & Financial & $\begin{array}{l}\text { Appliance } \\
\text { Incentives }\end{array}$ & 13 & 26 & $6.7-8.0$ \\
\hline & Financial & $\begin{array}{l}\text { On-Bill } \\
\text { Financing }\end{array}$ & 13 & 22 & $6.6-7.4$ \\
\hline & Regulatory & $\begin{array}{l}\text { Building } \\
\text { Codes }\end{array}$ & 8 & 19 & $0.5-0.8$ \\
\hline & Regulatory & $\begin{array}{l}\text { Aggressive } \\
\text { Appliance } \\
\text { Policy }\end{array}$ & 16 & 40 & $0.6-0.7$ \\
\hline & Information & $\begin{array}{l}\text { Market } \\
\text { Priming }\end{array}$ & 100 & 119 & $2.7-3.6$ \\
\hline \multirow[t]{3}{*}{ Commercial } & Financial & Financing & 31 & 77 & $6.4-6.6$ \\
\hline & Regulatory & $\begin{array}{l}\text { Building } \\
\text { Codes }\end{array}$ & 8 & 34 & $3.5-4.6$ \\
\hline & Information & Benchmarking & 16 & 61 & $0.7-1.2$ \\
\hline \multirow[t]{4}{*}{ Industrial } & Financial & Motor Rebate & 4 & 2 & $9.3-11.5$ \\
\hline & Regulatory & $\begin{array}{l}\text { Motor } \\
\text { Standard }\end{array}$ & 3 & 8 & $2.4-3.9$ \\
\hline & Information & $\begin{array}{l}\text { Advanced } \\
\text { Manufacturing } \\
\text { Initiative }\end{array}$ & 6 & 16 & $3.0-4.8$ \\
\hline & Financial & $\begin{array}{l}\text { CHP } \\
\text { Incentives }\end{array}$ & 23 & 29 & $1.5-2.3$ \\
\hline
\end{tabular}

Although the target technologies, barriers, and energy consumers may be common to two or more policies, the modeling of policy integration in GT-NEMS is straightforward since the GTNEMS levers for each individual policy have no overlap. The supply-side modules, the economics and emission modules, and all three end-use sector modules were used together to incorporate feedback loops between multiple segments of the economy to examine policy impacts. By using the IHS Global Dynamics general equilibrium model, the GT-NEMS analysis optimizes energy prices and quantities across energy fuels and across sectors of end-use demand. 


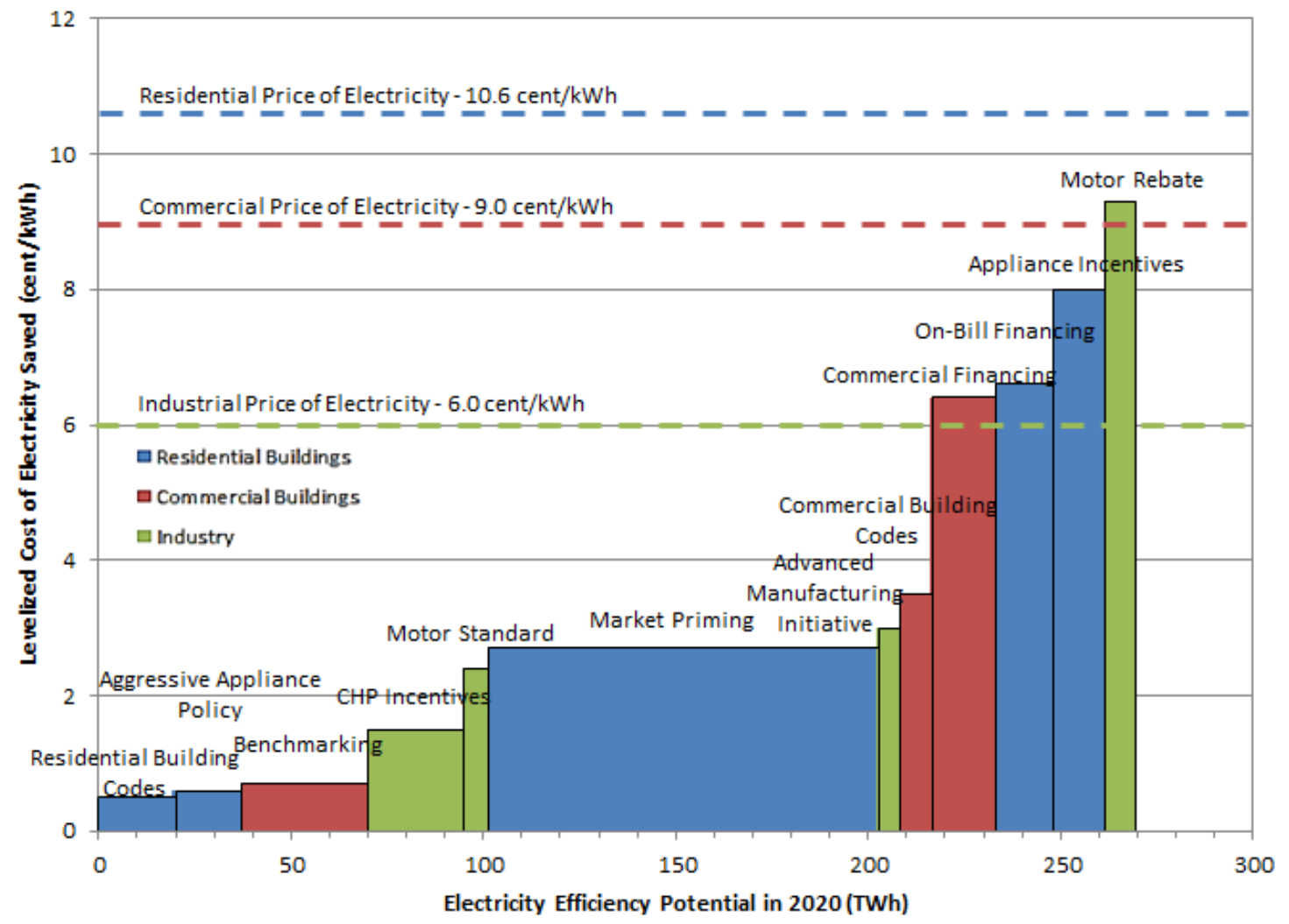

Figure 6.1 Supply Curve for Electricity Efficiency Policies in 2020

A careful reconciliation of the potential estimations from individual policies and the Integrated Policy scenario reveals the dynamics among energy-efficiency policies. Together with the levelized cost estimations, the reconciled electricity-savings potentials produce a policy supply curve. Supply curves for energy-efficient equipment have been evaluated since the early 1980's (Meier, Wright, and Rosenfeld, 1983; Brown, Levine, Romm, Rosenfeld, and Koomey, 1998), culminating with the well-known study by McKinsey \& Co. (2009). Supply curves for energyefficiency policies are a recent extension of this approach.

Figure 6.1 indicates that regulatory policies have relatively low levelized costs of electricity and financial policies have relatively high LCOEs. In fact, the weighted average LCOE estimations suggests that financing policies have higher levelized cost than regulatory and information policies when considering cumulative electricity savings (Table 6.2). Similarly, a previous analysis of energy efficiency in the U.S. South concluded that the two least cost-effective policies involved financial subsidies (Brown, et al., 2010). The CHP Incentive, as an exception, offers subsidies for industrial CHP systems while having very low levelized cost because of its significant electricity-savings by utilizing waste heat.

Currently, the national average electricity price for rate payers is approximately $9.0 \mathrm{cent} / \mathrm{kWh}$. Taking the average price as a benchmark, all twelve policies except for Motor Rebate are costeffective (i.e., having LCOEs lower than the average electricity price), representing $98 \%$ of the 
savings. All financial policies except for the CHP Incentive have levelized costs higher than the national average electricity price. Benchmarking the policies using sector-specific retail rates, Motor Rebate is the only energy-efficiency policy that is not cost-effective.

Table 6.2 The Levelized Cost of Electricity Efficiency by Type of Policy (in cents/kWh)

\begin{tabular}{l|c|c|c|c}
\hline \multirow{2}{*}{$\begin{array}{l}\text { Type of } \\
\text { Energy-Efficiency Policy }\end{array}$} & \multicolumn{2}{c|}{$\begin{array}{c}\text { LCOE } \\
\text { in cents/kWh } \\
\text { (Lower bound)* }\end{array}$} & \multicolumn{2}{c}{$\begin{array}{c}\text { LCOE } \\
\text { in cents/kWh } \\
\text { (Upper bound)** }\end{array}$} \\
\cline { 2 - 5 } & EI & US & EI & US \\
\hline Information Policies & 2.1 & 2.1 & 2.9 & 2.9 \\
Regulations & 2.8 & 3.4 & 3.5 & 4.1 \\
Financing Policies & 4.6 & 4.8 & 4.7 & 5.0 \\
\hline Information Policies & 3.0 & 3.3 & 3.6 & 3.9 \\
\hline
\end{tabular}

$* 3 \%$ discount rate for public and private costs.

$* * 7 \%$ discount rate for private costs and $3 \%$ discount rate for public costs.

Our estimation of the weighted average LCOE of 3.0-3.6 cent $/ \mathrm{kWh}$ is in the middle range of cost estimates from previous studies (all cost estimates are reported in 2009\$). An ex ante estimation by the Electric Power Research Institute (EPRI) found the levelized cost of energy efficiency programs to be $\$ 0.022-0.032 / \mathrm{kWh}$ (EPRI, 2009). Another study developed an average estimation of the cost of saved energy to be $\$ 0.026 / \mathrm{kWh}$ based on utility and state evaluations and reports for electricity programs in 14 states (Friedrich et al, 2009). Other ex post estimations have reported higher levelized costs for energy efficiency. For example, Arimura, et al. (2011) estimate that utility-operated demand-side management programs between 1992 and 2006 saved electricity at a program cost averaging $\$ 0.05 / \mathrm{kWh}$ using a $5 \%$ discount rate, with a $90 \%$ confidence interval ranging from $\$ 0.03$ to $\$ 0.98 / \mathrm{kWh}$. Auffhammer, Blumstein and Fowlie (2008) use utility panel data to construct weighted average cost estimates for demand-side management programs. Their findings suggest low cost-effectiveness, ranging from $\$ 0.053$ to $\$ 0.151 / \mathrm{kWh}$.

Cost estimations of energy efficiency depend on accurate assessments of energy savings, which can be problematic because of free ridership (Gellings et al., 2006). Alcott and Greenstone (2009) question these ex ante estimates of cost-effectiveness by noting that programs typically reduce electricity demand by only 1-2\%, which does not suggest a large energy-efficiency gap. Alternatively, it could be that the energy-efficiency programs were simply underfunded and unable to completely address market failures. 


\subsection{The Achievable Potential of Electricity Savings}

In the Eastern Interconnection, the electricity consumption is forecasted to grow at an average rate of $0.77 \%$ per year and to rise to 3,200 TWh in 2035 in the reference case. With the twelve energy efficiency policies, the growth of electricity consumption slows down to an average rate of $0.35 \%$ per year. The combination of twelve policies could save the region about $190 \mathrm{TWh}$ (6.6\%) of electricity in 2020, and $332 \mathrm{TWh}(10.3 \%)$ of electricity in 2035 (Figure 6.2).

The energy-efficiency potential driven by the bundle of twelve policies largely comes from the residential sector, with significant savings from the commercial and industrial sectors as well (Figure 6.3). In the Integrated Policy scenario, the residential sector is estimated to save 13.2\% of electricity in 2035, which is slightly lower than the estimated savings (15.4\% in 2035) from the residential Policy Bundle. Similarly, the estimated savings potential from the commercial sector is 7.9\% in 2035 under the Integrated Policy case, lower than the estimation (8.4\% in 2035) for the commercial sector Policy Bundle. In contrast, the industrial sector potential in the Integrated Policy case is estimated to be comparable (10.4\% in 2035) to the savings potential of the industrial Policy Bundle. The electricity from industrial CHP generation that is sold back to the grid is not shown in Figure 6.3. An additional 39 TWh are generated by CHP systems (28 TWh are consumed at the industrial plant and $11 \mathrm{TWh}$ are sold back to the grid).

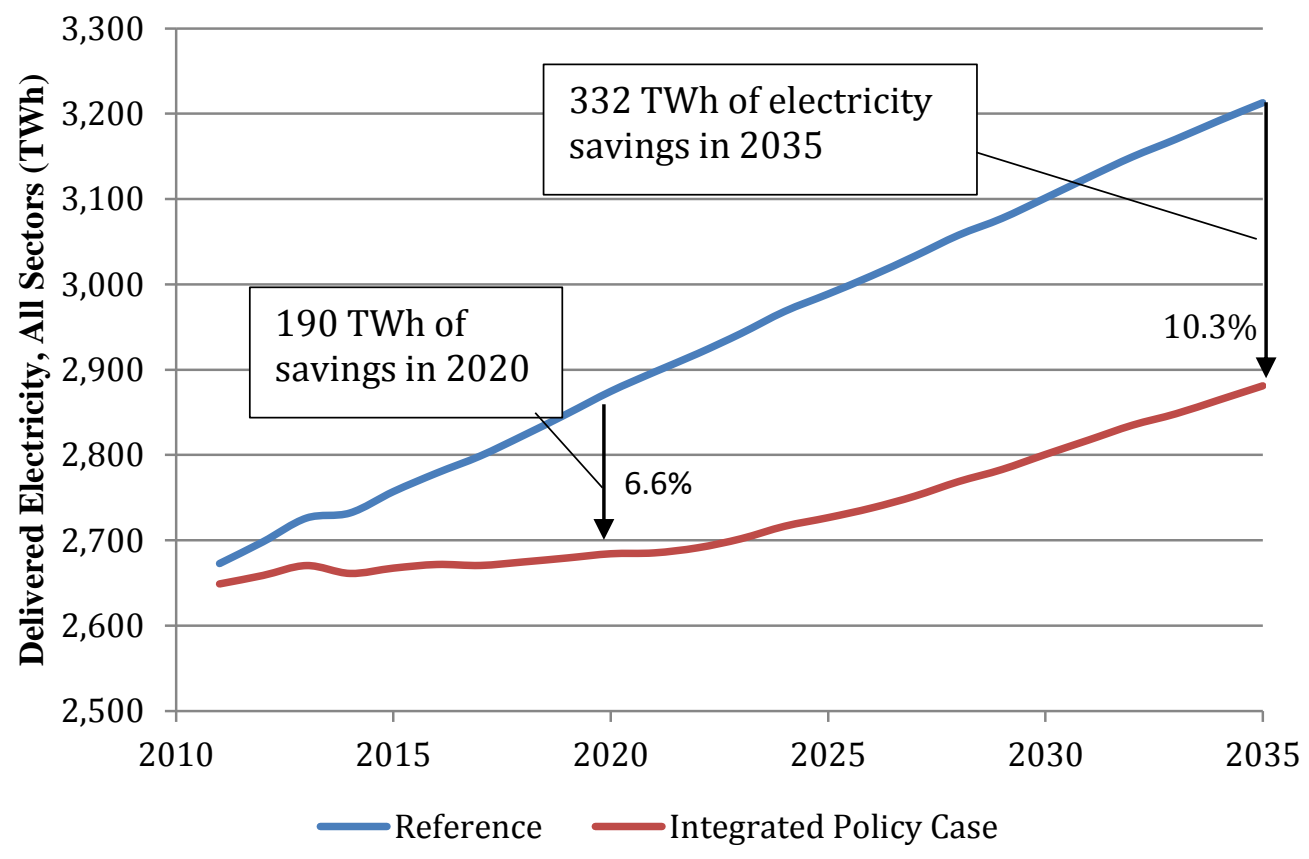

Figure 6.2 Electricity Savings from the Integrated Policy Case in the Eastern Interconnection 


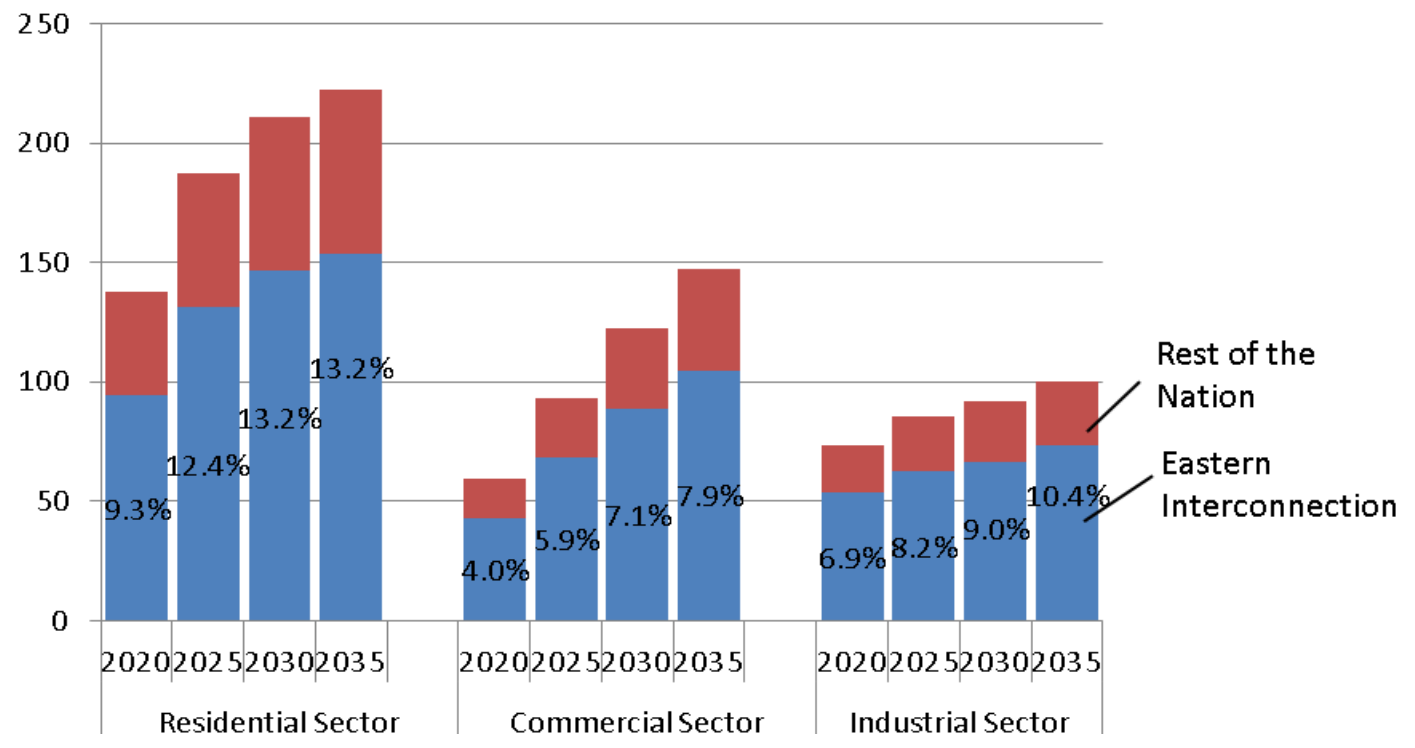

Figure 6.3 Electricity-Savings Potential by Sector, Based on the Integrated Policy Case (in TWh)

Table 6.3 illustrates the achievable potential for electricity savings as a percentage of Reference case consumption in 2020. The energy-efficiency policies are estimated to generate the highest savings potentials (as a percentage-of-consumption) in the residential and industrial sectors of the South (i.e., the South Atlantic, East South Central and West South Central regions). For the commercial sector, the same three Census divisions have the highest percent savings estimates, but the rank order is different: with the West South Central; having the highest percent, and the East South Central division having the third highest estimate of percent savings potential.

Table 6.3 Electricity-Savings Potential in 2020, by Census Division (as percentages of Reference case consumption in 2020)

\begin{tabular}{l|ccc|c}
\hline Census Division & $\begin{array}{c}\text { Residential } \\
\text { Sector }\end{array}$ & $\begin{array}{c}\text { Commercial } \\
\text { Sector }\end{array}$ & $\begin{array}{c}\text { Industrial } \\
\text { Sector }\end{array}$ & $\begin{array}{l}\text { Eastern } \\
\text { Interconnection }\end{array}$ \\
\hline New England & $7.98 \%$ & $2.88 \%$ & $5.40 \%$ & \\
Middle Atlantic & $7.71 \%$ & $3.27 \%$ & $5.29 \%$ & \\
East North Central & $7.81 \%$ & $4.13 \%$ & $6.60 \%$ & \\
West North & & & & \\
Central & $6.40 \%$ & $3.33 \%$ & $6.02 \%$ & \\
South Atlantic & $11.19 \%$ & $4.54 \%$ & $8.13 \%$ & \\
East South Central & $8.52 \%$ & $3.63 \%$ & $7.98 \%$ & \\
West South & $13.39 \%$ & $4.55 \%$ & $6.88 \%$ & \\
Central & & & & \\
\hline Eastern Intercon- & $9.3 \%$ & $4.0 \%$ & $6.9 \%$ & $6.6 \%$ \\
nection & & & & \\
\hline
\end{tabular}


The electricity-savings potential was proportioned to the state-level in accordance with the share of energy consumption each state held within its own census division. Figure 6.4 illustrates the achievable potential for electricity savings by state in 2020. A large portion of the total savings is estimated to be available in the South Atlantic region, especially Florida. In that same year, the highest savings potentials in the residential and commercial sectors reside in three states: Florida, North Carolina, and Virginia. The highest savings potentials in the industrial sector reside in in Ohio, Kentucky, Indiana, and Illinois (see Table D.1 for details).

In contrast, our twelve policies suggest much smaller savings potentials in some of the states of the West North Central and New England regions. Especially low across all three sectors in 2020 are Vermont, Rhode Island, and New Hampshire. The reason for the disproportionate distribution of electricity savings among states is partially due to differences among state economic structures and partially due to the differences in each state's share of the energy market.

Figure 6.4 Achievable Potential for Electricity Savings by State in 2020

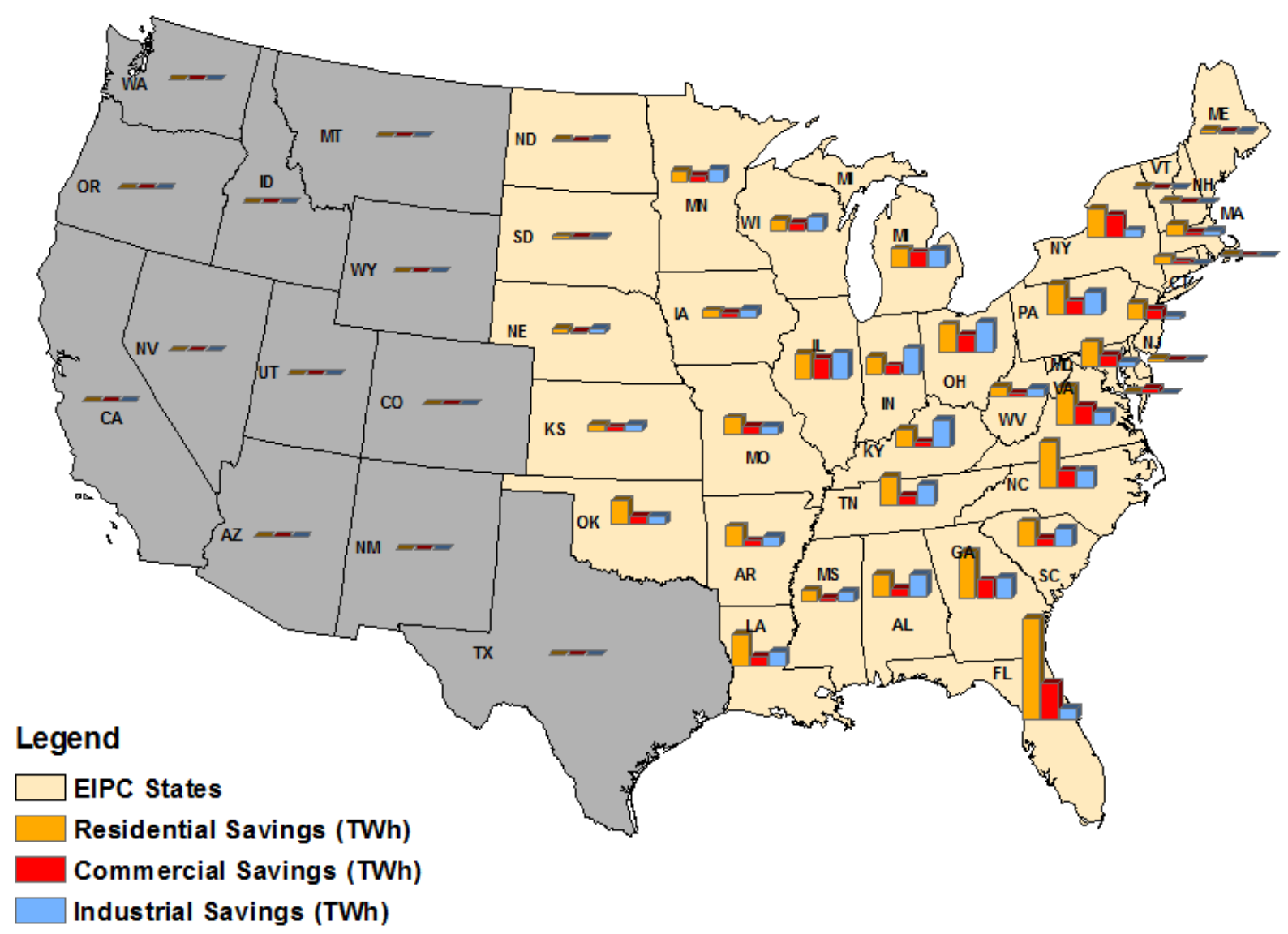




\subsection{Policy Impacts on Electricity Rates and the Power Sector}

Generally, the energy-efficiency policies are projected to reduce electricity retail rates in all three end-use sectors (Table 6.3). For retail prices, New England and Middle Atlantic exhibit higher rates than the other census divisions in the Eastern Interconnection, and large rate decreases occur in these two divisions. New England has the biggest decrease in commercial and industrial electricity rates. The biggest decline in residential retail rates happens in the West North Central division. The East South Central division, on the other hand, experiences essentially no reductions in either commercial or industrial electricity rates.

Table 6.4 Electricity Rate Changes in 2020, Reference versus Integrated Policy Case

\begin{tabular}{l|l|c|c|c}
\hline Census Division & Scenario & $\begin{array}{c}\text { Residential Retail } \\
\text { Rate (cent/kWh) }\end{array}$ & $\begin{array}{c}\text { Commercial Retail } \\
\text { Rate (cent/kWh) }\end{array}$ & $\begin{array}{c}\text { Industrial Retail } \\
\text { Rate (cent/kWh) }\end{array}$ \\
\hline New England & Reference & 17.7 & 12.0 & 7.8 \\
& Integrated Policy Case & 17.6 & 11.3 & 7.2 \\
& Change & -0.1 & -0.7 & -0.6 \\
\hline \multirow{2}{*}{ Middle Atlantic } & Reference & 14.6 & 11.2 & 6.3 \\
& Integrated Policy Case & 14.4 & 11.0 & 6.0 \\
& Change & -0.2 & -0.2 & -0.3 \\
\hline \multirow{2}{*}{ West North Central } & Reference & 8.5 & 7.1 & 5.3 \\
& Integrated Policy Case & 7.9 & 7.0 & 5.2 \\
& Change & -0.6 & -0.1 & -0.1 \\
\hline \multirow{2}{*}{ East North Central } & Reference & 10.0 & 8.4 & 5.9 \\
& Integrated Policy Case & 9.6 & 8.3 & 5.8 \\
& Change & -0.4 & -0.1 & -0.1 \\
\hline \multirow{2}{*}{ West South Central } & Reference & 9.7 & 7.2 & 5.4 \\
& Integrated Policy Case & 9.2 & 7.0 & 5.2 \\
& Change & -0.5 & -0.2 & -0.2 \\
\hline South Atlantic & Reference & 10.8 & 9.0 & 6.5 \\
& Integrated Policy Case & 10.5 & 9.1 & 0.5 \\
& Change & -0.3 & 7.9 & 5.2 \\
\hline \multirow{2}{*}{ East South Central } & Reference & 8.3 & 7.9 & 0.2 \\
& Integrated Policy Case & 7.9 & 0 & \\
\hline
\end{tabular}

Although the absolute value of the rate decrease never exceeds 0.7 cents $/ \mathrm{kWh}$, it is estimated to result in large energy expenditure savings for customers. With the energy-efficiency policies, residential customers are estimated to save about $\$ 13$ billion in 2020. Similarly, commercial customers will save $\$ 5$ billion and industrial customers will save $\$ 4$ billion in 2020 .

Interestingly, the regions with the largest decreases in electricity rates do not correspond to the regions with the highest electricity savings potentials (Tables 6.1 and 6.2). In 2020, New England is estimated to have the biggest decreases in electricity rates but only moderate electricity-savings potential. 


\section{Electricity Price Changes (\%) by Census Division in 2020}

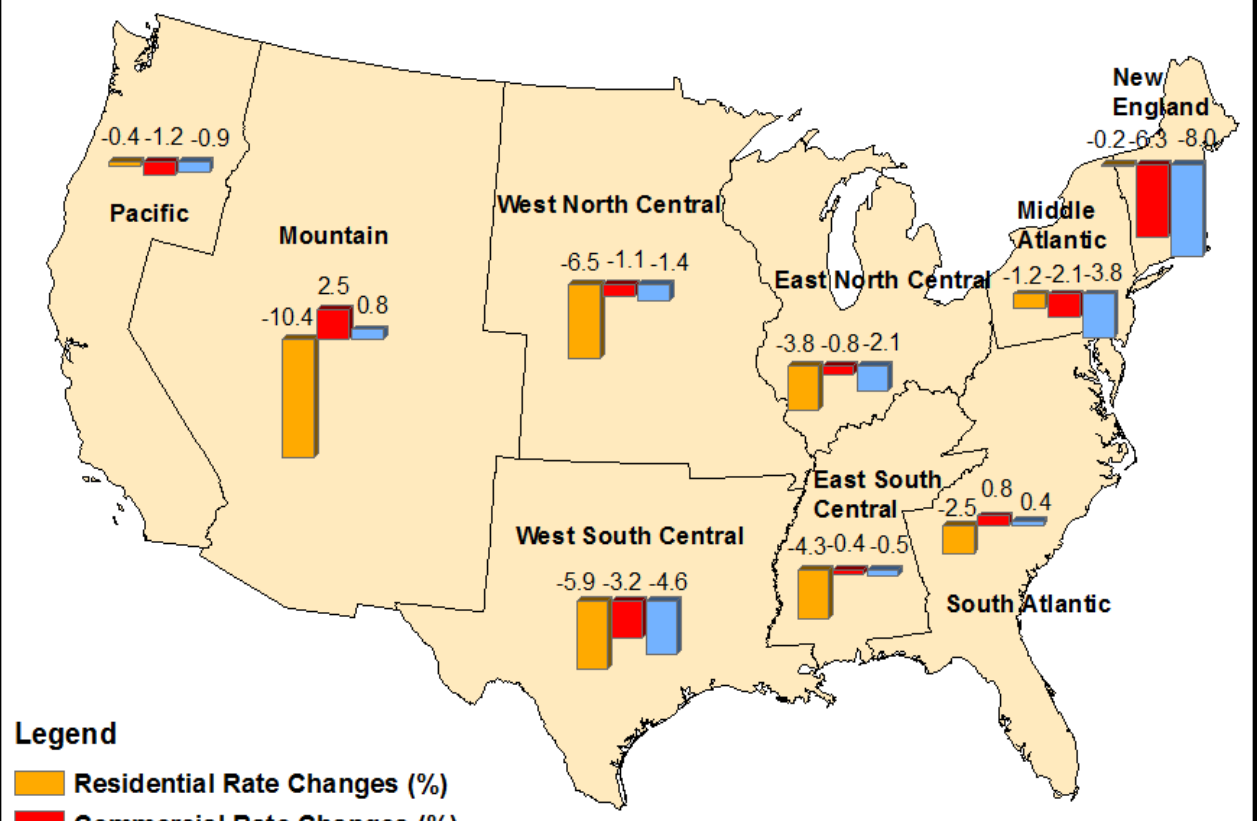

Commercial Rate Changes (\%)

Industrial Rate Changes (\%)

Electricity Price Changes (\%) by Census Division in 2035

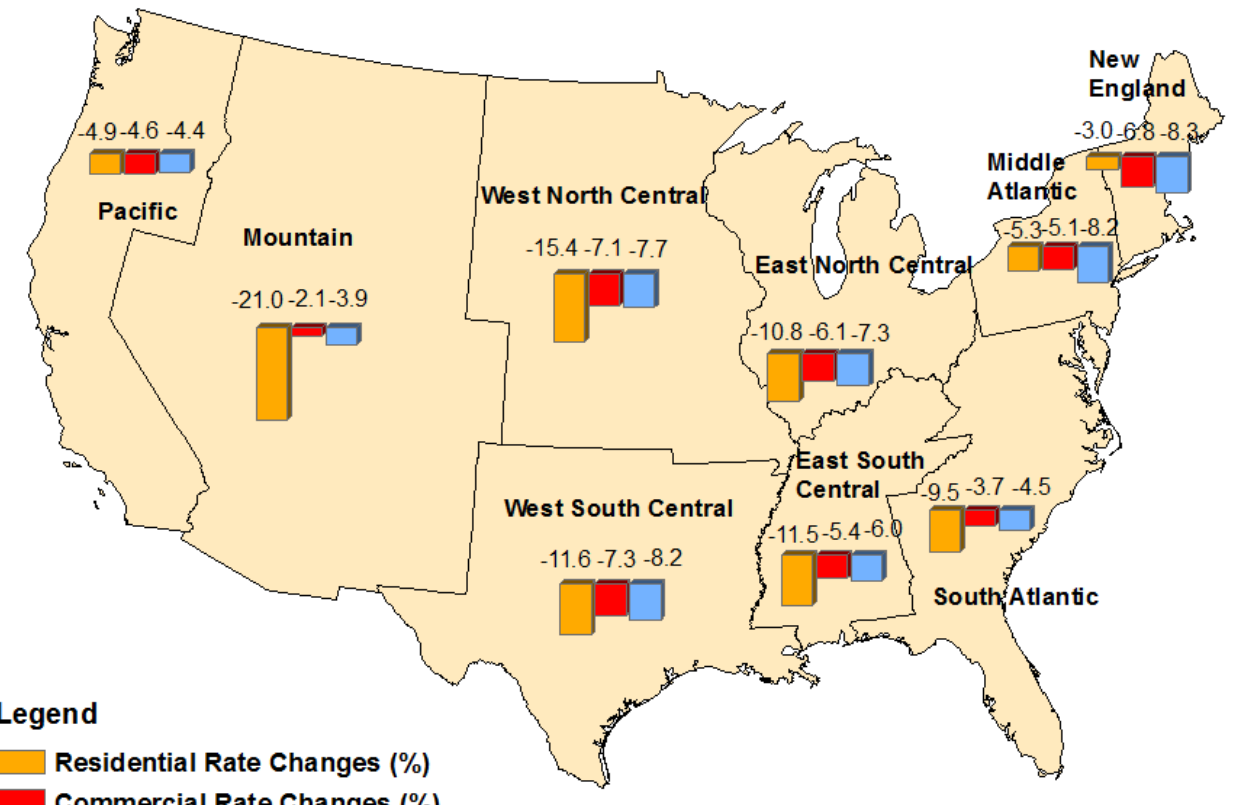

Commercial Rate Changes (\%)

Industrial Rate Changes (\%)

Figure 6.5 Electricity Price Changes by Census Division 
On the other hand, the South Atlantic is the only census division with rate increases in 2020 and it has only a moderate rate decreases in 2035, but it is estimated to have the most electricity savings in the Eastern Interconnection. This suggests that electricity savings dynamics, including the rebound effect, may play an important role in this rate change - consumers tend to demand more electricity services when rates are low.

Similar to the South Atlantic states, the Mountain states experience higher commercial electricity rates on average in 2020 under the Integrated Policy case. But rates drop across the board in the Integrated Policy case in comparison with the Reference case after 2025. As shown in Figure 6.5, the electricity retail rate decrease is universal in 2035.

A principal driver of the electricity rate decreases is the decline in consumption from improved end-use efficiencies. The electricity market can be treated as a partially competitive market. Consistent with economic theory, energy-efficiency policies drive down demand, which results in a new equilibrium with lower prices as a result of competition.

In the Integrated Policy case, low consumption levels and low electricity retail rates are estimated to influence the power sector. Table 6.4 suggests that fewer power plants $(7.2 \%$ fewer in 2020 and $11.4 \%$ fewer in 2035) are being built as a result of the energy-efficiency policies in the Integrated Policy case. Natural gas power plants experience the greatest generation losses relative to the reference case as a result of the twelve policies $(9.1 \%$ less generation in 2020 , and $25.2 \%$ less generation in 2035). In the Integrated Policy case, electricity generated from renewable sources does not decrease as much as generation from other sources in 2020. By 2035, however renewables are reduced proportionately more than coal or nuclear $(9.6 \%$ versus $8.2 \%$ and $6.1 \%$ ), but natural gas generation is offset most dramatically - by more than $200 \mathrm{TWh}$ $(25.2 \%)$, when compared with the reference case. If natural gas hydrofracking continues to produce low-cost gas in the U.S., coal, nuclear and renewables might be further reduced while combined cycle natural gas plants would likely retain more of their market share.

Table 6.5 Electricity Generation by Source in the U.S. (in TWh) Reference Forecast versus Integrated Policy Case

\begin{tabular}{c|c|ccc|ccc}
\hline \multirow{2}{*}{ Fuel Type } & $\mathbf{2 0 1 0}$ & \multicolumn{3}{|c|}{$\mathbf{2 0 2 0}$} & \multicolumn{3}{c}{$\mathbf{2 0 3 5}$} \\
\cline { 2 - 8 } & $\begin{array}{c}\text { Reference } \\
\text { Forecast }\end{array}$ & $\begin{array}{c}\text { Reference } \\
\text { Forecast }\end{array}$ & $\begin{array}{c}\text { Integrated } \\
\text { Policy } \\
\text { Case }\end{array}$ & $\begin{array}{c}\text { \% } \\
\text { Change }\end{array}$ & $\begin{array}{c}\text { Reference } \\
\text { Forecast }\end{array}$ & $\begin{array}{c}\text { Integrated } \\
\text { Policy Case }\end{array}$ & $\begin{array}{c}\text { \% } \\
\text { Change }\end{array}$ \\
\hline Coal & 1812 & 1879 & 1738 & $-7.5 \%$ & 2082 & 1912 & $-8.2 \%$ \\
Petroleum & 39.45 & 39.02 & 36.84 & $-5.6 \%$ & 41.32 & 39.41 & $-4.6 \%$ \\
Natural Gas & 779.1 & 696.4 & 632.7 & $-9.1 \%$ & 914.1 & 683.6 & $-25.2 \%$ \\
Nuclear & 802.9 & 877.3 & 823.6 & $-6.1 \%$ & 874.4 & 821.3 & $-6.1 \%$ \\
Renewables & 371 & 519.3 & 494.6 & $-4.8 \%$ & 567.3 & 512.9 & $-9.6 \%$ \\
\hline Total & 3804 & 4013 & 3726 & $-7.2 \%$ & 4483 & 3972 & $-11.4 \%$ \\
\hline $\begin{array}{c}\text { Energy- } \\
\text { Efficiency }\end{array}$ & & & & & & & \\
Potential & & & $\mathbf{2 8 7}$ & & & & \\
\hline
\end{tabular}


Figure 6.6 also illustrates the policy impacts on the power sector. In the Reference case, the share of power generated from natural gas grows from $17 \%$ in 2020 to $20 \%$ in 2035 . But this growth is estimated to be largely eliminated by energy-efficiency policies in the Integrated Policy case. Although the share of electricity from coal goes up to $48 \%$ in the Integrated Policy case, electricity generation from coal grows only slightly. This suggests that most of the new coal power plants with relatively lower carbon technologies will not be built in the policy case.

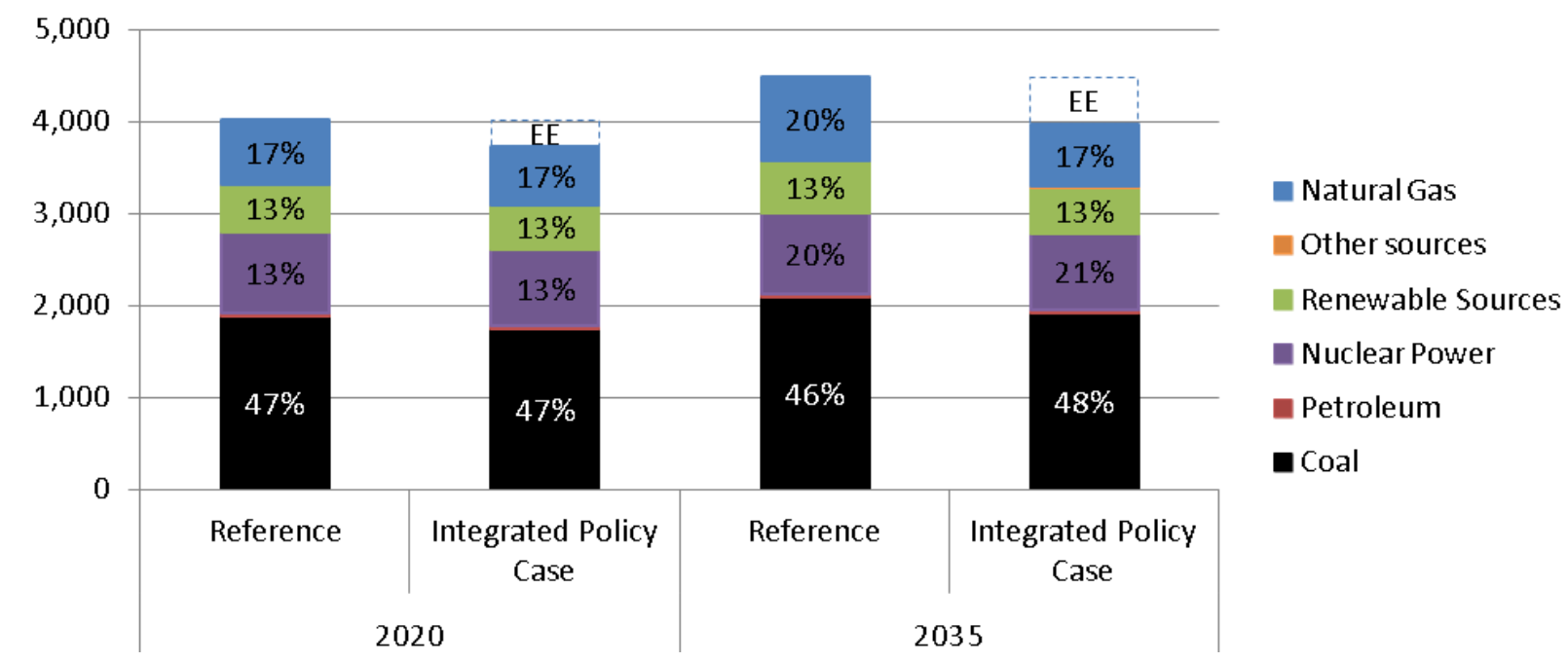

Figure 6.6 Power Generation by Source in the U.S., in TWh (EE=Energy Efficiency)

\subsection{Policy Impacts on Other Fuels and Carbon Emissions}

Although the twelve energy-efficiency policies aim to shrink electricity consumption, most have spillover benefits that may also cause significant savings in natural gas and other energy sources (Table 6.5). In 2020, the Eastern Interconnection could save 0.5 quadrillion Btus of natural gas with energy-efficiency policies. The savings potential in natural gas could grow to 1.5 quads in 2035 , which is about $38 \%$ of the total energy-savings potential.

Table 6.6 Energy-Savings Potential of Natural Gas and Total Energy

\begin{tabular}{|c|c|c|c|c|c|c|c|c|}
\hline & \multicolumn{8}{|c|}{ Energy Savings (Quads) } \\
\hline & \multicolumn{4}{|c|}{ Natural Gas } & \multicolumn{4}{|c|}{ Total Energy } \\
\hline & 2020 & 2025 & 2030 & 2035 & 2020 & 2025 & 2030 & 2035 \\
\hline El & 0.5 & 0.9 & 1.3 & 1.5 & 2.6 & 3.3 & 3.6 & 4.0 \\
\hline U.S. & 0.9 & 1.6 & 2.1 & 2.3 & 3.5 & 4.7 & 5.3 & 5.6 \\
\hline
\end{tabular}

Meanwhile, energy-efficiency policies exhibit significant potential in total energy savings in the Eastern Interconnection, as well as the other regions of the nation. Table 6.4 suggests that the nation could benefit from these policies, resulting in significant energy savings every year.

Figure 6.7 illustrates the forecast of total energy consumption in the Eastern Interconnection in the reference case and the Integrated Policy case. In 2020, energy efficiency policies are 
estimated to save 2.6 quads $(3.6 \%)$ of energy, which is four times the energy savings in electricity for that year. In 2035, the potential of savings in total energy will grow to 4.0 quads (5.2\%), which is 3.5 times the energy savings in electricity for that year.

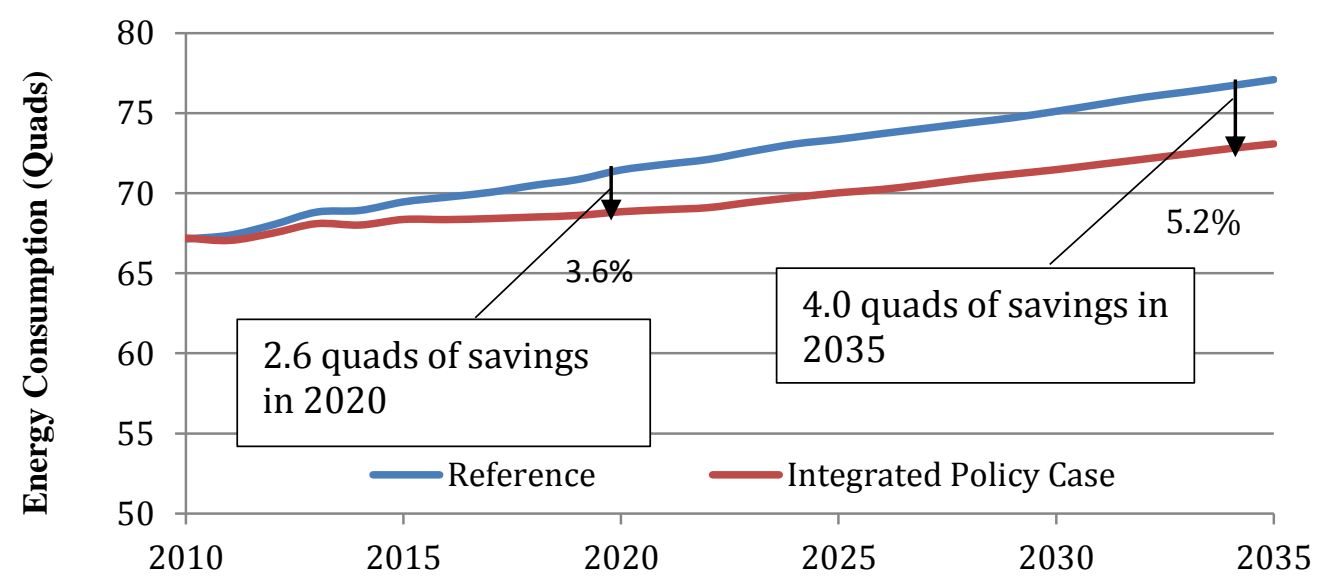

Figure 6.7 Total Energy Savings in the Eastern Interconnection (Quads)

These sizable reductions in energy consumption are associated with reductions in carbon dioxide emissions. Figure 6.8 suggests that the energy-efficiency policies could reduce carbon emissions by 161 million tonnes of $\mathrm{CO}_{2}(4.0 \%)$ in 2020 , while the potential for emission reductions increases to 246 million tonnes of $\mathrm{CO}_{2}(5.6 \%)$ in 2035.

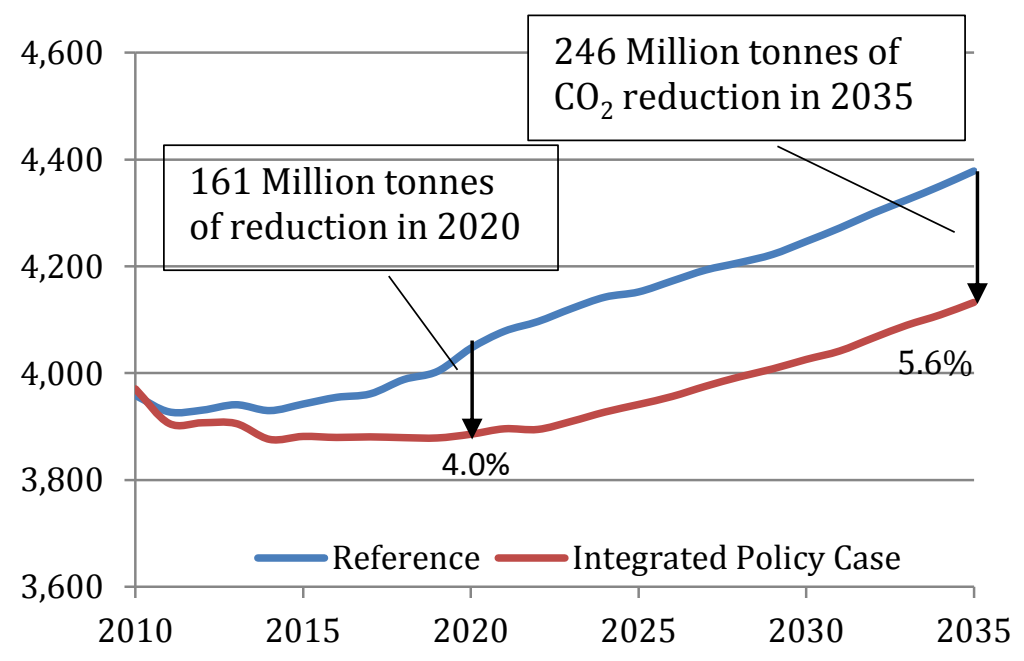

Figure 6.8 $\mathrm{CO}_{2}$ Emissions in the Eastern Interconnection (Million Tonnes)

The percent of carbon emission reductions is slightly higher than the percent of reductions in energy consumption, which suggests that the energy savings are larger in more carbon-intensive 
energy sources (Table 6.6). The energy efficiency policies are clearly estimated to generate larger savings in electricity, which is more carbon-intensive than natural gas.

Table 6.7 Reduction in $\mathrm{CO}_{2}$ Emissions

\begin{tabular}{l|cccc}
\hline & \multicolumn{4}{|c}{ Reduction in CO Cmissions $^{\text {(Million Tonnes) }}$} \\
& 2020 & 2025 & 2030 & 2035 \\
\hline $\begin{array}{l}\text { Eastern } \\
\text { Interconnection }\end{array}$ & 161 & 211 & 221 & 246 \\
United States & 211 & 270 & 291 & 317 \\
\hline
\end{tabular}

Energy savings throughout the nation would produce carbon emission reductions in a manner similar to that observed in the Eastern Interconnection. Table 6.5 suggests that the other regions of the country would also experience significant reduction in carbon emissions produced by energy-efficiency policies.

\subsection{Policy Impacts on Energy Intensity and GDP}

The impact of energy-efficiency policies on different sectors of the economy can be compared through energy intensity metrics. Residential building energy intensity is measured by primary energy per household, while commercial building energy intensity is measured by primary energy use per square footage.

Two intensity measures were constructed for the industrial sector since electricity represents a relatively small part of industrial energy use. The usual industrial energy intensity is measured by primary energy per dollar of shipment, and the industrial electricity intensity is constructed similarly as electricity per dollar of shipment. The energy intensity of the whole economy is represented by primary energy use per GDP.

Figure 6.9 suggests that energy efficiency policies and programs would reduce the energy intensity in residential and commercial buildings more than the energy intensity of the industrial sector or the economy as a whole. For example, in 2020, energy use per household decreases by $10.6 \%$, and energy use per square footage of commercial building decreases by $4.4 \%$, while energy use per GDP declines by only $3.3 \%$. 


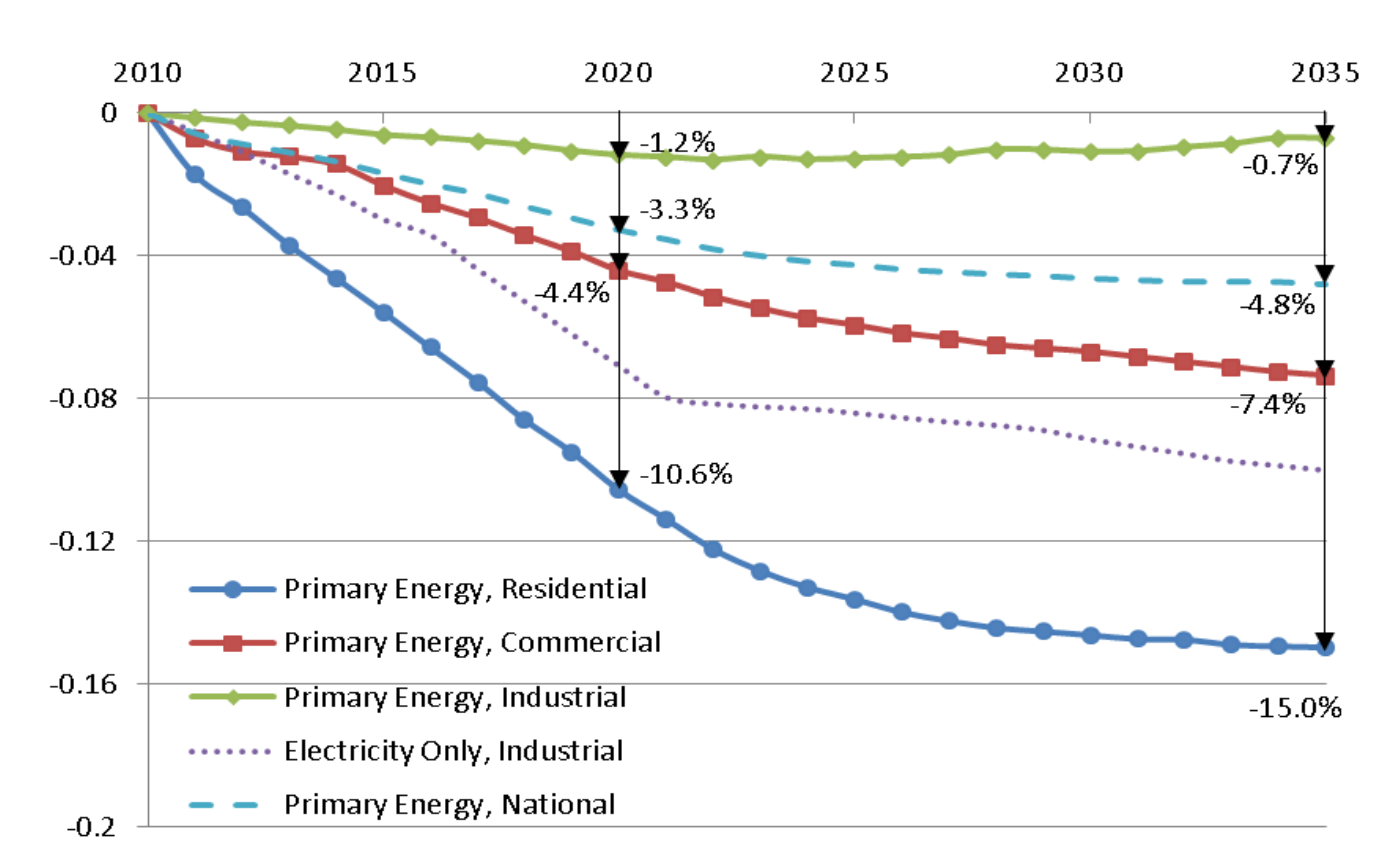

Figure 6.9 Forecasted Changes in Energy Intensity by Economic Sectors

To the contrary, industrial energy intensity is much less influenced by the twelve energyefficiency policies than energy intensity of the nation. Figure 6.8 illustrates that the energy use per dollar of shipment decreases by only $1.2 \%$ in 2020, which is barely half of the intensity decline of the nation. However, our policies target only the electricity savings potentials in the industrial sector, while electricity represents merely one third of industrial energy consumption. The industrial electricity intensity, measured by electricity use per dollar of shipment, is estimated to decrease by $7.1 \%$ in 2020 , suggesting that our policies could be quite influential in transforming industrial energy systems.

Table 6.7 suggests that our energy-efficiency policies have a negligible negative impact on GDP. The national GDP is estimated by NEMS to grow $\$ 15$ Billion $(0.08 \%)$ less in the policy case in 2020, which is equivalent to only 7 hours of delay in GDP growth. In 2035, the GDP is estimated to drop by $\$ 47$ Billion $(0.17 \%)$, which is equivalent to about 25 hours of delay in GDP growth.

Table 6.8 GDP Impact

\begin{tabular}{l|l|r|r|r|r}
\hline Scenario & GDP (Billion 2009\$) & $\mathbf{2 0 2 0}$ & $\mathbf{2 0 2 5}$ & $\mathbf{2 0 3 0}$ & $\mathbf{2 0 3 5}$ \\
\hline Reference & GDP & 19,168 & 22,021 & 25,000 & 28,260 \\
\hline & GDP & 19,152 & 22,009 & 24,974 & 28,213 \\
& Change & $-0.08 \%$ & $-0.05 \%$ & $-0.10 \%$ & $-0.17 \%$ \\
Integrated Policy Case & Delay (hour) & 7 & 7 & 15 & 25 \\
\hline
\end{tabular}

*Numbers are percentage change relative to the Reference case

** "Delay" in GDP growth is defined as the number of days in a year required to make up the difference between GDP in the Reference case versus GDP in the Integrated Policy scenario. 
The higher equipment investments prompted by the twelve policies would divert the capital that could have been invested in other economic activities. Results from GT-NEMS suggest that this reallocation of capital resources would affect the national GDP, albeit to a small extent. In addition, the policies would reduce energy consumption and production, which also has GDP consequences. As an energy-economic model, GT-NEMS is capable of modeling the macroeconomic impact of any energy policy by incorporating Global Insight's model of the U.S. economy in its Macroeconomic Activity Module (MAM). Both energy demand and supply sides interact with MAM through a Cobb-Douglas production function to calculate the national GDP. However, the IHS Global Insights model assumes the U.S. economy has a 0.07 energy elasticity, which means that a $1 \%$ decrease in energy supply decreases potential GDP by $0.07 \%$ (EIA, 2012), but unlike input-output models such as IMPLAN, the reduction in energy expenditures is not recycled back into the economy to reflect re-spending of the energy savings. As a result, NEMS tends to produce estimates of decreased GDP when energy-efficiency investments increase (Laitner, 2013).

\subsection{Discussion and Conclusion}

With energy-efficiency policies, we estimate that the Eastern Interconnection could costeffectively achieve significant savings in electricity consumption by 2035. Driven by policy, this achievable potential for greater electric end-use efficiency is relatively low compared with some prior assessments of the technical and economic potential. Our review of the literature, however, indicates that this estimated potential for the Eastern Interconnection is comparable to many estimates of the achievable potential for increased electric end-use efficiency at various scales of analysis, ranging from the metropolitan to the national.

The electricity savings benefit of energy-efficiency policies is accompanied by other benefits, including natural gas savings, savings in other fuel types, and reduced carbon emissions. In addition, the twelve energy-efficiency policies are able to drive electricity retail prices down in many regions and produce large energy bill savings for consumers. The electric power sector is also affected by these policies, in that generation growth is slowed in the Integrated Policy case, reducing the need for capital-intensive new generation. Overall, these policies are able to decrease the energy and carbon intensity of the Eastern Interconnection with no significant impact on GDP growth.

In sum, this study offers a reliable assessment of achievable potential and an in-depth analysis of the impacts of energy-efficiency policies in the Eastern Interconnection. 


\section{References}

Amstalden, R.W., M. Kost, C. Nathani, and D.M. Imboden. (2009) "Economic potential of energy-efficient retrofitting in the Swiss residential building sector: The effects of policy instruments and energy price expectations" Energy Policy.

Arimura, Toshi, Shanjun Li, Richard Newell, and Karen Palmer. 2011. "Cost-Effectiveness of Electricity Energy Efficiency Programs.” NBIR Working Paper Series, October.

Auffhammer, Maximilian, Carl Blumstein, and Meredith Fowlie ( 2008). "Demand Side Management and Energy Efficiency Revisited.” The Energy Journal 29(3): 91-104

Baek, Youngsun, Stanton W. Hadley, Rocío Uría-Martínez, Gbadebo Oladosu, Alexander M. Smith, Fangxing Li, Paul N. Leiby, Russell Lee. (2012) Eastern Interconnection Demand Response Potential. Oak Ridge: Oak Ridge National Laboratory, ORNL/TM-2012/303.

Bell, C.J., S. Nadel, and S. Hayes. 2011. On-Bill Financing for Energy Efficiency Improvements. Washington, DC: American Council for an Energy Efficient Economy.

Bingaman Bill. Clean Energy Standard and Act of 2012. 610, U.S.C. 2601 (2012)

Brown, M. A. (1993). The effectiveness of codes and marketing in promoting energy-efficient home construction. Energy Policy, 21(4), 391-402. Retrieved from http://www.sciencedirect.com/science/article/pii/0301421593902790

Brown, M. A. and B. K. Sovacool. 2011. Climate Change and Global Energy Security: Technology and Policy Options, MIT Press.

Brown, M. A., M. Cox, \& Cortes, R. (2010). Transforming Industrial Energy Efficiency. The Bridge, 22-30.

Brown, M. A., M. Cox, \& P. Baer. 2012. "Reviving manufacturing with a federal cogeneration policy." Energy Policy. http://dx.doi. org/10.1016/j.enpol.2012.08.070.

Brown, M. A., Etan Gumerman, Xiaojing Sun, Youngsun Baek, Joy Wang, Rodrigo Cortes, and Diran Soumonni. 2010. Energy Efficiency in the South (Atlanta: Southeast Energy Efficiency Alliance), April, http://www.seealliance.org/programs/se-efficiency-study.php.

Brown, Marilyn A., Roderick Jackson, Matt Cox, Rodrigo Cortes, Benjamin Deitchman, and Melissa Lapsa. 2011. Making Industry Part of the Climate Solution: Policy Options to Promote Energy Efficiency. Oak Ridge National Laboratory, ORNL/TM-2010/78, May, 275 pages. http://info.ornl.gov/sites/publications/Files/Pub23821.pdf.

Brown, Marilyn A., Mark D. Levine, Joseph P. Romm, Arthur H. Rosenfeld, and Jonathan G. Koomey. 1998. "Engineering-Economic Studies of Energy Technologies to Reduce Greenhouse Gas Emissions: Opportunities and Challenges." Annual Review of Energy and the Enivronment 23: 287-385. 
Brown, M. A., Levine, M. D., Short, W., \& Koomey, J. G. (2001). Scenarios for a clean energy future. Energy Policy, 29(14), 1179-1196. Retrieved from http://www.sciencedirect.com/science/article/pii/S0301421501000660

Brown, Marilyn A., John A. "Skip” Laitner, Sharon “Jess” Chandler, Elizabeth D. Kelly, Shruti Vaidyanathan, Vanessa McKinney, Cecelia "Elise" Logan, and Therese Langer. 2009. Energy Efficiency in Appalachia: How much more is available, at what cost, and by when? Prepared for the Appalachian Regional Commission, http://www.arc.gov/research/researchreportdetails.asp?REPORT_ID=70

Brown, Marilyn A., Matt Cox, and Xiaojing Sun. 2012. "Modeling the Impact of a Carbon Tax on the Commercial Buildings Sector," Proceedings of the ACEEE Summer Study on Energy Efficiency in Buildings, Pacific Grove, CA.

Burr, A.C., C. Keicher, and D. Leipziger. 2011. Building Energy Transparency: A Framework for Implementing US Commercial Energy Rating and Disclosure Policy. Institute for Market Transformation. http://www.imt.org/uploads/resources/files/IMT Building_Energy_Transparency_Report.pdf

Chirarattananon, S., Chaiwiwatworakul, P., Hien, V. D., Rakkwamsuk, P., \& Kubaha, K. (2010). Assessment of energy savings from the revised building energy code of Thailand. Energy, 35(4), 1741-1753. Retrieved from http://www.sciencedirect.com/science/article/pii/S0360544209005477

Committee on Climate Change Science and Technology Integration (CCCSTI). 2009. Strategies for the Commercialization and Deployment of Greenhouse Gas Intensity-Reducing Technologies and Practices" Washington, D.C.: Department of Energy, DOE/PI-0007.

Cox, Matt, Marilyn A. Brown, and Xiaojing Sun. 2012. "Making Buildings Part of the Climate Solution by Overcoming Information Gaps through Benchmarking," Georgia Institute of Technology, School of Public Policy Working Paper \#72 (http://www.spp.gatech.edu/aboutus/workingpapers).

Croucher, M. (2011). Potential problems and limitations of energy conservation and energy efficiency. Energy Policy, 39(10), 5795-5799. doi:10.1016/j.enpol.2011.07.011

Database of State Incentives for Renewables and Efficiency (DSIRE). (2012). Federal Incentives/Policies for Renewables and Efficiency. Database of State Incentives for Renewables \& Efficiency. Retrieved from http://www.dsireusa.org/summarytables/finee.cfm

Deitchman, B., Brown, M. A., \& Wang, Y. (2012). Making Buildings Part of the Climate Solution with Flexible Innovative Financing. Georgia Institute of Technology, School of Public Policy Working Paper 
Dietz, T. (2010). Narrowing the US energy efficiency gap. Proceedings of the National Academy of Sciences, 107(37), 16007.

DOC Bureau of Economic Analysis. (2012). Gross Domestic Product by State. http://www.bea.gov/iTable/iTable.cfm?ReqID=70\&step=1

DOE. (2012). Building Energy Codes Program. Retrieved from http://www.energycodes.gov/adoption/states

Electric Power Research Institute (EPRI). (2009). Assessment of Achievable Potential from Energy Efficiency and Demand Response Programs in the U.S. (2010-2030). Manager. Palo Alto.

Elliott, RN. 2007. "Impact of Proposed Increases to Motor Efficiency Performance Standards." Washington, DC: American Council for an Energy-Efficient Economy.

Energy Information Administration (EIA). 2006. Manufacturing Energy Consumption Survey (MECS) http://www.eia.doe.gov/emeu/mecs/mecs2006/2006tables.html

Energy Information Administration (EIA). (2009). The national energy modeling system: An overview 2009. http://www.eia.gov/oiaf/aeo/overview/index.html

Energy Information Administration (EIA). 2011. Annual Energy Outlook 2011. DOE/EIA 0383(2011). http://www.eia.gov/forecasts/aeo/pdf/0383(2011).pdf

Energy Information Administration (EIA). 2012. Model Documentation Report: Macroeconomic Activity Module (MAM) of the National Energy Modeling System. http://www.eia.gov/forecasts/nemsdoc/macroeconomic/pdf/m065(2012).pdf

Energy Information Administration (EIA, SEDS). 2010. State Energy Data System. http://www.eia.doe.gov/states/_seds.html

EPRI. (2009). Assessment of Achievable Potential from Energy Efficiency and Demand Response Programs in the U.S. (2010-2030). Manager. Palo Alto

Fayaz, R., \& Kari, B. M. (2009). Comparison of energy conservation building codes of Iran, Turkey, Germany, China, ISO 9164 and EN 832. Applied Energy, 86(10), 1949-1955. Retrieved from http://www.sciencedirect.com/science/article/pii/S0306261908003425

Feng, D., Sovacool, B. K., \& Minh Vu, K. (2010). The barriers to energy efficiency in China: Assessing household electricity savings and consumer behavior in Liaoning Province. Energy Policy, 38(2), 1202-1209.

Fleiter, T., Fehrenbach, D., Worrell, E., \& Eichhammer, W. (2012). Energy efficiency in the German pulp and paper industry - A model-based assessment of saving potentials. Energy, 40(1), 84-99. doi:10.1016/j.energy.2012.02.025 
Ben Foster, Anna Chittum, Sara Hayes, Max Neubauer, Seth Nowak, Shruti Vaidyanathan, Kate Farley, Kaye Schultz, and Terry Sullivan. 2012. The 2012 State Energy Efficiency Scorecard (American Council for an Energy-Efficient Economy), Report Number E12C.

Freidrich, Katherine, Maggie Eldridge, Dan York, Patti Witte, and Marty Kushler (2009). Saving Energy Cost-Effectively: A National Review of the Cost of Energy Saved through Utility- Sector Energy Efficiency Programs. ACEEE Report Number U092, September. Washington, DC: ACEEE

Geller, H. (1997). National appliance efficiency standards in the USA: cost-effective federal regulations. Energy and Buildings, 26(1), 101-109. doi:10.1016/S0378-7788(96)01020-1

Geller, Howard. 2002. Energy Revolution: Policies for a Sustainable Future (Island Press).

Gellings, C., Wikler, G., \& Ghosh, D. (2006). Assessment of U . S . Electric End-Use Energy Efficiency Potential. The Electricity, 19(9), 55-69

Granade, H. C., Creyts, J., Derkach, A., Farese, P., Nyquist, S., \& Ostrowski, K. (2009). Unlocking Energy Efficiency in the U.S. Economy.

Hadley, S. 2003. The Potential for Energy Efficiency and Renewable Energy in North Carolina.

Hirst, E., \& Brown, M. (1990). "Closing the efficiency gap: barriers to the efficient use of energy." Resources, Conservation and Recycling, 3(4), 267-281.

ICF International. (2010). Effect of a 30 percent investment tax credit on the economic market potential for combined heat and power. Washington, DC: USCHPA and WADE. http://www.uschpa.org/files/public/USCHPA WADE_ITC_Report_FINAL v4.pdf

International Energy Agency. (2007). Mind the Gap. Quantifying Principal-Agent Problems in Energy Efficiency.

Jaffe, A. B., \& Stavins, R. N. (1994). "The energy-efficiency gap: What does it mean?" Energy Policy, 22(10), 804-810.

Johnson Controls/IFMA. 2011. 2011 Energy Efficiency Indicator Global Survey Results. http://www.institutebe.com/Energy-Efficiency-Indicator/2011-global-results.aspx.

Kammen, D. M. 2009. “Financing energy efficiency.” Scientific American 19(21).

Kneifel, J. (2010). Life-cycle carbon and cost analysis of energy efficiency measures in new commercial buildings. Energy and Buildings, 42(3), 333-340. Retrieved from http://www.sciencedirect.com/science/article/pii/S0378778809002254

Laitner, J.S. (Skip). 2013. Personal communication, Economic and Human Dimensions Research 
Associates, January 8.

Laitner, John A. "Skip," Steven Nadel, R. Neal Elliott, Harvey Sachs, and Siddiq Kahn. 2012. The Long-Tern Energy Efficiency Potential: What the Evidence Suggests. Washington, DC: American Council for an Energy-Efficient Economy.

Levine, M.D., Koomey, J.G., McMahon, J.E., Sanstad, A., Hirst, E., 1995. Energy Efficiency Policy and Market Failures. Annual Review of Energy and the Environment 20, 535-555.

Mackres, Eric, Max Neubauer, John A. "Skip" Laitner, Amanda Lowenberger, Jacob Talbot, and Casey J. Bell, Jeffry Rexhausen, Irem Yelkenci, and Jameshia Peterson. 2011. The Energy Efficiency Market in the Greater Cincinnati Region: Energy Savings Potential and Strategies to Improve Performance of Residential and Nonprofit Buildings, ACEEE Research Report 118, December.

McKane, A., \& Hasanbeigi, A. (2011). Motor systems energy efficiency supply curves: A methodology for assessing the energy efficiency potential of industrial motor systems. Energy Policy, 39(10), 6595-6607. doi:10.1016/j.enpol.2011.08.004

McNeil, M. a., \& Bojda, N. (2012). Cost-effectiveness of high-efficiency appliances in the U.S. residential sector: A case study. Energy Policy, 45, 33-42.

doi:10.1016/j.enpol.2011.12.050

Meier, Alan, Janice Wright, and Arthur H. Rosenfeld. 1983. Supplying Energy through Greater Efficiency: The Potential for Conservation in California's Residential Sector. Berkeley, CA: University of California Press.

Meier, A. K. (1997). Observed energy savings from appliance efficiency standards. Energy and Buildings, 26(1), 111-117. doi:10.1016/S0378-7788(96)01021-3

Nadel, S., Shipley, A., \& Elliott, R. N. (2004). The Technical, Economic and Achievable Potential for Energy-Efficiency in the U . S . - A Meta-Analysis of Recent Studies Analysis of Recent Studies. 2004 ACEEE Summer Study on Energy Efficiency in Buildings.

National Academies. 2009. Real Prospect for Energy Efficiency in the United States. Washington, DC: The National Academies Press.

Nelson, H. T. (2012). Lost opportunities: Modeling commercial building energy code adoption in the United States. Energy Policy, 49(0), 182-191. Retrieved from http://www.sciencedirect.com/science/article/pii/S0301421512004454

Neubauer, et al,. (2011). Advancing Energy Efficiency in Arkansas: Opportunities for a Clean Energy Economy. Washington DC: American Council for an Energy Efficient Economy. 
Neuhoff, K., K. Stelmakh, H. Amecke, A. Novikova, J. Deason, and A. Hobbs. 2012. "Financial Incentives for Energy Efficiency Retrofits in Buildings," Proceedings of the ACEEE Summer Study on Energy Efficiency in Buildings, Pacific Grove, CA.

Nevin, Rick and Gregory Watson, 1998. "Evidence of Rational Market Values for Home Energy Efficiency", The Appraisal Journal, Vol. 68, pp. 401-409.

New York State Energy Research and Development Authority (NYSERDA). August, 2003. Energy Efficiency and Renewable Energy Resource Development Potential in New York State, Final Report.

Oak Ridge National Laboratory. http://www.ornl.gov/ webworks/cppr/y2006/rpt/116643.pdf

Office of Management and Budget (OMB). 2002. Guidelines and Discount Rates for Benefit Cost Analysis of Federal Programs (http://www.whitehouse.gov/omb/rewrite/circulars/a094/a094.html).

Office of Management and Budget (OMB). (2003). Circular A-4. http://www.whitehouse.gov/sites/default/files/omb/assets/regulatory_matters_pdf/a-4.pdf

Office of Management and Budget (OMB). 2009. 2010 Discount Rates for OMB Circular No. A94, December 8 http://www.whitehouse.gov/omb/assets/memoranda_2010/m10-07.pdf

Prindle, Bill. 2010. From Shop Floor to Top Floor: Best Business Practices in Energy Efficiency. Washington, DC: Pew Center.

Reichard, G., \& Papamichael, K. (2005). Decision-making through performance simulation and code compliance from the early schematic phases of building design. Automation in Construction, 14(2), 173-180. Retrieved from http://www.sciencedirect.com/science/article/pii/S0926580504000743

Rufo, M., Coito, F., 2002. California's Secret Energy Surplus: The Potential for Energy Efficiency. The Energy Foundation, San Francisco. http://www.ef.org/news_reports.cfm?program=viewall\&sort=creationdate.

Sadineni, S. B., France, T. M., \& Boehm, R. F. (2011). Economic feasibility of energy efficiency measures in residential buildings. Renewable Energy, 36(11), 2925-2931. Retrieved from http://www.sciencedirect.com/science/article/pii/S0960148111001789

Saygin, D., Patel, M. K., Worrell, E., Tam, C., \& Gielen, D. J. (2011). Potential of best practice technology to improve energy efficiency in the global chemical and petrochemical sector. Energy, 36(9), 5779-5790. doi:10.1016/j.energy.2011.05.019

Scott, M. J., Roop, J. M., Schultz, R. W., Anderson, D. M., \& Cort, K. A. (2008). The impact of DOE building technology energy efficiency programs on U.S. employment, income, and investment. Energy Economics, 30(5), 2283-2301. Retrieved from http://www.sciencedirect.com/science/article/pii/S0140988307001119 
Sun, Xiaojing, Marilyn A. Brown, Roderick Jackson, and Matt Cox. 2012. "Making Buildings Part of the Climate Solution by Enforcing Aggressive Commercial Building Codes," Georgia Institute of Technology, School of Public Policy Working Paper \#71 (http://www.spp.gatech.edu/aboutus/workingpapers).

Tonn, B., \& Peretz, J. H. (2007). State-level benefits of energy efficiency. Energy Policy, 35(7), 3665-3674. doi:10.1016/j.enpol.2007.01.009

U.S. Department of Energy, Industrial Technologies Program (DOE/ITP). 2008. Improving Motor and Drive System Performance. Washington, DC: DOE. http://www1.eere.energy.gov/industry/bestpractices/pdfs/motor.pdf

Vine, E., du Pont, P., \& Waide, P. (2001). Evaluating the impact of appliance efficiency labeling programs and standards: process, impact, and market transformation evaluations. Energy, 26(11), 1041-1059. doi:10.1016/S0360-5442(01)00053-6

Worrell, E., \& Price, L. (2001). Policy scenarios for energy efficiency improvement in industry. Energy Policy, 29(April 2001), 1223-1241.

Xnergy Inc. 2002. United States Industrial Electric Motor Systems Market Opportunities. Assessment. Burlington, MA: Xnergy. 


\section{Appendix A. GT-NEMS Modeling of Residential Energy Efficiency Policies}

To assess the electricity savings potential, energy consumption forecast by GT-NEMS was modeled with five residential energy efficiency policies, including Appliance Incentives, Aggressive Appliance Policy, Building Energy Codes, On-Bill Financing and Market Priming. GT-NEMS modeling of each of the five policies took distinct approaches in the purpose of separating policy impacts by avoiding modeling overlaps.

Appliance Incentives offer 30\% subsidy to reduce the capital cost for the most efficient technologies in residential buildings based on the technology inventory of GT-NEMS. A list of 25 selected technologies from the major end-uses eligible for incentives can be found in Table A.1. Capital costs of these technologies (from the rtekty input file) were reduced by $30 \%$ in the Appliance Incentives policy scenario.

Table A.1 Most Efficient Home Appliances and Equipment

\begin{tabular}{|c|c|c|c|c|}
\hline End-Use & Equipment Type & $\begin{array}{l}\text { Average Cost } \\
\text { (\$2007) }\end{array}$ & $\begin{array}{l}\text { Average } \\
\text { Efficiency }\end{array}$ & $\begin{array}{c}\text { Available } \\
\text { Years }\end{array}$ \\
\hline \multirow{8}{*}{ Space Heating } & Fuel Oil Furnace 3 & 4,983 & 0.95 & $2009-2023$ \\
\hline & Fuel Oil Radiator 3 & 4,513 & 0.95 & $2012-2022$ \\
\hline & Electric Heat Pump 4 & 3,567 & 3.14 & 2014-2021 \\
\hline & Geothermal Heat Pump 2 & 6,414 & 5 & 2010-2018 \\
\hline & Kerosene Furnace 3 & 4,983 & 0.95 & $2009-2023$ \\
\hline & LPG Furnace 5 & 2,470 & 0.96 & 2009-2019 \\
\hline & Natural Gas Furnace 5 & 2,470 & 0.96 & $2009-2020$ \\
\hline & Natural Gas Radiator 3 & 4,513 & 0.95 & 2012-2022 \\
\hline \multirow{4}{*}{ Space Cooling } & Central Air Conditioner 4 & 5,290 & 6.504 & 2011-2019 \\
\hline & Electric Heat Pump 4 & 3,567 & 5.325 & 2014-2021 \\
\hline & Geothermal Heat Pump 2 & 5,749 & 30 & 2011-2021 \\
\hline & Room Air Conditioner 3 & 900 & 3.52 & 2012-2026 \\
\hline Clothes Washing & Clothes Washer 3 & 958 & 0.114 & $2008-2022$ \\
\hline Dishwashing & Dishwasher 3 & 1,181 & 1.1 & 2010-2020 \\
\hline \multirow{4}{*}{ Water Heating } & Fuel Oil Water Heater 3 & 2,400 & 0.68 & $2012-2026$ \\
\hline & Electric Water Heater 5 & 1,430 & 2.4 & $2009-2023$ \\
\hline & LPG Water Heater 4 & 852 & 0.746 & 2014-2022 \\
\hline & Natural Gas Water Heater 4 & 852 & 0.746 & 2014-2023 \\
\hline \multirow{3}{*}{ Cooking } & Electric Stove 2 & 400 & 601 & $2006-2050$ \\
\hline & LPG Stove 2 & 500 & 0.42 & $2006-2050$ \\
\hline & Natural Gas Stove 2 & 500 & 0.42 & $2006-2050$ \\
\hline \multirow{2}{*}{ Clothes Drying } & Electric Clothes Dryer 2 & 500 & 3.74 & $2009-2023$ \\
\hline & Natural Gas Clothes Dryer 2 & 515 & 0.931 & $2007-2028$ \\
\hline Refrigeration & Refrigerator 4 & 1,107 & 399 & $2009-2023$ \\
\hline Freezing & Freezer 3 & 626 & 290 & 2010-2032 \\
\hline
\end{tabular}

Note: The cost, efficiency and available years for each equipment type vary by region. The efficiency for different equipment types are measured by different metrics. 
In the Building Energy Codes policy case, four new codes were added to the residential building codes profile (in the rtektyc input file) to force shell efficiency improvements. These codes were modeled with relatively high heating and cooling shell efficiency, and relatively high shell installation costs, trying to mimic the periodic code updates.

In the Reference case, new residential buildings are built in compliance to five different levels of codes: no code, IECC 2006 code, Energy Star code, forty-percent above IECC 2006 code, and the most efficient code: PATH code. In this study, the Building Code scenario were set up based on EIA's Expanded Standards and Codes side case, where three new codes were added to the code profile: 'IECC 2006+', 'IECC 2006++', and 'IECC 2006+++' to reflect code improvements. We managed to add one more code, the 'New Code' to push further shell efficiency improvement. Table A.2 shows the details about the residential building codes in our policy case.

Table A.2 Building Energy Codes Profile for Residential Buildings

\begin{tabular}{lccc}
\hline Building Codes & $\begin{array}{c}\text { Average Shell } \\
\text { Installation Cost }\end{array}$ & $\begin{array}{c}\text { Average Heating Shell } \\
\text { Efficiency Factor }\end{array}$ & $\begin{array}{c}\text { Average Cooling Shell } \\
\text { Efficiency Factor }\end{array}$ \\
\hline 'No IECC' & 7 & 1.21 & 1.15 \\
'IECC 2006' & 5,251 & 0.81 & 1.06 \\
'Energy Star' & 5,508 & 0.79 & 1.03 \\
'FORTY\%' & 6,797 & 0.68 & 0.97 \\
'PATH' & 7,868 & 0.51 & 0.93 \\
'IECC 2006+' & 5,580 & 0.69 & 0.90 \\
'IECC 2006++' & 6,018 & 0.65 & 0.85 \\
'IECC 2006+++' & 6,128 & 0.61 & 0.80 \\
'NEW CODE' & 7,392 & 0.56 & 0.85 \\
\hline
\end{tabular}

Note: The cost and efficiency factors for each building shell type vary by region.

The policy case also forces early retirement of less stringent codes. For example, Energy Star, Forty and IECC 2006+ retire in the same year, which is five years later than IECC 2006's retirement; IECC 2006++ retires at 2023 for all regions; IECC 2006+++ retires at 2028 for all regions; New Code and PATH, which are the two most efficiency codes, are available for all years for all regions.

New houses built in compliance to new codes are able to save energy significantly for home owners due to the high shell efficiency with better insulation and building design. They eventually gain market share, although new codes have higher shell installation costs than existing codes (Figure A.1). 


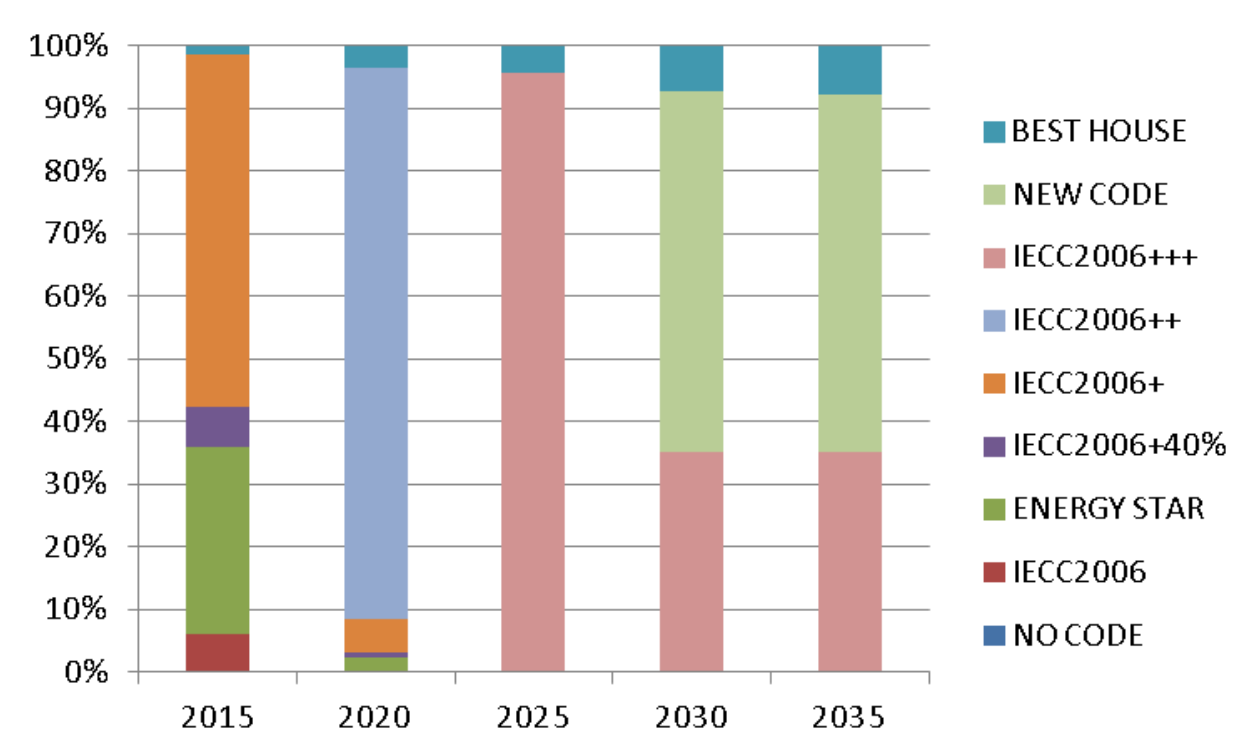

Figure A.1 Share of New Houses Built in the Policy Case

The On-bill Financing program offers zero-interest loans to the most efficient house appliances and equipment. The technologies eligible for no interest loans are the same technologies that are eligible for appliance subsidies as listed in Table A.1. In GT-NEMS modeling, two new parameters for residential technologies were added to the rtekty input file: CAPDIST assigns interest rate (or discount rate for non-eligible technologies), and CAPHOR assigns payback time (or time horizon for non-eligible technologies) for residential technologies.

To realize the input file changes, cost calculation equations in the residential module source code were also modified. In the reference case, the life-cycle costs for residential technologies are calculated as following:

$$
L F C Y_{y, e s, b, r, v}=C A P I T A L_{e s}+O P C O S T_{y e s, b, r, v} *\left(\frac{1-(1+D I S T)^{-H O R I Z O N}}{D I S T}\right)
$$

With interest rate option, we changed the life-cost equation to:

$$
L F C Y_{y, e s, b, r, v}=\left(A N N U A L P A Y_{\mathrm{es}}+O P C O S T_{\mathrm{yes}, b, r, v}\right) *\left(\frac{1-(1+D I S T)^{-H O R I Z O N}}{D I S T}\right)
$$

When interest rate equals to $0 \%$, we have,

$$
A N N U A L P A Y=\frac{\text { CAPITAL }}{\text { CAPHOR }}
$$

When interest rate is greater than $0 \%$, we have,

$$
A N N U A L P A Y=C A P I T A L * \frac{C A P D I S R T}{1-(1+C A P D I S R T)^{-C A P H O R}}
$$

Where, LFCYCLE is the lifecycle costs for appliances;

CAPITAL: the capital costs for appliances;

OPCOST: the operational costs for appliances;

DIST: the discount rate for the operational cost during the life time of the appliances HORIZON: the appliance life time

ANNUALPAY: the annual payment for on-bill financing equipment 
CAPHOR: the payback time

CAPDIST: the interest rate

In the rtekty input file, the selected technologies with high efficiencies were assigned with $0 \%$ interest rate and 10-years payback time, indicating that the life-cycle costs for these technologies were calculated with the revised equation. Other technologies were assigned with the default setting, and their life-cycle costs were calculated with the original equation.

The Market Priming policy also target at the same set of technologies as shown in Table A.1, but with different GT-NEMS lever. In this policy scenario, market assistance programs offer consumers with information, technical support, and educational demonstration to lower the private discount rate for the most efficient technologies. GT-NEMS modeling of this policy changed the hurdle rates of these technologies to $7 \%$ by modifying the beta 2 parameter for the logit model of technology choice in the rtehty input file.

The Aggressive Appliance Policy forces rapid market turnover for residential technologies by retiring the least efficient technologies from the market place. Assuming aggressive appliance standards, the policy forces some of the technologies to retire from the market at 2012. In GTNEMS, the selected technologies were made either unavailable after 2012, or assigned a hurdle rate equals to $100 \%$ in the rtehty input file. A list of house appliances and equipment forced retired in this policy scenario is shown in Table A.3.

Table A.3 Residential Technologies Forced Early Retirement

\begin{tabular}{llrr}
\hline End-Use & Equipment Type & Average Efficiency & Available Years \\
\hline & Fuel Oil Furnace 1 & 0.82 & $2010-2032$ \\
& Fuel Oil Radiator 1 & 0.825 & $2010-2031$ \\
& Electric Heat Pump 1 & 2.35 & $2014-2028$ \\
Space Heating & Kerosene Furnace 1 & 0.82 & $2010-2032$ \\
& LPG Furnace 1 & 0.818 & $2010-2032$ \\
& Natural Gas Furnace 1 & 0.818 & $2010-2032$ \\
& Natural Gas Radiator 1 & 0.815 & $2010-2031$ \\
\hline \multirow{3}{*}{ Space Cooling } & Central Air Conditioner1 & 3.899 & $2009-2039$ \\
& Electric Heat Pump 1 & 4.003 & $2014-2028$ \\
& Room Air Conditioner 1 & 3.103 & $2013-2027$ \\
\hline Clothes Washing & Clothes Washer 1 & 0.160 & $2012-2022$ \\
\hline Dish Washing & Dishwasher 1 & 0.587 & $2010-2024$ \\
\hline \multirow{5}{*}{ Water Heating } & Fuel Oil Water Heater 1 & 0.585 & $2011-2032$ \\
& Electric Water Heater 1 & 0.925 & $2011-2032$ \\
& LPG Water Heater 1 & 0.59 & $2006-2050$ \\
& Natural Gas Water Heater 1 & 0.605 & $2011-2032$ \\
\hline Refrigeration & Refrigerator 1 & 428.7 & $2013-2027$ \\
\hline Freezing & Freezer 1 & 347.5 & $2010-2032$ \\
\hline
\end{tabular}

Note: The efficiency and available years for each equipment type vary by region. The efficiency for different equipment types are measured by different metrics. 


\section{Appendix B. GT-NEMS Modeling of Commercial Energy Efficiency Policies}

We estimate the magnitude of technology investment costs in the commercial sector separately for new purchases, replacements, and retrofits. In each case, the calculation is based on GTNEMS estimates of service demand (SD) for energy.

- New Purchases

$\bigcirc \mathrm{SD}_{\text {new }} \times(\mathrm{Cost} / 8760) \times 1 / \mathrm{CF}=$ Investment Cost

- $\mathrm{SD}_{\text {new }}$ is a KSDOUT output, as are $\mathrm{SD}_{\text {replacement }}$ and $\mathrm{SD}_{\text {surviving }}$

CF is the equipment-specific capacity factor

- Replacements

SD $\mathrm{S}_{\text {replacement }} \mathrm{x}(\mathrm{Cost} / 8760) \times 1 / \mathrm{CF}=$ Investment Cost

- Retrofits

$$
\begin{aligned}
& \text { Where } \mathrm{SD}_{\text {total }}=\mathrm{SD}_{\text {new }}+\mathrm{SD}_{\text {replacement }}+\mathrm{SD}_{\text {surviving }} \text { and } 0.022 \text { is the average } \\
& \text { amount of commercial floorspace undergoing a retrofit } \\
& \text { This proportions the surviving service demand to the commercial sector } \\
& \text { retrofit average }
\end{aligned}
$$

In the Benchmarking policy case, GT-NEMS uses a combination of discount rates and the rate for U.S. government ten-year Treasury notes to calculate consumer hurdle rates used in making equipment-purchasing decisions. While the macroeconomic module of GT-NEMS determines the rate for ten-year Treasury notes endogenously, the discount rates are inputs to the model. Modifying these inputs is the primary means of estimating the impact of benchmarking for the commercial sector in this analysis. This is done in two steps: first, by updating the discount rates to reflect a broader selection of the literature; and second, by adjusting the updated discount rates to account for the effects of a national benchmarking policy.

To illustrate, Table B.1 presents the 2015 hurdle rates used in GT-NEMS across scenarios for two major end-uses in the commercial sector, space heating and lighting (these values represent the sum of the Treasury bill rates and the discount rates). 
Table B.1: Discount Rates Across Scenarios for Space Heating and Lighting in 2015

\begin{tabular}{c|c|c|c}
\hline \multicolumn{2}{c|}{ \% of Population } & \multicolumn{2}{c}{ Discount Rate* } \\
\hline Reference & $\begin{array}{c}\text { Bench- } \\
\text { marking }\end{array}$ & Reference & $\begin{array}{c}\text { Bench- } \\
\text { marking }\end{array}$ \\
\hline \multicolumn{4}{|c}{ Space Heating } \\
\hline 27 & 14.2 & 1005.75 & 40.4 \\
\hline 23 & 14.3 & $\mathbf{1 0 5 . 7 5}$ & 19.6 \\
\hline 19 & 14.3 & 50.75 & 15.4 \\
\hline 18.6 & 14.3 & 30.75 & $\mathbf{1 2 . 4}$ \\
\hline 10.7 & 14.3 & 20.75 & 9.8 \\
\hline 1.5 & 14.3 & 12.25 & 7.4 \\
\hline 0.2 & 14.3 & 5.75 & 4.8 \\
\hline
\end{tabular}

Lighting

\begin{tabular}{c|c|c|c}
\hline 27 & 14.2 & 1005.75 & 57.3 \\
\hline 23 & 14.3 & $\mathbf{1 0 5 . 7 5}$ & 40.8 \\
\hline 18.6 & 14.3 & 50.75 & 36.5 \\
\hline 18.6 & 14.3 & 30.75 & $\mathbf{3 3}$ \\
\hline 8.8 & 14.3 & 20.75 & 30.4 \\
\hline 1.5 & 14.3 & 12.25 & 26.9 \\
\hline 2.5 & 14.3 & 5.75 & 21.7 \\
\hline
\end{tabular}

*Discount rates presented include the projected Treasury bill rate for 2015. Bold numbers represent the median estimate for the specific scenario.

Source: Cox, Brown, and Sun, 2012.

The National Building Code is modeled, in part, by assuming a more rapid rate of commercial shell efficiency improvement, as shown in Table B.2. 
Table B.2. Commercial Building Shell Efficiency Improvement*

\begin{tabular}{lcc|}
\hline & New Construction & Existing Buildings \\
\hline EIA Reference case & $14 \%$ & $6 \%$ \\
EIA High Tech Case & $17.4 \%$ & $7.5 \%$ \\
Building Code Scenario & $30 \%$ & $19 \%$ \\
\hline \multicolumn{2}{l}{${ }^{*}$ Improvement of 2035 efficiency over 2003 efficiency }
\end{tabular}

In the Commercial Financing policy case, a 30\% subsidy was provided to 107 technologies, based on a prior analysis of the impact of implementing a carbon tax (Brown, Cox, and Sun, 2012). The subsidized technologies are listed in Table B.3.

Table B.3 Incentivized Technologies in Financing Policy Case

\begin{tabular}{|c|c|c|c|c|c|c|}
\hline End-use & $\begin{array}{l}\text { Fuel } \\
\text { type }\end{array}$ & Technology & $\begin{array}{l}\text { Average } \\
\text { efficiency }\end{array}$ & $\begin{array}{l}\text { Average } \\
\text { cost }\end{array}$ & $\begin{array}{l}\text { First } \\
\text { available } \\
\text { year }\end{array}$ & $\begin{array}{l}\text { Last } \\
\text { available } \\
\text { year }\end{array}$ \\
\hline & & comm_GSHP-heat 2011 & & & & \\
\hline & & high & 4.90 & 150.00 & 2011 & 2052 \\
\hline & & comm_GSHP-heat 2011 & & & & \\
\hline & & high $10 \%$ ITC w MACRS & 4.90 & 108.00 & 2011 & 2016 \\
\hline & & comm_GSHP-heat 2011 typ & 3.50 & 120.00 & 2011 & 2052 \\
\hline & & comm_GSHP-heat 2011 typ & & & & \\
\hline & & $10 \%$ ITC w MACRS & 3.50 & 87.00 & 2011 & 2016 \\
\hline & & comm_GSHP-heat 2020-30 & & & & \\
\hline & & typical & 4.00 & 120.00 & 2020 & 2052 \\
\hline & & rooftop_ASHP-heat 2007 & & & & \\
\hline & & high & 3.40 & 96.67 & 2003 & 2052 \\
\hline & & rooftop_ASHP-heat 2030 & & & & \\
\hline & Electricity & high & 3.80 & 96.67 & 2030 & 2052 \\
\hline & & gas_boiler 2011 high & 0.95 & 37.08 & 2011 & 2052 \\
\hline & & gas_furnace 2011 high & 0.94 & 9.76 & 2011 & 2052 \\
\hline & & res_type_gasHP-heat 2020 & & & & \\
\hline & & typical & 1.50 & 150.00 & 2020 & 2052 \\
\hline Space & Natural & res_type_gasHP-heat 2030 & & & & \\
\hline \multirow[t]{8}{*}{ Heating } & Gas & typical & 1.50 & 141.67 & 2030 & 2052 \\
\hline & & centrifugal_chiller 2007 & & & & \\
\hline & & high & 7.30 & 43.33 & 2003 & 2052 \\
\hline & & centrifugal_chiller 2007 mid & & & & \\
\hline & & range & 6.90 & 40.83 & 2003 & 2052 \\
\hline & & centrifugal_chiller 2010 & & & & \\
\hline & & typical & 6.40 & 36.67 & 2010 & 2052 \\
\hline & & centrifugal_chiller 2020 & & & & \\
\hline Space & & typical & 7.00 & 36.67 & 2020 & 2052 \\
\hline Cooling & Electricity & centrifugal_chiller ASHRAE & 6.10 & 35.42 & 2003 & 2052 \\
\hline
\end{tabular}




\begin{tabular}{|c|c|c|c|c|}
\hline \multicolumn{5}{|l|}{ 90.1-2004 } \\
\hline $\begin{array}{l}\text { high } \\
\text { comm_GSHP-cool } 2011\end{array}$ & 8.15 & 150.00 & 2011 & 2052 \\
\hline high $10 \%$ ITC w MACRS & 8.15 & 108.00 & 2011 & 2016 \\
\hline $\begin{array}{l}\text { comm_GSHP-cool } 2011 \text { typ } \\
\text { comm_GSHP-cool } 2011 \text { typ }\end{array}$ & 4.10 & 120.00 & 2011 & 2052 \\
\hline $\begin{array}{l}\text { 10\% ITC w MACRS } \\
\text { comm_GSHP-cool 2020-30 }\end{array}$ & 4.10 & 87.00 & 2011 & 2016 \\
\hline $\begin{array}{l}\text { typical } \\
\text { reciprocating_chiller } 2007\end{array}$ & 4.10 & 120.00 & 2020 & 2052 \\
\hline $\begin{array}{l}\text { high } \\
\text { reciprocating_chiller } 2020\end{array}$ & 3.52 & 47.08 & 2003 & 2052 \\
\hline $\begin{array}{l}\text { high } \\
\text { reciprocating_chiller } 2020\end{array}$ & 3.63 & 42.08 & 2020 & 2052 \\
\hline $\begin{array}{l}\text { typical } \\
\text { reciprocating_chiller } 2030\end{array}$ & 3.20 & 38.75 & 2020 & 2052 \\
\hline $\begin{array}{l}\text { high } \\
\text { res_type_central_AC } 2003\end{array}$ & 3.78 & 42.08 & 2030 & 2052 \\
\hline $\begin{array}{l}\text { installed base } \\
\text { res_type_central_AC } 2030\end{array}$ & 2.84 & 47.84 & 2003 & 2003 \\
\hline $\begin{array}{l}\text { typical } \\
\text { res_type_central_AC }\end{array}$ & 4.40 & 80.95 & 2030 & 2052 \\
\hline $\begin{array}{l}\text { NAECA standard-pre-2006 } \\
\text { rooftop_AC } 2003 \text { installed }\end{array}$ & 2.93 & 49.13 & 2003 & 2005 \\
\hline base & 2.70 & 58.33 & 2003 & 2003 \\
\hline rooftop_AC 2007 typical & 2.96 & 65.56 & 2003 & 2009 \\
\hline rooftop_AC 2010 high & 3.52 & 80.56 & 2011 & 2052 \\
\hline rooftop_AC 2011 typical & 3.28 & 66.67 & 2011 & 2052 \\
\hline $\begin{array}{l}\text { rooftop_AC } 2030 \text { high } \\
\text { rooftop_ASHP-cool } 2030\end{array}$ & 3.81 & 80.56 & 2030 & 2040 \\
\hline high & 3.81 & 96.67 & 2030 & 2040 \\
\hline screw_chiller 2020 high & 3.63 & 42.08 & 2020 & 2052 \\
\hline screw_chiller 2030 high & 3.91 & 42.08 & 2030 & 2052 \\
\hline $\begin{array}{l}\text { scroll_chiller } 2007 \text { typical } \\
\text { wall-window_room_AC }\end{array}$ & 2.93 & 36.25 & 2003 & 2052 \\
\hline $\begin{array}{l}2011 \text { typical } \\
\text { wall-window_room_AC }\end{array}$ & 3.05 & 33.81 & 2011 & 2052 \\
\hline 2020 typical & 3.22 & 33.81 & 2020 & 2052 \\
\hline $\begin{array}{l}\text { gas_water_heater } 2020 \\
\text { high }\end{array}$ & 0.95 & 26.40 & 2020 & 2052 \\
\hline HP water heater 2011 & & & & \\
\hline $\begin{array}{l}\text { typical } \\
\text { HP water heater } 2020\end{array}$ & 2.30 & 225.00 & 2011 & 2052 \\
\hline typical & 2.30 & 210.71 & 2020 & 2052 \\
\hline Solar water heater 2010 typ & 2.50 & 249.12 & 2010 & 2052 \\
\hline
\end{tabular}




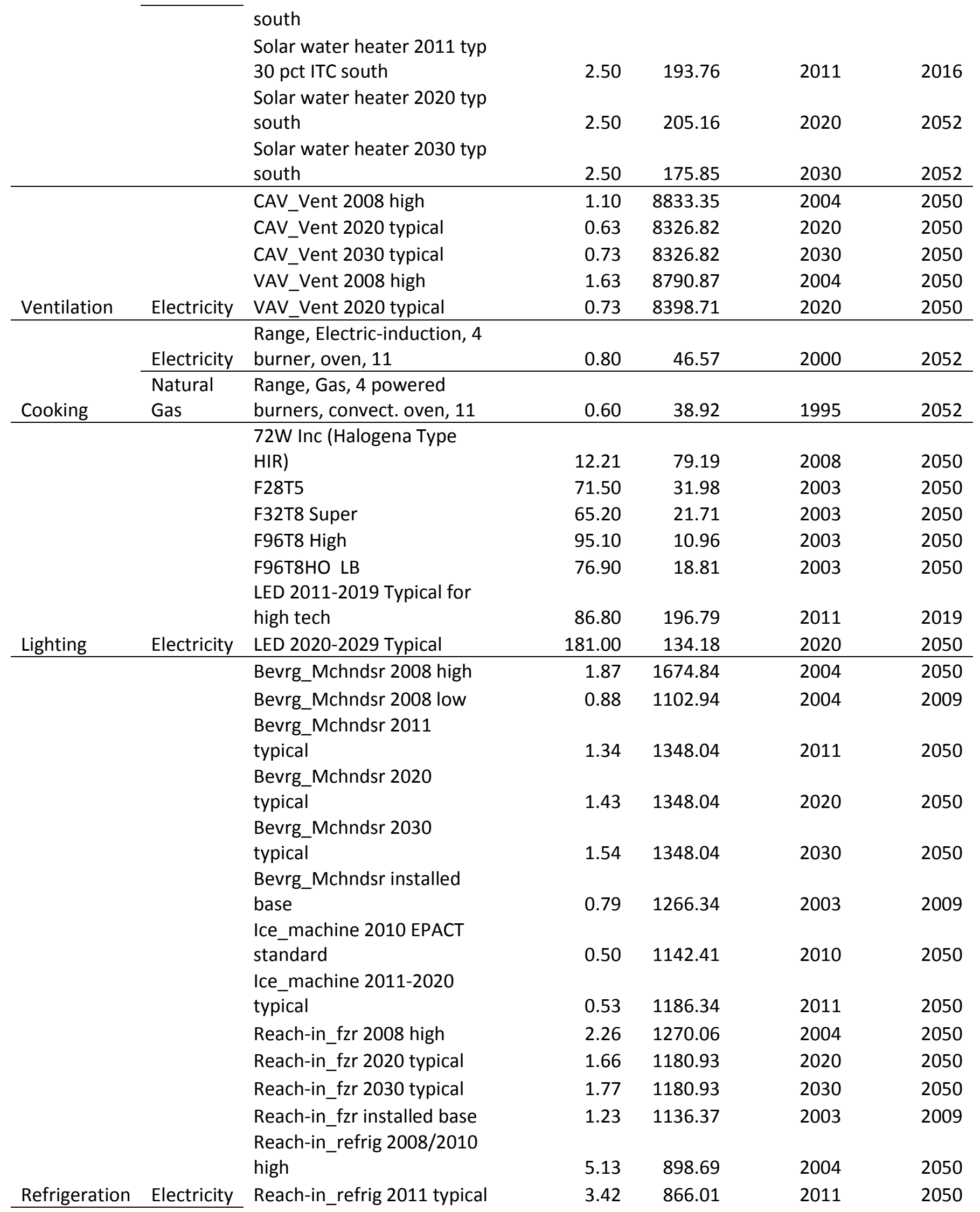




\begin{tabular}{|c|c|c|c|c|}
\hline Reach-in_refrig 2020 typical & 3.67 & 866.01 & 2020 & 2050 \\
\hline Reach-in_refrig 2030 typical & 3.85 & 866.01 & 2030 & 2050 \\
\hline \multicolumn{5}{|l|}{ Reach-in_refrig installed } \\
\hline \multicolumn{5}{|l|}{ Supermkt_compressor_rack } \\
\hline 2011 high & 3.06 & 130.72 & 2011 & 2050 \\
\hline \multicolumn{5}{|l|}{ Supermkt_compressor_rack } \\
\hline 2011 typical & 2.75 & 116.71 & 2011 & 2050 \\
\hline \multicolumn{5}{|l|}{ Supermkt_compressor_rack } \\
\hline 2020 high & 3.06 & 130.72 & 2020 & 2050 \\
\hline \multicolumn{5}{|l|}{ Supermkt_compressor_rack } \\
\hline 2020 typical & 2.81 & 116.71 & 2020 & 2050 \\
\hline \multicolumn{5}{|l|}{ Supermkt_compressor_rack } \\
\hline 2030 high & 3.06 & 130.72 & 2030 & 2050 \\
\hline \multicolumn{5}{|l|}{ Supermkt_compressor_rack } \\
\hline 2030 typical & 2.87 & 116.71 & 2030 & 2050 \\
\hline \multicolumn{5}{|l|}{ Supermkt_condenser 2008} \\
\hline high & 27.84 & 32.25 & 2004 & 2050 \\
\hline \multicolumn{5}{|l|}{ Supermkt_condenser 2020} \\
\hline typical & 22.27 & 25.80 & 2020 & 2050 \\
\hline \multicolumn{5}{|l|}{ Supermkt_condenser } \\
\hline installed base & 17.82 & 29.02 & 2003 & 2050 \\
\hline \multicolumn{5}{|l|}{ Supermkt_display_case } \\
\hline 2008 high-2012 standard & 3.02 & 436.28 & 2004 & 2050 \\
\hline \multicolumn{5}{|l|}{ Supermkt_display_case } \\
\hline 2011 typical & 2.57 & 303.92 & 2011 & 2011 \\
\hline \multicolumn{5}{|l|}{ Supermkt_display_case } \\
\hline 2020 high & 3.42 & 436.28 & 2020 & 2050 \\
\hline \multicolumn{5}{|l|}{ Supermkt_display_case } \\
\hline installed base & 2.45 & 303.92 & 2003 & 2011 \\
\hline Vend_Machine 2008 low & 0.53 & 2201.69 & 2004 & 2012 \\
\hline \multicolumn{5}{|l|}{ Vend_Machine 2008-10 } \\
\hline high-2013 standard & 1.06 & 2621.85 & 2004 & 2050 \\
\hline \multicolumn{5}{|l|}{ Vend_Machine 2008-10 } \\
\hline typical & 0.75 & 2341.74 & 2004 & 2012 \\
\hline Vend_Machine 2011 high & 1.17 & 2621.85 & 2011 & 2050 \\
\hline Vend_Machine 2011 typical & 0.84 & 2341.74 & 2011 & 2012 \\
\hline Vend_Machine 2020 high & 1.24 & 2621.85 & 2020 & 2050 \\
\hline Vend_Machine 2030 high & 1.32 & 2621.85 & 2030 & 2050 \\
\hline Walk-In_fzr 2008 high & 1.21 & 2148.16 & 2004 & 2050 \\
\hline \multicolumn{5}{|l|}{ Walk-In_fzr 2009 EISA stnd- } \\
\hline 2010 typical & 1.83 & 2068.59 & 2009 & 2050 \\
\hline Walk-In_fzr 2020 typical & 1.86 & 2068.59 & 2020 & 2050 \\
\hline Walk-In_fzr 2030 typical & 1.89 & 2068.59 & 2030 & 2050 \\
\hline Walk-In_fzr installed base & 0.81 & 1650.90 & 2003 & 2008 \\
\hline Walk-In_refrig 2008 high & 6.73 & 725.11 & 2004 & 2050 \\
\hline
\end{tabular}


Walk-In_refrig 2009 EISA

stnd-2010 typical

$\begin{array}{llll}6.24 & 710.16 & 2009 & 2050\end{array}$

Walk-In_refrig 2020 typical

$\begin{array}{llll}6.54 & 710.16 & 2020 & 2050\end{array}$

Walk-In_refrig 2030 typical

$6.94 \quad 710.16$

2030

2050

Walk-In_refrig installed

base

$2.73 \quad 490.52$

2003

2008 


\section{Appendix C. GT-NEMS Modeling of Industrial Energy Efficiency Policies}

The Motor Rebate policy offers a 30\% subsidy for premium motor. GT-NEMS modeling of this policy was to increase the dealer rebate parameter (in the indmotor.xml input file) from $30 \%$ to 60\%. The Motor Standard policy assumes efficiency improvement in 2017 that systems using motor have additional $25 \%$ savings in energy. In order not to change history, the modification was made effective from 2017 in the industrial source code, ind.f.

In the CHP Incentive scenario, subsidies were applied to industrial CHP systems to promote efficient usage of waste heat in various industrial processes. A 10-year subsidy increasing from $15 \%$ in 2012 to $30 \%$ was applied to the total installed cost parameter in the indcogen.xml input file. To reflect the benefit share between customers and CHP retailers, a 15\% subsidy was applied for the first three years, rising by 5\% every year from 2015 and staying at $30 \%$ from 2017 to 2021. GT-NEMS represents CHP as a combination of eight technology systems, including two internal combustion CHP systems (ranging from 1 to $3 \mathrm{MW}$ ), five gas turbine CHP systems (3 to $40 \mathrm{MW}$ ) and one combined cycle system (with two $40 \mathrm{MW}$ gas turbines and a $20 \mathrm{MW}$ steam turbine). Investment costs are provided for each of these systems.

The Advanced Manufacturing Initiative policy mimics the voluntary plant upgrades by the private sector. It took the estimated electricity and natural gas savings from efficiency improvements reported from 2010 to 2012 in the Industrial Assessment Center (IAC) database (Table C.1). The percentage savings were applied to change the TPC parameter in the itech.txt input file.

Table C.1 Electricity and Natural Gas Saving Estimations from IAC Reports

\begin{tabular}{|l|c|c|c|c|c|c|c|c|}
\hline \multirow{2}{*}{\multicolumn{1}{c|}{ Industry }} & \multicolumn{3}{|c|}{ Electricity savings } & \multicolumn{5}{c|}{ Natural Gas } \\
\cline { 2 - 9 } & Northeast & Midwest & South & West & Northeast & Midwest & South & West \\
\hline 311 Food & $47.58 \%$ & $47.98 \%$ & $37.48 \%$ & $47.08 \%$ & $0.58 \%$ & $25.75 \%$ & $2.00 \%$ & $0.00 \%$ \\
\hline 322 Paper & $29.20 \%$ & $31.24 \%$ & $15.06 \%$ & $11.51 \%$ & $5.19 \%$ & $15.98 \%$ & $11.15 \%$ & $0.00 \%$ \\
\hline 325 Chemicals & $62.73 \%$ & $13.04 \%$ & $51.98 \%$ & $35.74 \%$ & $-32.64 \%$ & $25.06 \%$ & $-3.76 \%$ & $-98.63 \%$ \\
\hline 327 Non Metals & $9.82 \%$ & $20.23 \%$ & $46.18 \%$ & $37.26 \%$ & $5.12 \%$ & $29.45 \%$ & $0.00 \%$ & \\
\hline 331 Iron and Steel & $15.14 \%$ & $57.13 \%$ & $28.02 \%$ & $5.03 \%$ & $13.75 \%$ & $18.44 \%$ & $3.44 \%$ & $2.61 \%$ \\
\hline 332 Fabricated Metals & $29.27 \%$ & $46.89 \%$ & $42.70 \%$ & $28.74 \%$ & $-49.03 \%$ & $16.55 \%$ & $11.15 \%$ & N/A \\
\hline 333 Machinery & $19.61 \%$ & $54.08 \%$ & $45.88 \%$ & $40.35 \%$ & $29.22 \%$ & $53.70 \%$ & $27.33 \%$ & N/A \\
\hline $\begin{array}{l}334 \text { Computers and } \\
\text { Electronics }\end{array}$ & $79.76 \%$ & $58.39 \%$ & $15.75 \%$ & $31.06 \%$ & $28.54 \%$ & $22.85 \%$ & $7.08 \%$ & N/A \\
\hline $\begin{array}{l}336 \text { Transportation } \\
\text { Equipment }\end{array}$ & $17.42 \%$ & $40.24 \%$ & $56.61 \%$ & $9.93 \%$ & $16.85 \%$ & $4.79 \%$ & N/A & N/A \\
\hline 335 Electrical & $8.88 \%$ & $12.20 \%$ & $24.35 \%$ & $36.22 \%$ & $21.71 \%$ & $21.81 \%$ & $3.55 \%$ & N/A \\
\hline 321 Wood & $22.94 \%$ & $38.47 \%$ & $34.16 \%$ & $76.18 \%$ & $23.14 \%$ & $3.86 \%$ & $55.09 \%$ & \\
\hline 326 Plastics Others & $44.69 \%$ & $26.43 \%$ & $27.64 \%$ & $24.39 \%$ & $15.24 \%$ & $480.64 \%$ & $16.78 \%$ & $10.36 \%$ \\
\hline 313 Textile & $5.25 \%$ & & $24.03 \%$ & & $4.61 \%$ & & $8.81 \%$ & \\
\hline 314 Textile product & $89.25 \%$ & $10.83 \%$ & $13.15 \%$ & $13.20 \%$ & $-11.25 \%$ & $95.10 \%$ & $23.81 \%$ & $29.45 \%$ \\
\hline $\begin{array}{l}324 \text { Petroleum and } \\
\text { Coal }\end{array}$ & $13.98 \%$ & $16.05 \%$ & $6.64 \%$ & $12.65 \%$ & $74.27 \%$ & $16.57 \%$ & $20.72 \%$ & $3.57 \%$ \\
\hline
\end{tabular}




\section{Appendix D. State Results}

Table D.1. Electricity Efficiency Potential By State (TWh)

\begin{tabular}{|c|cc|cc|cc|}
\hline & \multicolumn{2}{|c|}{ Residential } & \multicolumn{2}{c|}{ Commercial } & \multicolumn{2}{c|}{ Industrial } \\
\cline { 2 - 7 } & $\mathbf{2 0 2 0}$ & $\mathbf{2 0 3 5}$ & $\mathbf{2 0 2 0}$ & $\mathbf{2 0 3 5}$ & $\mathbf{2 0 2 0}$ & $\mathbf{2 0 3 5}$ \\
\hline AL & 2.85 & 4.16 & 0.92 & 2.39 & 2.88 & 3.92 \\
AR & 2.51 & 3.84 & 0.67 & 1.48 & 1.21 & 1.62 \\
CT & 1.04 & 1.79 & 0.44 & 1.23 & 0.18 & 0.22 \\
DC & 0.22 & 0.37 & 0.51 & 1.27 & 0.03 & 0.04 \\
DE & 0.50 & 0.85 & 0.23 & 0.57 & 0.26 & 0.35 \\
FL & 13.25 & 22.52 & 4.89 & 12.23 & 1.58 & 2.17 \\
GA & 6.07 & 10.32 & 2.42 & 6.04 & 2.75 & 3.76 \\
IA & 0.91 & 1.44 & 0.66 & 1.50 & 1.09 & 1.57 \\
IL & 3.21 & 5.41 & 2.68 & 6.30 & 3.37 & 4.76 \\
IN & 2.28 & 3.85 & 1.24 & 2.90 & 3.50 & 4.94 \\
KS & 0.90 & 1.42 & 0.53 & 1.21 & 0.80 & 1.16 \\
KY & 2.40 & 3.51 & 0.80 & 2.07 & 3.69 & 5.03 \\
LA & 4.21 & 6.44 & 1.29 & 2.88 & 1.92 & 2.57 \\
MA & 1.58 & 2.71 & 0.59 & 1.65 & 0.80 & 1.00 \\
MD & 3.17 & 5.38 & 1.38 & 3.46 & 0.49 & 0.68 \\
ME & 0.34 & 0.59 & 0.13 & 0.38 & 0.14 & 0.17 \\
MI & 2.42 & 4.08 & 1.99 & 4.67 & 2.23 & 3.14 \\
MN & 1.45 & 2.30 & 0.76 & 1.73 & 1.57 & 2.25 \\
MO & 2.26 & 3.58 & 1.08 & 2.46 & 1.20 & 1.72 \\
MS & 1.62 & 2.37 & 0.54 & 1.40 & 1.31 & 1.78 \\
NC & 6.17 & 10.48 & 2.43 & 6.07 & 2.35 & 3.21 \\
ND & 0.26 & 0.42 & 0.15 & 0.33 & 0.29 & 0.42 \\
NE & 0.63 & 1.00 & 0.33 & 0.76 & 0.76 & 1.09 \\
NH & 0.34 & 0.59 & 0.15 & 0.41 & 0.09 & 0.11 \\
NJ & 2.11 & 4.00 & 1.43 & 3.60 & 0.54 & 0.67 \\
NY & 3.60 & 6.83 & 2.82 & 7.06 & 0.87 & 1.10 \\
OH & 3.65 & 6.16 & 2.39 & 5.61 & 4.02 & 5.68 \\
OK & 3.15 & 4.81 & 1.06 & 2.35 & 1.06 & 1.43 \\
PA & 3.84 & 7.29 & 1.70 & 4.26 & 2.84 & 3.56 \\
RI & 0.24 & 0.41 & 0.12 & 0.34 & 0.05 & 0.06 \\
SC & 3.30 & 5.61 & 1.13 & 2.83 & 2.38 & 3.25 \\
SD & 0.27 & 0.43 & 0.14 & 0.32 & 0.18 & 0.26 \\
TN & 3.68 & 5.38 & 1.20 & 3.13 & 2.67 & 3.64 \\
VA & 5.01 & 8.51 & 2.42 & 6.06 & 1.56 & 2.14 \\
VT & 0.17 & 0.29 & 0.07 & 0.18 & 0.07 & 0.08 \\
WV & 1.54 & 2.60 & 1.11 & 2.61 & 1.82 & 2.57 \\
& 1.29 & 2.20 & 0.41 & 1.03 & 1.03 & 1.41 \\
\hline
\end{tabular}

